\title{
Bulk Nanostructured Materials
}

4

C. C. $\operatorname{Koch}^{1 *}$, T. G. Langdon ${ }^{2,3}$, E. J. Lavernia ${ }^{4}$

1. Department of Materials Science and Engineering, North Carolina State University, Raleigh, NC 27695, USA

2. Departments of Aerospace \& Mechanical Engineering and Materials Science, University of Southern California, Los Angeles, CA 90089, USA

*Corresponding author: email: carl_koch@ncsu.edu

\section{Abstract}

This paper will address three topics of importance to bulk nanostructured materials. Bulk nanostructured materials are defined as bulk solids with nanoscale or partly nanoscale microstructures. This category of nanostructured materials has historical roots going back many

21 decades but has relatively recent focus due to new discoveries of unique properties of some

22 nanoscale materials. Bulk nanostructured materials are prepared by a variety of severe plastic

23 deformation methods, and these will be reviewed. Powder processing to prepare bulk

24 nanostructured materials requires that the powders be consolidated by typically combinations of 25 pressure and temperature, the latter leading to coarsening of the microstructure. The thermal 26 stability of nanostructured materials will also be discussed. An example of bringing 27 nanostructured materials to applications as structural materials will be described in terms of the cryomilling of powders and their consolidation. 


\section{I. INTRODUCTION}

31 Bulk nanostructured materials are defined as bulk solids with nanoscale or partly nanoscale

32 microstructures. This category of nanostructured materials has historical roots going back many

33 decades but has relatively recent focus due to new discoveries of unique properties of some

34 nanoscale materials.

35 Early in the last century, when "microstructures" were revealed primarily with the optical 36 microscope, it was recognized that refined microstructures, for example, small grain sizes, often

37 provided attractive properties such as increased strength and toughness in structural materials. A

38 classic example of property enhancement due to a refined microstructure- with features too small

39 to resolve with the optical microscope- was age hardening of aluminum alloys.

40 The field of nanocrystalline (or nanostructured) materials as a major identifiable activity in

41 modern materials science results to a large degree from the work in the 1980s of Gleiter and co-

42 workers [1] who synthesized nanoscale $(<100 \mathrm{~nm})$ grain size materials by the in situ

43 consolidation of nanoscale atomic clusters. These nanostructured materials exhibited

44 dramatically improved - or different - properties from conventional grain size (> $1 \mu \mathrm{m})$

45 polycrystalline or single crystal materials of the same chemical composition. This is the stimulus

46 for the tremendous appeal of these materials.

47 There are a number of processing methods to produce bulk nanostructured materials. These

48 include the inert gas condensation method pioneered by Gleiter [1], electrodeposition [2],

49 crystallization of amorphous precursors [3], severe plastic deformation methods [4], or the

50 consolidation of nanoscale powder precursors [5]. The nanoscale powder precursors may be

51 nanoscale powders produced by a variety of chemical methods [6] or powders which are micron 
52 or tens of microns in size but with a nanoscale grain size produced by ball milling of powders.

53 The methods to be emphasized in this short review will be those that involve either severe plastic

54 deformation of bulk materials, or the severe plastic deformation (mechanical attrition) of

55 powders followed by consolidation into bulk.

56 The paper will begin with a review of severe plastic deformation techniques. This will be

57 followed by a consideration of the problem of the stabilization of nanoscale grain size in

58 powders during their consolidation which involves elevated temperatures. The concluding

59 section will give an example of aluminum alloys prepared by mechanical alloying and

60 consolidated by conventional commercial processing such as extrusion. Their grain size is

61 stabilized by nanoscale precipitates of oxides and nitrides. A summary will discuss the existing

62 or potential applications of bulk nanostructured materials.

64 II. BULK NANOSTRUCTURED MATERIALS BY SEVERE PLASTIC 65 DEFORMATION

66 Metal processing is generally based on conventional procedures, such as rolling, extrusion

67 and drawing, in which one of the dimensions of the work-piece is significantly reduced during

68 the processing operation. Nevertheless, alternative procedures are now available where

69 exceptionally high strains may be imposed without incurring any major changes in the overall

70 dimensions of the samples. This type of processing relates to the application of severe plastic

71 deformation (SPD) and the processing has been defined formally as "any method of metal

72 forming under an extensive hydrostatic pressure that may be used to impose a very high strain on

73 a bulk solid without the introduction of any significant change in the overall dimensions of the

74 sample" [7]. In practice, SPD processing provides a unique opportunity for achieving 
75 exceptional grain refinement, typically to the sub-micrometer or even the nanometer level, and

76 thereby it provides the potential for obtaining superior properties that cannot be achieved using

77 more conventional techniques.

78 The following section provides a brief historical review of the development of SPD processing

79 leading up to the recognition that these procedures may be used to produce exceptionally small

80 grain sizes in metals and the following sections describe the more recent developments of these

81 procedures and the potential for attaining unusual and useful properties in bulk metallic solids.

\section{A. The Development of SPD as a Processing Tool}

83 SPD processing is generally considered a very new metallurgical tool but in fact

84 comprehensive analyses have shown that the general principles of SPD were employed over 852000 years ago in ancient China [8, 9]. Thus, in the Han dynasty in China around $200 \mathrm{BC}$ a new

86 and effective forging technique was developed for the fabrication of steel for use in swords. This

87 technique consisted of repetitively forging and folding a metal to produce very high strength as

88 in the famous Bai-Lian steels and later a similar technique was used in the processing ultrahigh

89 carbon Wootz steels in ancient India [10] and then Damascus steels in the Middle East [11].

90 Despite the remarkable success of this approach in achieving high strengths, these procedures

91 were followed by medieval artisans without any formal understanding of the fundamental

92 scientific principles associated with the processing.

93 The first scientific approach to SPD processing may be traced to the work of P.W. Bridgman

94 at Harvard University dating from the 1930's onwards [12]. Bridgman single-handedly

95 investigated the processing of metals using a combination of compression and torsional straining

96 and thus he essentially introduced the procedure that is known today as High-Pressure Torsion

97 (HPT). Subsequently, in 1946, Bridgman received the Nobel Prize in Physics for his work on 
98 the effects of high pressures on bulk metals. Over a period of many years, Bridgman amassed a

99 large volume of data on the applications of high pressures to a remarkably wide range of 100 materials and this work was summarized in a book published in 1952 [13] and more recently in a 101 comprehensive review article [14]. Following Bridgman, the principles of HPT were further 102 developed extensively by scientists working in the Soviet Union [15]. A second important 103 development occurred, also in the Soviet Union, when Segal and co-workers [16] processed 104 metals using the procedure that is now known as Equal-Channel Angular Pressing (ECAP). 105 Nevertheless, all of this work on HPT and ECAP was devoted exclusively to examining the 106 experimental parameters associated with the development of these techniques in the production 107 of high-strength materials and there was no reference to the underlying microstructure that is 108 now recognized to play a major role in determining the fundamental physical properties of the 109 material.

110 In practice, the evolution of SPD processing through microstructural analysis required the 111 introduction of sophisticated analytical tools such as high-resolution transmission electron 112 microscopy and, more recently, electron backscatter diffraction. The first recognition of the 113 importance of these microstructural effects again occurred in the Soviet Union with the work of 114 Valiev and his colleagues in the late 1980's [17]. These investigations provided the first 115 demonstration that it was possible to achieve remarkable grain refinement in many metallic 116 alloys through the use of SPD processing. For example, a grain size of $\sim 0.3 \mu \mathrm{m}$ was reported in 117 a superplastic $\mathrm{Al}-4 \% \mathrm{Cu}-0.5 \% \mathrm{Zr}$ alloy [17] even though in western countries at this time the 118 smallest attainable grain size in this alloy was generally considered to be about $\sim 3-5 \mu \mathrm{m}$ [18].

119 Later detailed reports of this work in the western literature $[19,20]$ provided the impetus for the 
120 subsequent rapid expansion of these SPD processing techniques to many laboratories around the

121 world.

122 In addition to ECAP and HPT, several other SPD procedures have been developed which 123 may be used effectively to process metals without incurring any changes in the overall 124 dimensions and providing the potential for achieving excellent grain refinement. Examples of 125 these methods include accumulative roll bonding (ARB) [21.22], multi-directional forging $126[23,24]$, multi-axial compression(MAC) [25,26], cyclic extrusion and compression [27,28], 127 repetitive corrugation and straightening $(\operatorname{RCS})[29,30]$ and twist extrusion $[31,32]$. Nevertheless, 128 ECAP and HPT are the two SPD procedures used most frequently in modern processing [33] 129 primarily because ECAP is simple to conduct in any laboratory and may be used to provide 130 reasonably large samples and HPT leads to an optimum refined microstructure. For example, in 131 comparisons between HPT and ECAP it was shown that HPT produces smaller grains [34, 35] 132 and a larger fraction of grain boundaries having high angles of misorientation [36]. The 133 superiority of HPT in producing exceptional grain refinement was also demonstrated in direct 134 comparisons with the alternative procedures of MAC [37] and RCS [38].

135 B. Characteristics of Bulk Nanostructured Materials Produced Using Conventional SPD

136 Processing by ECAP is a procedure where a sample, in the form of a bar or rod, is pressed 137 through a die constrained within a channel which is bent through an abrupt angle within the die 138 [39]. It has been shown that the strain imposed in a single pass in ECAP is dependent primarily 139 upon the angle subtended internally by the channel and also to a minor extent by the outer arc of 140 curvature where the two parts of the channel intersect. Thus, for a channel angle of $90^{\circ}$ and a 141 typical outer arc of curvature of $\sim 20^{\circ}$ the imposed strain is close to $\sim 1$ on each pass [40]. 142 Repetitive pressings may be undertaken to impose even higher strains and then the orientations 
143 of the samples in each pass become critical because these orientations affect the slip systems

144 within the specimen. For optimum conditions, samples in ECAP are generally processed using

145 route $\mathrm{B}_{\mathrm{C}}$ in which the billet is rotated in the same sense by $90^{\circ}$ about the longitudinal axis 146 between each pass [41].

147 Numerous reports are now available documenting the microstructures that may be achieved 148 using ECAP [42,43] but a comprehensive evaluation was presented where high purity $(99.99 \%)$ 149 aluminum was processed by ECAP at room temperature (RT) for up to 12 passes using a $90^{\circ}$ die 150 and then the samples were examined using orientation imagining microscopy (OIM) [44]. The 151 results are shown in Fig. 1 where the grain colors relate to the orientation of each grain as shown 152 in the unit triangle. In these images, high-angle grain boundaries (HAGBs) are defined as 153 boundaries having misorientations of more than $15^{\circ}$ and low-angle grain boundaries (LAGBs) 154 have misorientations between $2^{\circ}$ and $15^{\circ}$. Fig. 1(a) shows the initial unprocessed microstructure 155 where the grain size was $\sim 1 \mu \mathrm{m}$ and Figs. $1(\mathrm{~b})-(\mathrm{g})$ show the microstructures after processing by 156 ECAP at RT through 1 to 12 passes: it is important to note that (c)-(f) have similar 157 magnifications but a higher magnification is used in Fig. 1(g) to show more fully the final grain 158 structure. Inspection of these images shows that the grain structure evolves from elongated 159 subgrains to reasonably equiaxed ultrafine grains over 1 to 4 passes and thereafter the average 160 grain size and the grain aspect ratio remain reasonably constant up to 12 passes with a final grain 161 size of $\sim 1.2 \mu \mathrm{m}$. Measurements of the boundary misorientations showed the HAGBs accounted 162 for $\sim 74 \%$ of all boundaries after 12 passes and there was an increasingly weaker texture after 163 processing through higher numbers of passes. Hardness measurements taken after ECAP 164 processing have demonstrated that there is a high degree of homogeneity in these measurements 165 both on cross-sectional planes [45] and longitudinal planes [46] although there generally remains 
167 surface. Thus, processing by ECAP is an excellent procedure for achieving very significant

168 grain refinement and a very high degree of microstructural homogeneity. Furthermore, although

169 the results in Fig. 1 relate to high-purity Al where the minimum grain size is $\sim 1.2 \mu \mathrm{m}$, very

170 similar results were reported also in an $\mathrm{Al}-1 \% \mathrm{Mg}$ solid solution alloy where the minimum grain

171 size was $~ 700 \mathrm{~nm}[47]$.
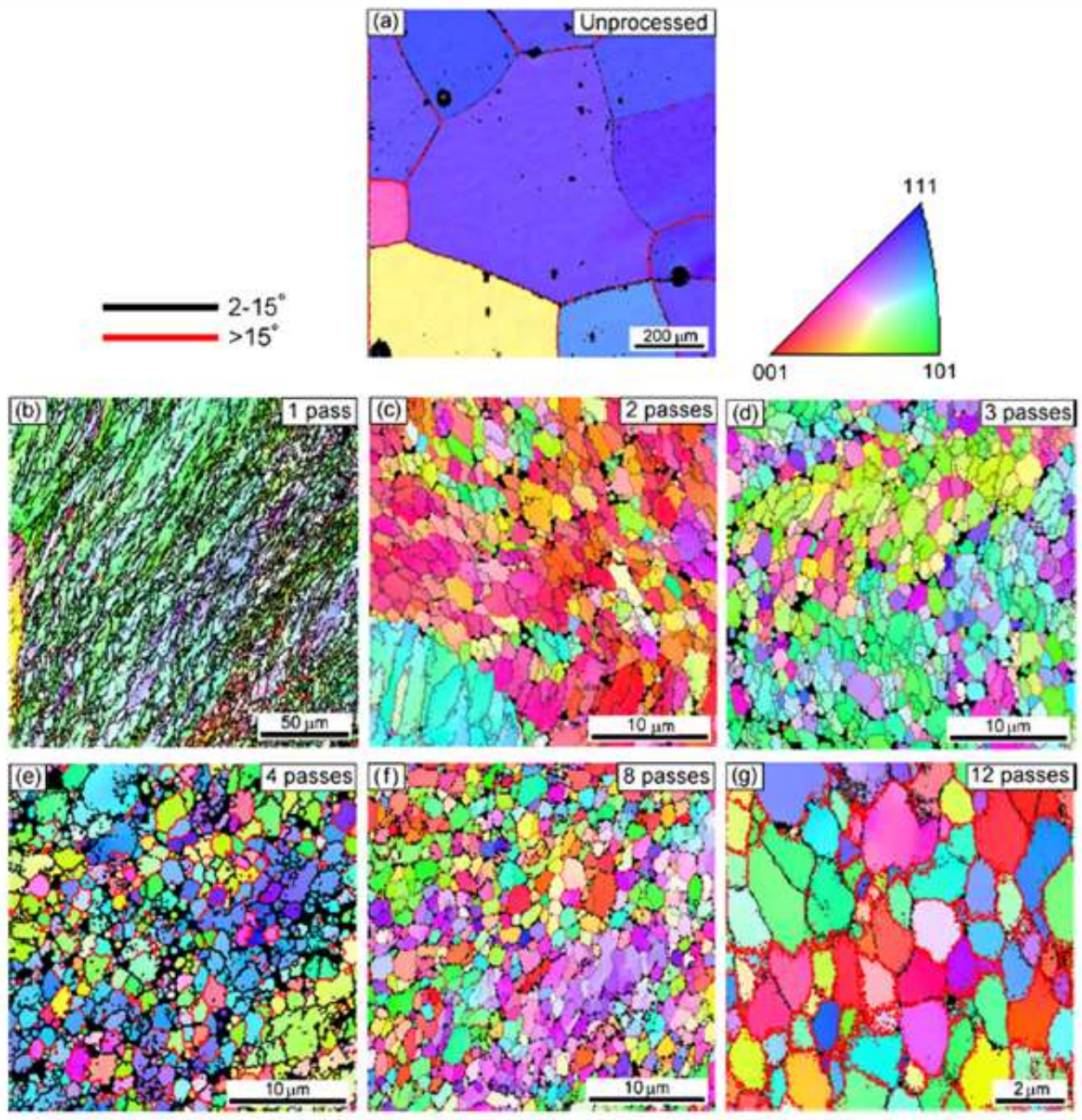

173 Figure 1 OIM images for high purity aluminum in (a) the initial unprocessed condition and after

174 ECAP through (b) 1, (c) 2, (d) 3, (e) 4, (f) 8 and (g) 12 passes using route BC at RT: the grain 175 colors correspond to the orientations in the unit triangle. Reprinted with permission from reference [44]. 
178 Processing by HPT is very different from ECAP because it generally uses a sample in the

179 form of a thin disk which is placed between two large anvils and subjected to a high applied

180 pressure and concurrent torsional straining [48]. Furthermore, processing by HPT leads to an

181 equivalent von Mises strain imposed on the disk, $\varepsilon_{\text {eq }}$, which is given by a relationship of the

182 form $[49,50]$ :

$183 \quad \varepsilon_{\text {eq }}=\frac{2 \pi N r}{h \sqrt{3}}$

184 where $r$ and $h$ are the radius and height (or thickness) of the disk, respectively and $N$ represents

185 the number of HPT turns. Inspection of Eq. (1) shows that the imposed strain varies across the

186 disk with a maximum value at the outer edge and a strain equal to zero where $r=0$ at the center

187 of the disk. Thus, it is reasonable to anticipate that the microstructure and measurements of the

188 microhardness will vary significantly across the HPT disk and this suggests that it may be

189 impossible to achieve a high degree of homogeneity. In practice, however, early +experiments

190 showed that it was both possible to achieve a reasonable level of homogeneity after a sufficiently

191 large number of turns [51] and also that the degree of inhomogeneity in HPT disks decreases

192 with increasing strain [52]. It was demonstrated by theoretical analysis that the development of

193 homogeneity may be anticipated based on an application of strain gradient plasticity modeling

194 [53] and detailed experiments showed that excellent hardness homogeneity may be achieved 195 throughout the disks at high strains by measuring the hardness values on sectional planes after 196 straining [54]. The evolution towards a saturation microstructure at high strains may occur in 197 different ways depending upon the extent of any recovery and the precise role of strengthening 198 and weakening [55]. This evolution was examined in a recent comprehensive review which 199 summarizes HPT data for a large number of materials [56]. 


\section{Cu-0.1 wt. \% Zr \\ HPT: $6.0 \mathrm{GPa}$, RT}

\section{$\mathrm{N}=1 / 4$ turn}

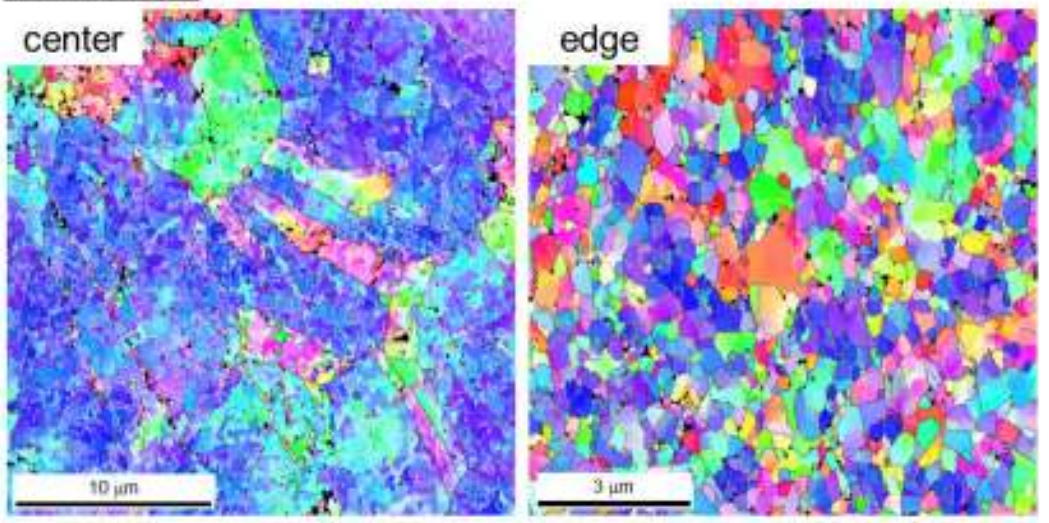

(a)

\section{$\mathrm{N}=5$ turns}

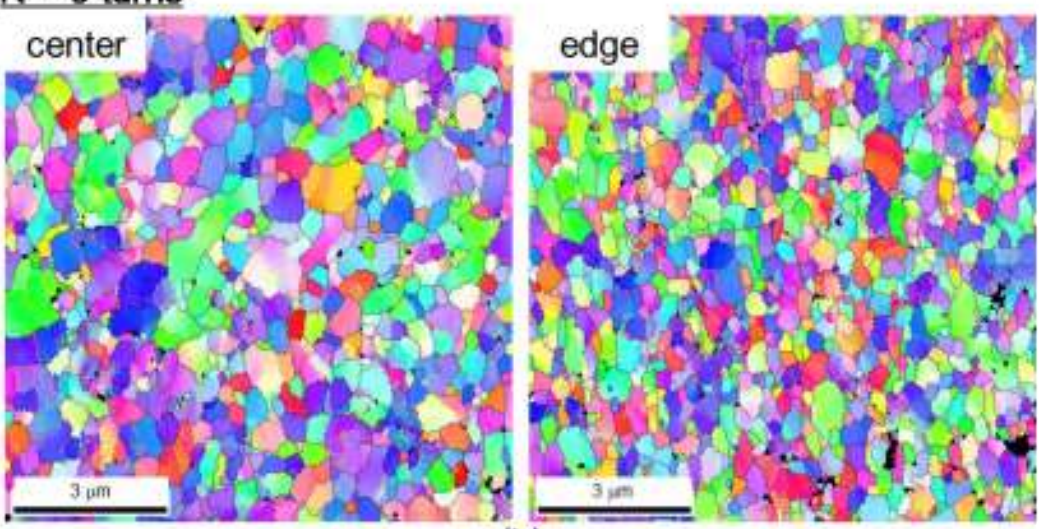

(b)

$\mathrm{N}=10$ turns

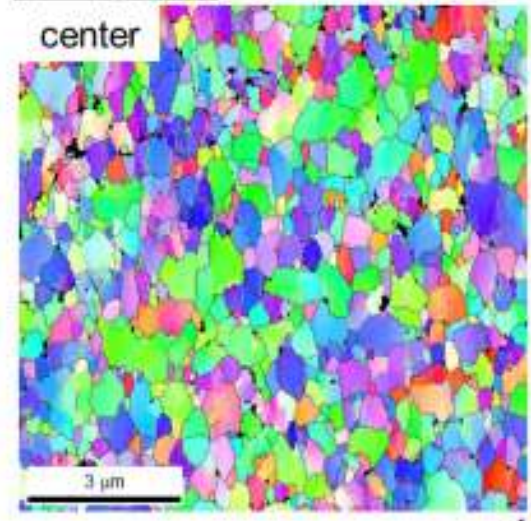

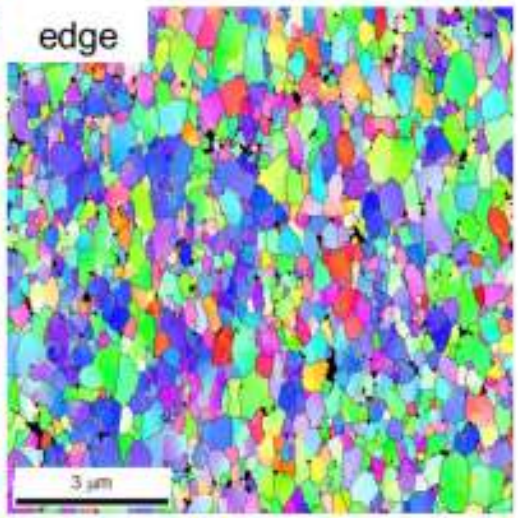

(c)

Figure 2. EBSD orientation images of $\mathrm{Cu}-0.1 \% \mathrm{Zr}$ disks processed by HPT for (a) 1/4 turn, (b) 5 turns and (c) 10 turns: the columns display images from the center of the disk (on left) and at the edge of the disk (on right). Reprinted with permission from reference [57]. 
205 Figure 2 shows electron backscatter diffraction (EBSD) images of the microstructural 206 evolution in a $\mathrm{Cu}-0.1 \% \mathrm{Zr}$ alloy processed by HPT at RT under an applied pressure of $6.0 \mathrm{GPa}$ 207 where the three rows relate to $1 / 4,5$ and 10 turns and the two columns correspond to the 208 approximate center of the disk on the left and near the edge of the disk on the right, respectively 209 [57]. The grain size initially was $\sim 20 \mu \mathrm{m}$ but the images show the occurrence of very extensive 210 grain refinement during HPT processing such that after 10 turns the measured grain sizes were $211 \sim 270$ and $\sim 230 \mathrm{~nm}$ at the center and near the edge, respectively.

\section{C. Recent Developments in Processing by ECAP}

213 Processing by ECAP can be achieved easily in the laboratory but it is a labor-intensive 214 process because of the need to press the same billet through the die a number of times. 215 Accordingly, much attention has been devoted to developing other approaches that may have 216 more use in industrial applications [58-60]. A simple procedure to avoid the need for multiple 217 pressings in ECAP is to construct a multi-pass die in which a high strain is imposed in a single 218 pass [61]. This procedure works well and produces results which are essentially identical to 219 those achieved using a series of separate passes through a conventional ECAP die [61] but 220 nevertheless it has the disadvantage that it exposes the die to large loads which require special 221 technical solutions. A second problem in conventional ECAP is that is produces billets having 222 gross distortions at either end and this leads to a wastage of material of an estimated order of $223 \sim 30-50 \%$ [62]. In practice, this wastage may be avoided by using an ECAP die having two

224 parallel channels since the second channel restores the original shape of the billet and effectively 225 eliminates the end effects [62]. Accordingly, this approach has been used successfully in several 226 investigations [63-65]. 
The most effective procedure for improving on conventional ECAP, and for producing long

228 samples with lengths of up to $>1 \mathrm{~m}$, is to combine ECAP with the Conform process which was

229 developed over forty years ago in the atomic energy industry in the U.K. [66,67]. Basically, the

230 Conform process permits the continuous extrusion forming of wires using the frictional forces

231 between a wire introduced from a continuous roll and a grove machined into a rotating wheel.

232 This leads to a transition from an initial circular cross-section of the wire to a rectangular cross-

233 section and, by inserting an ECAP step in the form of an abrupt abutment which displaces the

234 wire through $90^{\circ}$ at the exit channel, it is feasible to impose a strain of $\sim 1$ as in conventional

235 ECAP and to achieve significant grain refinement. Furthermore, unlike conventional ECAP, the

236 ECAP-Conform process may be used in the production of long rods which cannot be processed

237 using conventional ECAP dies. This ECAP-Conform process has been used successfully on

238 several different metals [68-75] and it is illustrated schematically in Fig. 3 [72]. An example of

239 the grain refinement achieved using this procedure is given by results on an Al-6061 alloy where

240 an initial equiaxed grain size of $\sim 350 \mu \mathrm{m}$ was reduced to elongated grains with lengths of $1.5 \mu \mathrm{m}$

241 and widths of $\sim 700 \mathrm{~nm}$ after a single pass through the ECAP-Conform die and to lengths of $\sim 1.2$

$242 \mu \mathrm{m}$ and widths of $\sim 150 \mathrm{~nm}$ after 4 passes [72]. 


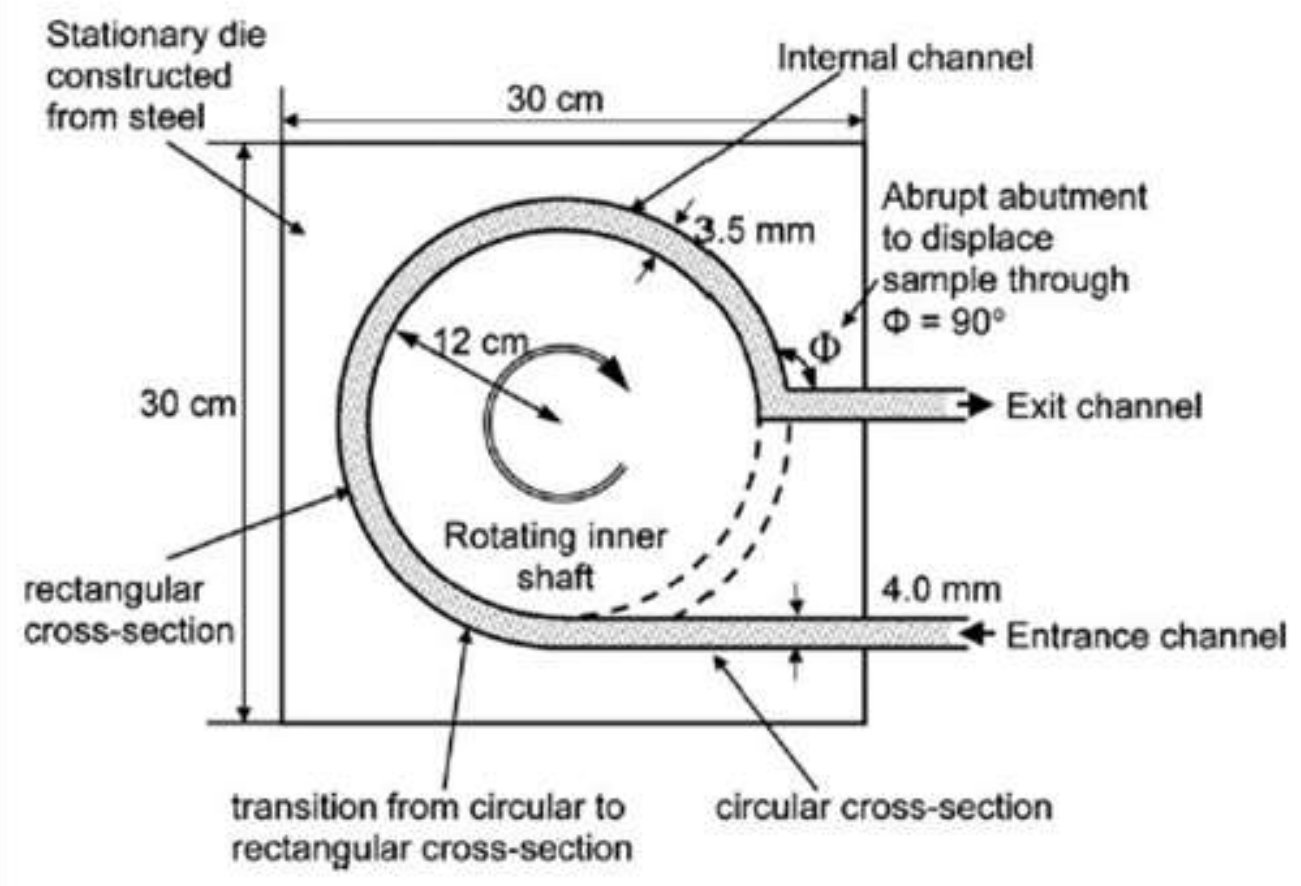

244 Figure 3. Schematic illustration of the principle of the ECAP-Conform process. Reprinted with permission from reference [72].

250 cleanings of the metal surfaces and multiple passes through ARB processing so that it is labor-

251 intensive. An alternative approach is to use the process of tube high-pressure shearing (t-HPS)

252 [76]. This latter procedure is based in part on the very early work of Bridgman [77] where tube

253 twisting was introduced as a method of avoiding the problems associated with a lack of strain at

254 the centers of the solid disks. However, the very early work was different because it was based

255 on using a tube sample and then twisting the top with respect to the bottom whereas in t-HPS the

256 sample is again in the form of a tube but the outer surface is sheared around the inner surface by 
257 placing the tube around a central mandrel, using pressure rings to hold the tube in place and 258 produce high hydrostatic pressures in the tube walls, and then using an outer cylinder to rotate 259 the outer surface with respect to the inner surface.

260 Several experiments have been conducted using t-HPS and the results are encouraging [78].

261 It was shown that, by using two different metals of an AB-type or with four initial interfaces of 262 an ABAB-type, it can be predicted theoretically that there should be a gradient distribution of 263 interfaces with denser stacking at the inner surface of the tube. This is consistent with 264 experiments and there are numerous other predictions based on different sets of initial interfaces 265 [78]. An important result from this work is that t-HPS can be used with an ABAB-type 266 bimetallic tube to produce a multilayered structure. An example is shown in Fig. 4 where the 267 two materials are $5 \mathrm{~N}$ and $4 \mathrm{~N}$ Al which were cut to give four interfaces with an ABAB-type 268 initial structure and then the tube was processed by 2 turns to give a very fine grain size $(<1 \mu \mathrm{m})$ 269 in the $4 \mathrm{~N} \mathrm{Al}$ and a much coarser grain size $(\sim 10 \mu \mathrm{m})$ in the $5 \mathrm{~N} \mathrm{Al}$ due to the easier grain growth. 270 It is clear from Fig. 4 that the microstructures of each separate component are very well defined 271 and accordingly the results show that this is an excellent procedure for producing a gradient 272 structure [78]. Furthermore, this result is important because of the current considerable interest 273 both in developing and using gradient structures [79-81] and in the fabrication of nano-laminated 274 structures [82]. 


\section{N-Al}

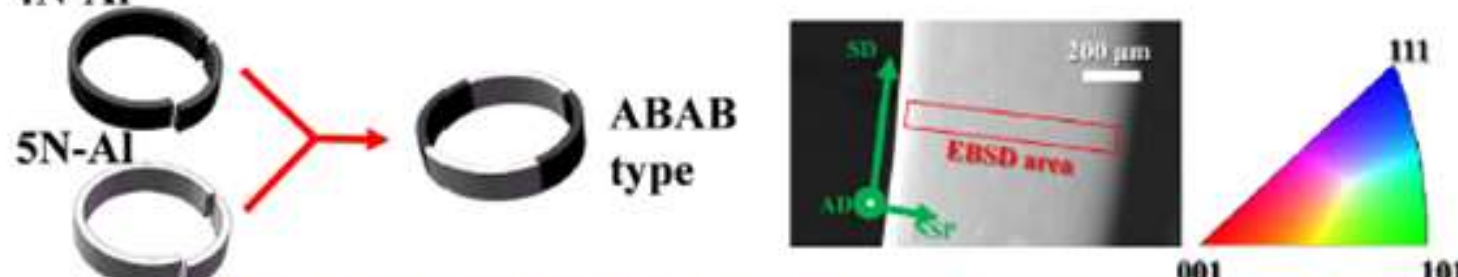

001

101

t-HPS 2 turns: $4 \mathrm{~N} / 5 \mathrm{~N} \mathrm{Al}$ multilayered structure

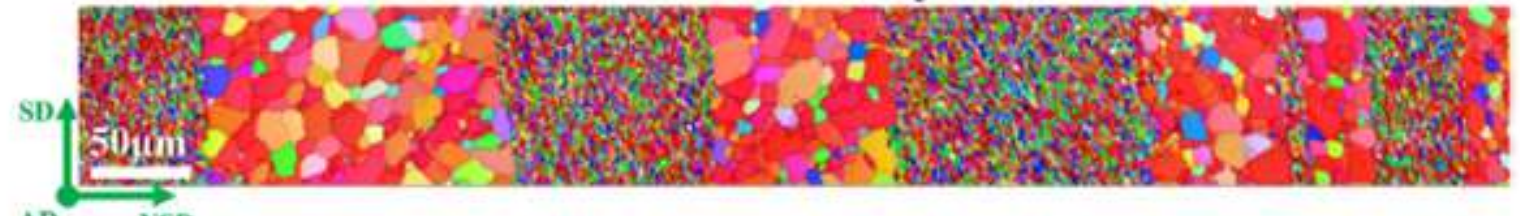

277 Figure 4. Multilayered structure with alternate distribution of finer and coarser grains fabricated

278 by an ABAB-type 5N-Al/4N-Al bimetallic tube with 2 turns of t-HPS at RT: the 4NAl layers

279 have finer grain size $(<1 \mu \mathrm{m})$ and the $5 \mathrm{~N} \mathrm{Al}$ layers have relatively coarser grains. Reprinted with permission from reference [78].

E. Using HPT to Process Metal Matrix Nanocomposites

Processing by HPT is generally used to achieve grain refinement in bulk solids. However,

284 the same process has been used also to consolidate metallic powders [83-97], composites [98-

285 102], amorphous compounds [103-107], machining chips [108-110] and ceramic powders [111].

286 Very recently, new approaches have been developed based on using HPT to bond dissimilar 287 metals and produce solid bulk metallic samples.

288 The use of dissimilar metals is well established in processing by ARB where sheets of 289 different materials may be conveniently stacked and then processed to form multi-layered 290 microstructures [112-116]. But experiments show that processing by ARB leads to anisotropic 291 plastic behavior, including in strength and ductility, because the properties depend critically upon 292 the precise testing direction cut from the finished product [117]. This suggests it may be 
293 advantageous to make use of the very high pressures inherent in HPT processing in order to 294 achieve a solid-state reaction.

295 The first attempt to bond dissimilar metals using HPT was in experiments where semi296 circular half-disks of $\mathrm{Al}$ and $\mathrm{Cu}$ were successfully bonded by HPT at RT using a total of up to 297100 revolutions [118]. Similar experiments were also conducted using four quarter-disks, two 298 each of pure $\mathrm{Cu}$ and an Al-6061 alloy, which were positioned to make a complete disk and then 299 processed by HPT for 1 turn at RT to fabricate an Al-Cu hybrid material [119]. This early work 300 confirmed the feasibility of this approach and accordingly extensive experiments were conducted 301 using a commercial purity aluminum Al-1050 alloy and a commercial ZK60 magnesium alloy 302 with the objective of using these materials to synthesize an Al-Mg multi-layered bulk 303 nanostructured material [120-123]. All processing in these experiments was conducted using 304 HPT at RT under quasi-constrained conditions $[124,125]$ with three separate disks placed in the 305 HPT facility in the stacking order of $\mathrm{Al} / \mathrm{Mg} / \mathrm{Al}$ with the $\mathrm{Mg}$ disk held between the two $\mathrm{Al}$ disks 306 but without using any glue or metal brushing treatment. All stacks of disks were processed 307 under an applied pressure of $6.0 \mathrm{GPa}$ with various numbers of turns up to a total of 10 308 revolutions using a constant rotation rate of $1 \mathrm{rpm}$.

309 Figure 5 shows three color-coded contour maps that display, using different colors, the 310 values of the measured Vickers microhardness recorded on vertical cross-sectional planes of the 311 disks after processing through 1, 5 and 10 turns, respectively [120]. After 1 turn the hardness is 312 of the order of $\sim 60-70 \mathrm{Hv}$ but after 5 turns the hardness has increased at the edges of the disk and 313 this hardness at the periphery increases even more after 10 turns. Thus, the hardness increases to $314 \mathrm{Hv} \approx 130$ at the edge after 5 turns but it further increases to $\mathrm{Hv} \approx 270$, equivalent to a tensile 315 strength of $\sim 865 \mathrm{MPa}$, after 10 turns. These hardness values are exceptionally high and they 
316 may be compared with values of $H v \approx 63-65$ [126] and $H v \approx 105-110$ [127] for the Al-1050 alloy

317 and the ZK60 alloy, respectively, after processing by HPT through 5 turns. Detailed

318 examination by transmission electron microscopy and energy-dispersive X-ray spectroscopy

319 revealed that this high hardness is due to the formation of intermetallic nano-layers of $\beta-\mathrm{Al}_{3} \mathrm{Mg}_{2}$

320 and the development after 10 turns of a nanostructured intermetallic compound of $\gamma-\mathrm{Al}_{12} \mathrm{Mg}_{17}$ in

321 the Al matrix in a supersaturated solid solution state. The extraordinary strength achieved in

322 these experiments through HPT processing of disks of dissimilar metals suggests there is a

323 potential for using this approach to fabricate a wide range of metal matrix nanocomposites

324 (MMNCs).

325

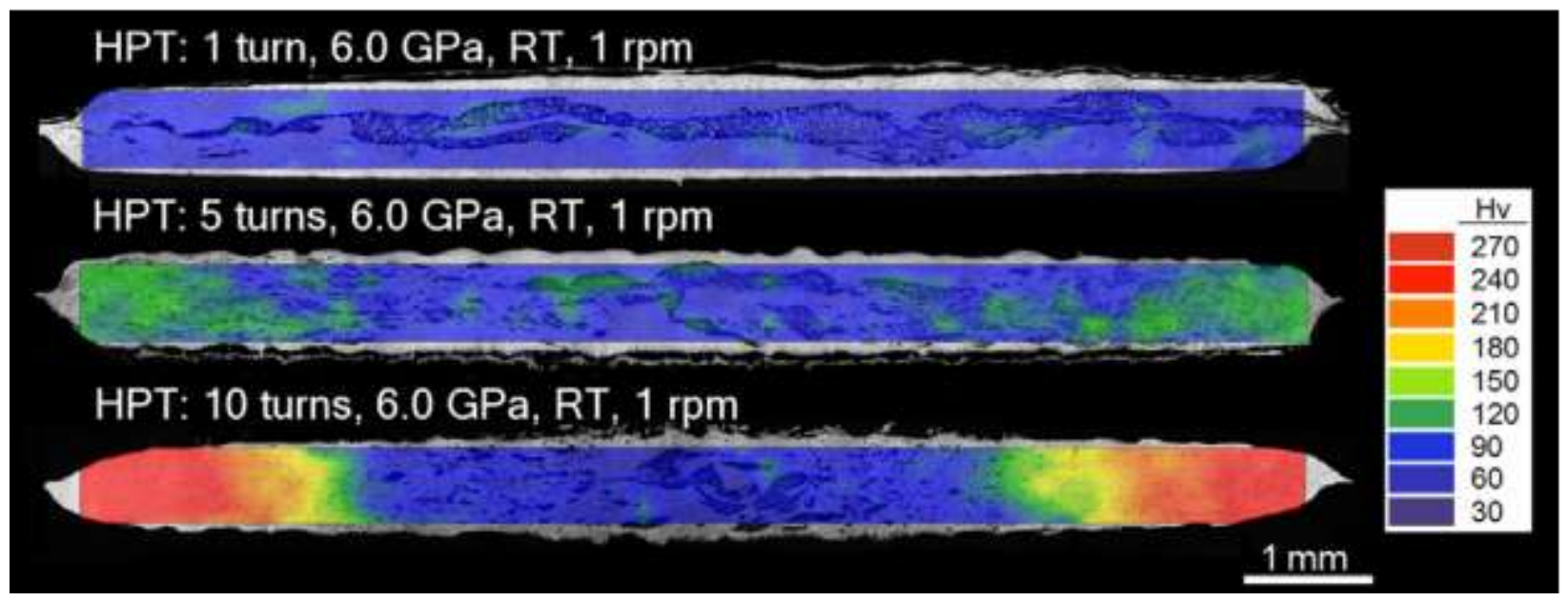

327 Figure 5. Color-coded contour maps of the Vickers microhardness for the Al/Mg system after 328 HPT for 1 turn (upper), 5 turns (center) and 10 turns (lower): the values associated with the 329 various colors are given in the hardness color key on the right. Reprinted with permission from reference [120].

Using the tensile strength of $\sim 865 \mathrm{MPa}$ at the edges of the disk in Fig. 5, the measured

333 strength at the outer edge after 10 turns gives a remarkable strength/weight ratio of $\sim 350 \mathrm{MPa}$

$334 \mathrm{~cm}^{3} \mathrm{~g}^{-1}$ and this specific strength is much higher than in many steels or Ti alloys and it is even 
335 comparable to some strong polymeric engineering composites [128]. Therefore, using the 336 diagram proposed earlier for a very wide range of materials as shown in Fig. 6 [128], it is now 337 appropriate to include the experimentally-synthesized Al-Mg system shown in Fig. 5 where this 338 is denoted in the diagram as HPT-induced aluminum MMNCs without delineating any upper 339 limits to the fracture toughness or the strength-to-weight ratio [122]. It is important to note, from 340 inspection of Fig. 6, that the new MMNC is far superior to conventional $\mathrm{Al}$ and $\mathrm{Mg}$ alloys 341 (shown by the regions in yellow and red, respectively). Although detailed experiments will be 342 required in the future to precisely define the limits of this approach, it is clear from these early 343 observations that HPT processing of dissimilar metals has a considerable potential for fabricating 344 MMNCs having unusually high strength. 


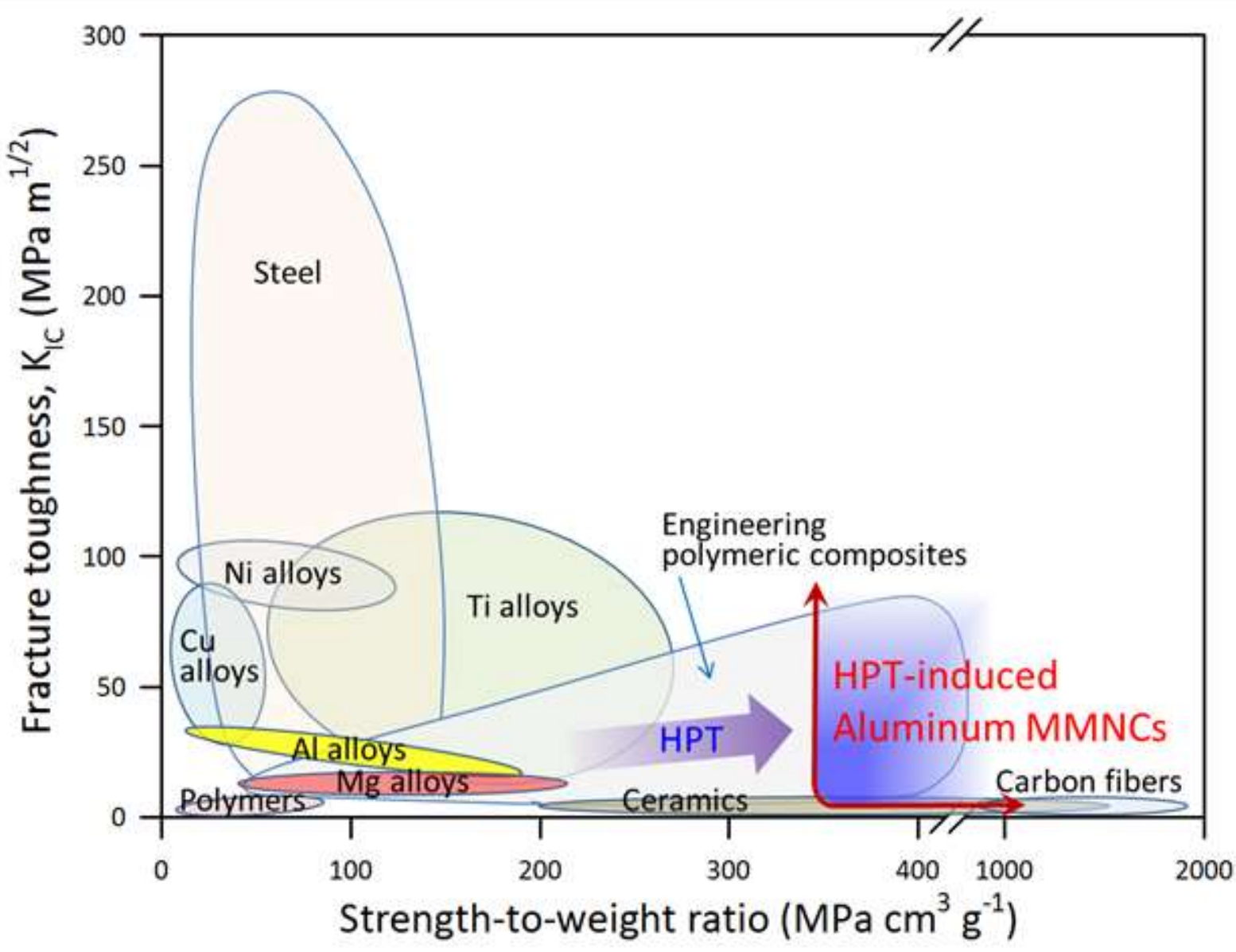

347 Figure 6. The range of fracture toughness and strength-to-weight ratio for many metals and 348 materials [128] where the synthesized Al-Mg system shown in Fig. 5 after HPT is incorporated 349 into the diagram as HPT-induced aluminum MMNCs without delineating any upper limits for these values. Reprinted with permission from reference [122].

\section{III.BULK NANOSTRUCTURED MATERIALS FROM POWDER PRECURSORS -THE NEED FOR GRAIN SIZE STABILIZATION.}

Because grain boundaries are non-equilibrium defects and increase the free energy of a

355 material, the large area of grain boundaries in nanostructured materials provides a large driving

356 force for grain growth. The nanocrystalline grain size is inherently unstable. Significant grain

357 growth, that is, doubling of the initial nanocrystalline grain size in 24 hours, has been observed at 358 room temperature in a number of pure, relatively low melting temperature elements such as Sn, 
$\mathrm{Pb}, \mathrm{Al}$, and $\mathrm{Mg}$ [129]. Günther et al. [130] studied grain growth in pure $\mathrm{Cu}, \mathrm{Ag}$, and $\mathrm{Pd}$ and

360 found grain growth occurring at much lower temperatures than those observed for

361 recrystallization of the elements after heavy cold deformation. In fact, grain growth in $\mathrm{Cu}$ and

362 Pd was observed even at room temperature. This is particularly dramatic for Pd which has a high

363 melting temperature of $1825 \mathrm{~K}\left(1552^{\circ} \mathrm{C}\right)$ such that room temperature is only 0.16 of the melting

364 temperature - a very low homologous temperature. Subsequently, Ames et al. [131] observed

365 the grain growth of $10 \mathrm{~nm}$ grain size $\mathrm{Pd}$ to 10 micron grain size after one month at room

366 temperature. In this case, as in the others of grain growth at room temperature, the initial growth

367 is abnormal. However, at longer times the grain growth changes to normal grain growth.

368 A general expression for grain growth in terms of the velocity of the boundary can be given

369 as: $V=M P$ where $M$ is the grain boundary mobility $=M_{o} \exp \left(-Q_{m} / R T\right)$, and $P=$ the driving

370 pressure $=C \gamma / r$, where $\gamma$ is the specific grain boundary energy, and $r$ is the average grain

371 radius.[132,133]. The two approaches for achieving stabilization of nanoscale grain sizes are

372 then to 1 , reduce the mobility, $M$, by various pinning mechanisms, or 2 . To reduce the driving

373 force for grain growth by reducing the specific grain boundary energy, $\gamma$.

\section{A. Kinetic stabilization theories and examples of experimental evidence}

375 There are a number of possible mechanisms that have been proposed that may limit the 376 mobility of nanocrystalline grain boundaries. These include porosity drag, solute drag, second 377 phase (Zener) drag, chemical ordering, and grain size stabilization. The most general 378 applicability to a variety of systems and the most important of these mechanisms are solute drag 379 and second phase (Zener) drag. 
First we discuss the solute drag mechanism. The Cahn [134] Lucke-Stuwe [135] models

381 provide good semi-quantitative account of the effects of solute on grain boundary mobility.

382 According to these models, at low velocities the velocity is inversely proportional to solute

383 concentration. At higher driving forces or lower solute concentrations, there is a transition to a

384 velocity regime where the velocity is independent of solute content. The effect of solute is less

385 at higher temperatures. The solute atmosphere becomes much weaker. Solute drag has been

386 used to explain experimental results of stabilization of a number of nanocrystalline materials, for

387 example $\mathrm{Ni}-1$ at.\% Si [136] and $\mathrm{Pd}-19$ at.\% $\mathrm{Zr}[137]$.

388 In the second phase (Zener) drag mechanism, the second phase may be a precipitate or 389 dispersoid (e.g. oxide). This pinning effect is less sensitive to temperature than solute drag, 390 especially if a dispersoid is resistant to coarsening. Particle size and distribution play a key role 391 in the effect. The expression for the pinning pressure exerted on the grain boundary by small 392 particles is, in the original Zener formulation [132]

$393 \quad P=3 f \gamma / 2 r$, where $\mathrm{f}$ is the volume fraction of particles randomly distributed of spherical 394 radius $r$, and $\gamma$ is the specific grain boundary energy. A refinement of this model [138] gives $D=$ $3950.17 d / f$ for low volume fractions, where $D$ is the critical grain size, $\mathrm{d}$ the particle size, and $\mathrm{f}$ the 396 volume fraction. A large number of experiments on stabilization of nanocrystalline grain sizes 397 have been explained using Zener drag, for example Fe - $10 \mathrm{Al}$ with dispersoids [139].

398 Other mechanisms for decreasing grain boundary mobility include porosity drag, chemical 399 ordering, and grain size effect. Porosity can reduce grain boundary mobility as demonstrated in 400 the grain growth of ceramic $\mathrm{TiO}_{2}$ prepared by the inert gas condensation method [140]. Reduced 401 grain growth has been observed for ordered nanocrystalline intermetallic compounds, for 402 example $\mathrm{Fe}_{3} \mathrm{Si}$ [141]. Grain size stabilization has been predicted by theoretical models and 
403 observed experimentally [142]. It is suggested that the decrease in free volume which occurs on

404 grain growth is offset by the non-equilibrium vacancy concentration increases in the matrix as

405 the excess free volume is released on grain growth.

\section{B. Thermodynamic stabilization theories}

The general concept of thermodynamic stabilization involves the segregation of solute atoms

408 to the grain boundaries such that the grain boundary energy may be reduced. The reduction of

409 excess interface Gibbs free energy, G, with increasing solute content can be described by the

410 Gibbs adsorption isotherm: $d \gamma=-\Gamma d \mu$ where $\mu$ is the chemical potential of the solute atom

411 dissolved in a matrix of solvent atoms, and $\Gamma$ is the excess amount of solute atoms segregated to

412 the boundary. Plots of $\gamma=d G / d A$ vs. global solute content show a reduction of $\gamma$ with

413 increasing solute content [143]. Large solute atoms intensify this and could reduce the excess

414 grain boundary free energy with possible grain boundary stabilization at $\gamma=0$. This $\gamma$ is not to

415 be confused with grain boundary cohesive energy. Weissmuller [144] was the first to apply

416 these ideas to stabilization of nanocrystalline grain size. His model was based on a dilute

417 solution limit. The equation has the following form: $\gamma=\gamma_{o}-\Gamma_{\text {sat }}\left[\Delta H_{\text {seg }}+R T \ln \left(x_{c}\right)\right]$ where $\gamma_{\mathrm{o}}$

418 is the grain boundary energy of the pure metal, $\Gamma_{\text {sat }}$ is the solute excess for fully saturated grain

419 boundary interface, $\Delta H_{\text {seg }}$ is the segregation enthalpy, and $R T \ln \left(x_{c}\right)$ represents the ideal mixing

420 entropy for bulk solute concentration $\mathrm{x}_{\mathrm{c}}$. This equation implies that the grain size at stabilization

421 decreases as the solute content increases at a fixed temperature. The analysis of Weissmuller

422 was extended by Kirchheim [145] to include the temperature dependence of grain size for a

423 metastable equilibrium state. The regular solution model of Trelewicz and Schuh [146]

424 eliminates many of the approximations in the previous models, for example, fully saturated grain

425 boundaries or dilute solution approximations. This model has grain boundary regions and bulk 
426 regions with variable volume fractions and solute concentrations separated by transitional bonds.

$427 \Delta G_{m i x}$ is obtained from the difference in the nearest neighbor bond energy and mixing entropy of

428 this system relative to equivalent volumes of unmixed pure A and pure B with no grain

429 boundary. The equilibrium state is obtained by simultaneous minimization of $\Delta G_{m i x}$ with respect

430 to variations of the solute concentration and the grain boundary volume fraction, subject to

431 conservation of solute. Elastic size misfit enthalpy was not included in this model. A

432 modification of the above model was presented by Saber et al. [147]. A regular solution model

433 for thermodynamic stabilization was based on the Wynblatt-Ku approximation [148] to

434 incorporate both chemical and elastic enthalpy. The equilibrium condition is defined by

435 minimization of the total Gibbs mixing free energy with respect to simultaneous variations in the

436 solute contents and volume fractions with the constraint of overall mass balance. The Lagrange

437 multiplier technique was used to obtain an explicit solution to the constrained equations in a

438 form easily solved using standard numerical software packages. Results for Fe-Zr alloys are 439 given in Figure 7 [147]. 

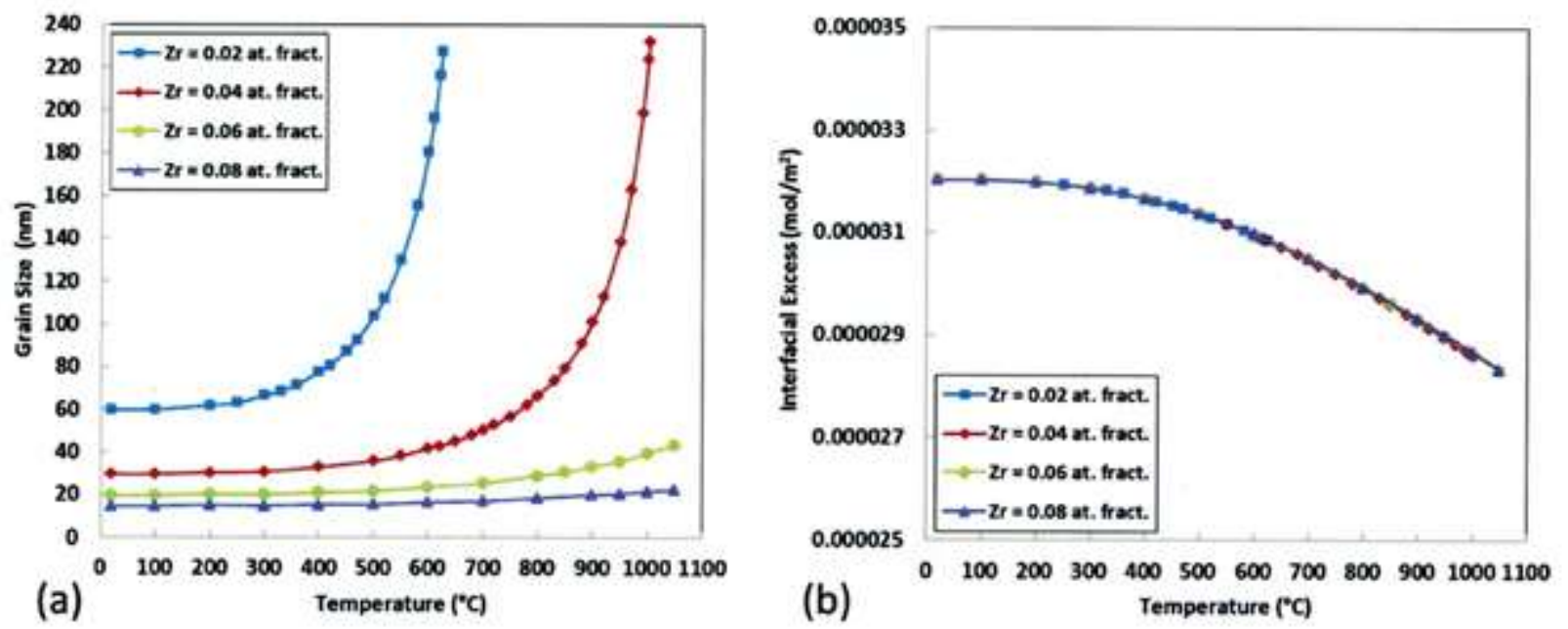

Figure 7. Model predictions of (a) grain size, and (b) interfacial solute excess for Fe-Zr alloys. Reprinted with permission from reference [147].

446 phase separation. Chookajorn et al. [149] addressed this problem using an analytical approach

447 based on the Trelewicz and Schuh [146] model. They simplified the problem by considering 448 only alloys with positive enthalpies of mixing. Stability maps of enthalpy of segregation vs. 449 enthalpy of mixing were constructed for several elements. One for tungsten is shown in Figure 4508.

Subsequently, Schuh and co-workers have extended the range of alloys and details of the 452 grain boundary structure by using Monte Carlo simulations to construct stability maps with six 453 different regions of nanocrystalline stability including duplex nanostructures [150]. 


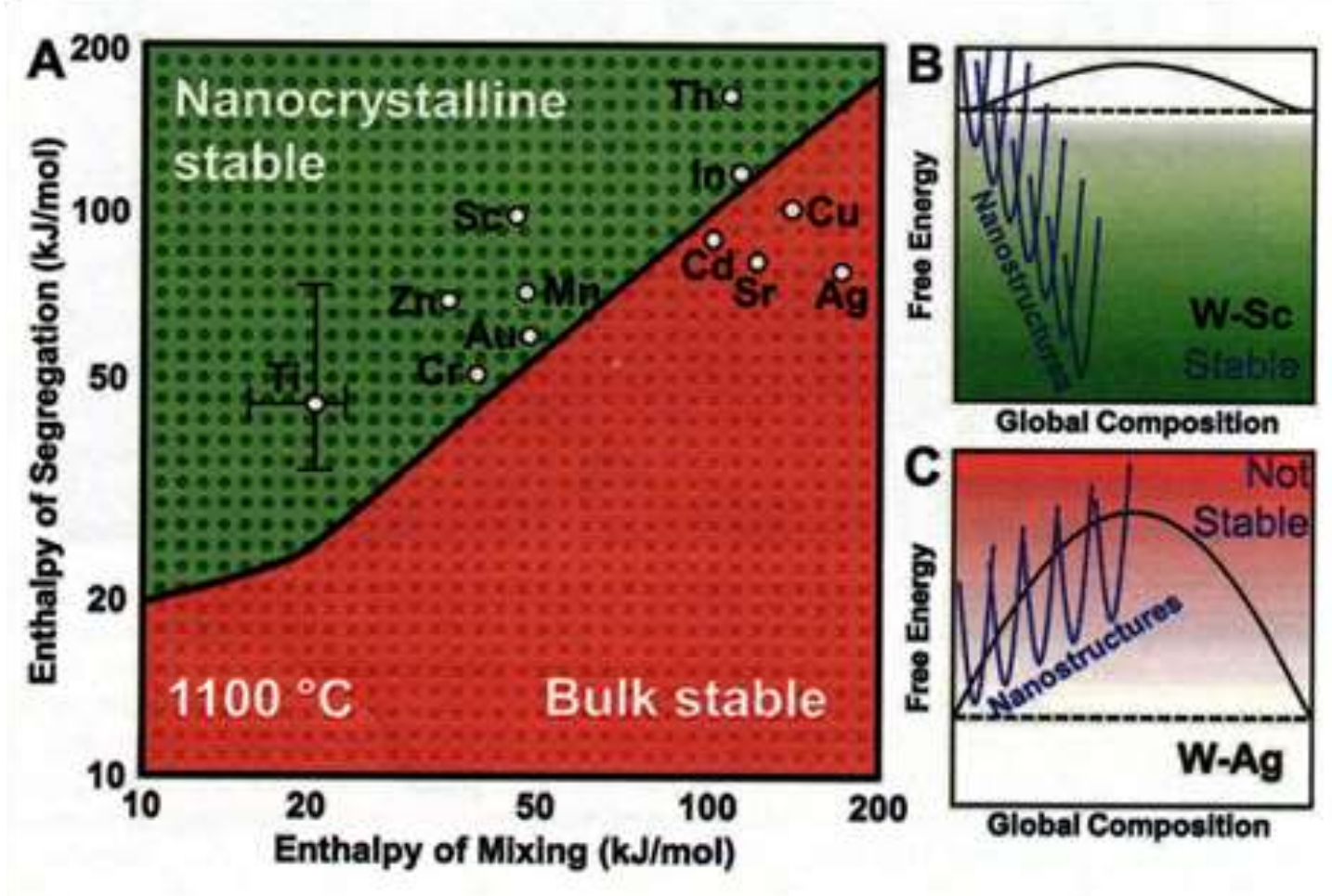

455 Figure 8 . The nanostructure stability map for tungsten-based alloys at $1100 \mathrm{oC}$, calculated on the 456 basis of variation of the enthalpy parameters. For each combination of parameters, the free 457 energy of nanocrystalline structures is compared to that of the bulk regular solution. An example 458 for the nanocrystalline stable region in given in (B) for W-Sc. A bulk stable case is given in (C) for W-Ag. Reprinted with permission from reference [149].

C. Complexions as possible sources of nanocrystalline grain size stabilization

Interface "complexions" are grain boundary "phases" in thermodynamic equilibrium that

462 have stable, finite thicknesses. They were first, and mostly, observed and studied in ceramic

463 materials. Dillon et al. [151] have created a categorization scheme for complexions based on

464 studies of $\mathrm{Al}_{2} \mathrm{O}_{3}$ doped with calcia, silica, magnesio, or neodymia. The six categories of 465 complexions were identified using high resolution TEM images of the grain boundaries. Rupert

466 [152] has recently reviewed the role of complexions in metallic nanocrystalline materials with 467 regard to thermal stability and deformation. Khalajhedayati and Rupert [153] had reported 468 remarkable thermal stability in nanocrystalline $\mathrm{Cu}-3$ at. $\% \mathrm{Zr}$ with a nanoscale $(54 \mathrm{~nm})$ grain 
469 size remaining after heating for a week at $1223 \mathrm{~K}\left(950^{\circ} \mathrm{C}\right)(98 \%$ of the solidus temperature!).

470 They attributed this stability to segregation at the grain boundary forming amorphous

471 intergranular films (complexions) and to Zener pinning by ZrC nano-particles.

472 D. Experimental evidence for thermal stability of nanocrystalline alloys

473 A few examples were given in the section on kinetic stabilization theories of experiments that

474 appear to support this mechanism. In this section, two examples of systems will be given where

475 there is possible contributions to thermal stabilization from both the thermodynamic and kinetic

476 mechanisms. Finally, a comparison will be made using the available data from the literature of

477 thermodynamic, kinetic, combinations of the two, and complexions for stabilization of 478 nanocrystalline alloys as a function of homologous temperature.

479 Example 1. Thermal stability of nanocrystalline $\mathrm{Fe}-\mathrm{Cr}$ alloys with $\mathrm{Zr}$ additions. The 480 influence of 1 to 4 at.\% $\mathrm{Zr}$ additions to $\mathrm{Fe}-10$ and 18 at.\% $\mathrm{Cr}$ alloys on the thermal stability of 481 the nanocrystalline microstructure was studied [154]. Grain sizes were determined by XRD, 482 channeling contrast FIB imaging, and TEM for isochronal annealing treatments up to $1273 \mathrm{~K}$ $483\left(1000^{\circ} \mathrm{C}\right)$. Grain size stabilization in the nanoscale range was maintained up to $1173 \mathrm{~K}\left(900^{\circ} \mathrm{C}\right)$ 484 by adding 2 at.\% Zr. This is illustrated in Figure 9 where a histogram of the bright field TEM 485 grain size data is given for the $\mathrm{Fe}-10$ at. $\% \mathrm{Cr}-2$ at. $\% \mathrm{Zr}$ sample annealed at $1173 \mathrm{~K}$. The 486 average grain size for this condition was determined to be $82 \mathrm{~nm}$. Analysis based on the Hall487 Petch strengthening and Orowan strengthening was used to extract the volume fraction of 488 intermetallic particles having a mean size of $20 \mathrm{~nm}$. Comparing the TEM grain size with the 489 calculated grain size from the Orowan hardening and Zener pinning models of $168 \mathrm{~nm}$ suggests 490 that thermodynamic stabilization may be contributing to the stabilization observed along with 491 Zener pinning. 
493 indicates that the bcc to fcc phase transformation does not influence the grain size stabilization in 494 these alloys.

495

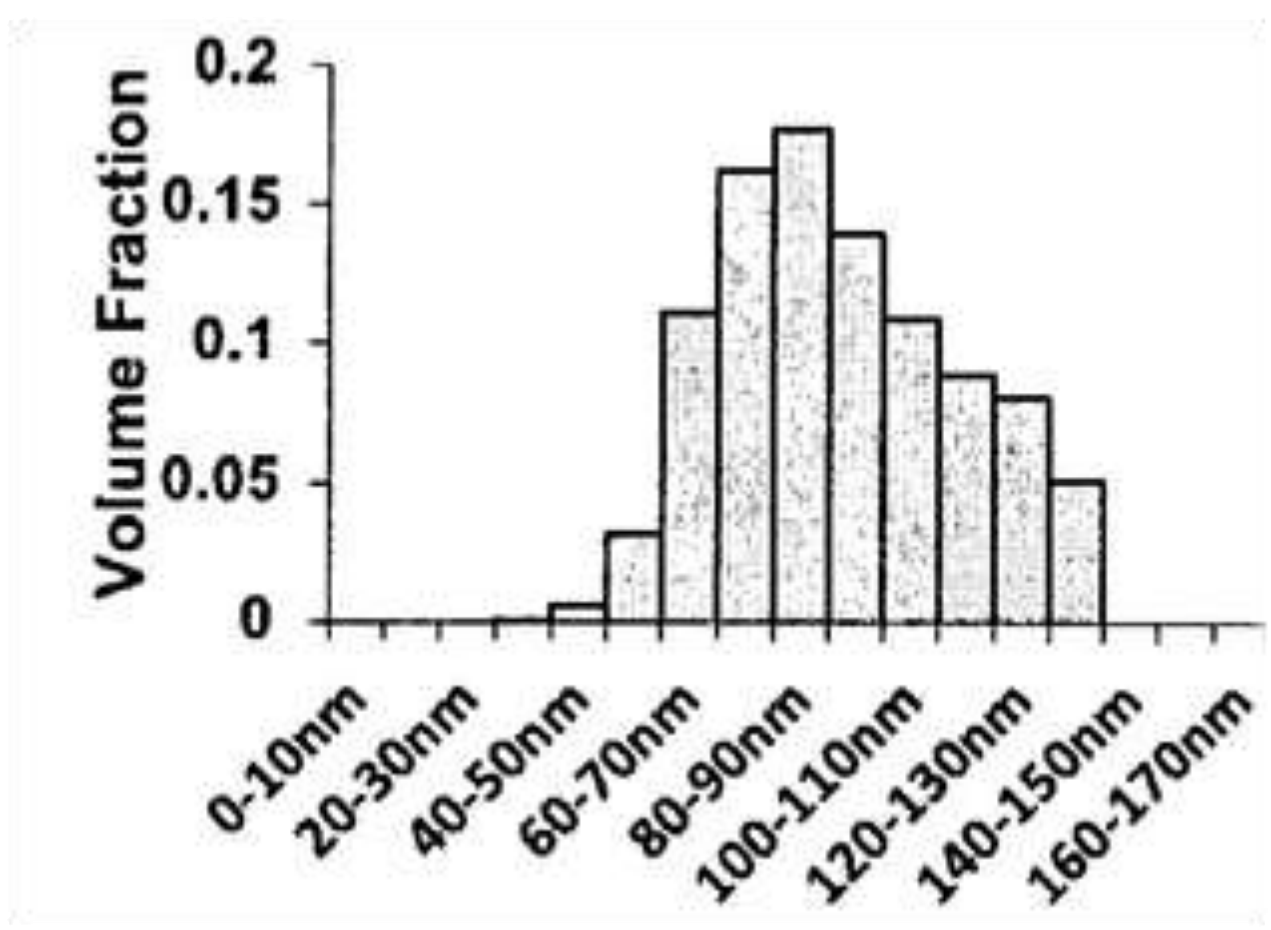

Figure 9. Bright field grain size histogram for $\mathrm{Fe}-10$ at. $\% \mathrm{Cr}-2$ at.\% $\mathrm{Zr}$ sample annealed at $1173 \mathrm{~K}\left(900^{\circ} \mathrm{C}\right)$. Reprinted with permission from reference [154].

Example 2: High temperature grain size stabilization of nanocrystalline $\mathrm{Fe}-\mathrm{Cr}$ alloys with $\mathrm{Hf}$ additions. Similar to example 1, the influence of 1 to 4 at.\% $\mathrm{Hf}$ additions on the thermal stability of nanocrystalline $\mathrm{Fe}-14 \mathrm{Cr}$ was studied [155]. Hf was selected as a solute addition because the enthalpy of formation of $\mathrm{HfO}_{2}$ is more negative than that of $\mathrm{ZrO}_{2}$ indicating that the second phase formation leading to Zener pinning effect might be enhanced compared to the $\mathrm{Zr}$ solute additions in Example 1. In addition, the prediction of thermodynamic stabilization for ternary alloys [156] suggests that $\mathrm{Hf}$ should be an effective solute for thermodynamic stabilization in $\mathrm{Fe}$ -14Cr. Again, XRD, high resolution TEM, channeling contrast FIB imaging, and microhardness 
508 were obtained for isochronal annealing temperatures up to $1373 \mathrm{~K}\left(1100^{\circ} \mathrm{C}\right)$. It was found that the

$509 \mathrm{Fe}-14 \mathrm{Cr}-4$ at.\% Hf alloy exhibited effective grain size stabilization in the nano-scale range up

510 to $1273 \mathrm{~K}\left(1000^{\circ} \mathrm{C}\right)$. The hardness of nearly $5.2 \mathrm{GPa}$ is maintained after annealing at $1273 \mathrm{~K}$.

511 The Hall-Petch plot for this alloy along with the base $\mathrm{Fe}-14 \mathrm{Cr}$ alloy is presented in Figure 10.

512 Employing the Hall-Petch grain size strengthening and Orowan particle strengthening

513 equations for $\mathrm{Fe}-14 \mathrm{Cr}-4$ at. $\% \mathrm{Hf}$ annealed at $900^{\circ} \mathrm{C}$, the deviation of grain size predictions

514 from the actual grain size suggests, as in Example 1, the possibility of a thermodynamic

515 stabilization mechanism contribution due to solute segregation to grain boundaries. The use of a

516 thermodynamic model [156] (prediction given in Figure 11) shows that thermodynamic

517 stabilization can be a viable additional mechanism in conjunction with Zener pinning for

518 stabilizing the nano-grains in $\mathrm{Fe}-4 \mathrm{Cr}-4$ at. $\% \mathrm{Hf}$ at $1173 \mathrm{~K}\left(900^{\circ} \mathrm{C}\right)$.

519 


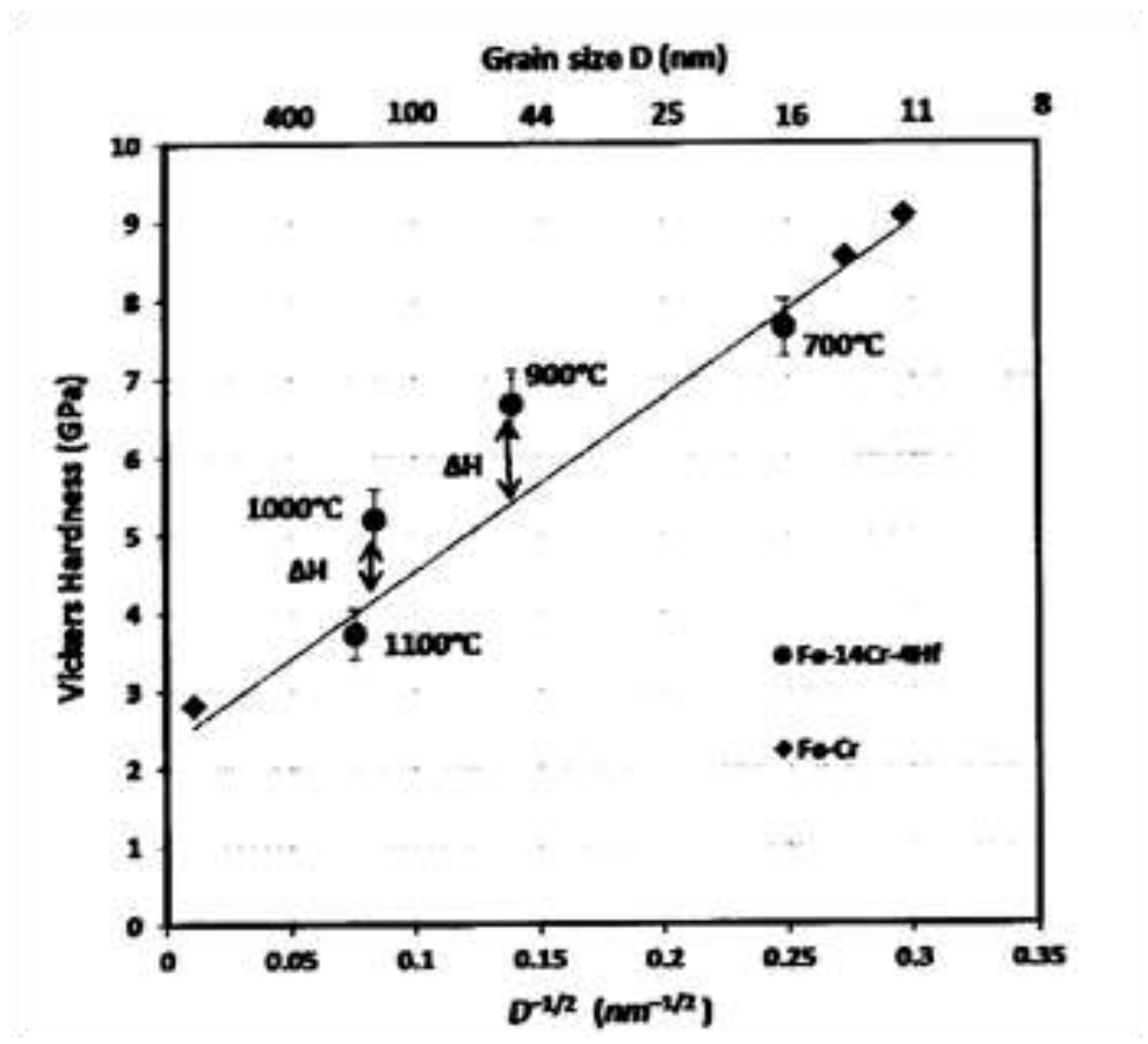

Figure 10. Hall-Petch plot of $\mathrm{Fe}-14 \mathrm{Cr}-4 \mathrm{Hf}$ alloy along with the base $\mathrm{Fe}-14 \mathrm{Cr}$ alloy. Reprinted with permission from reference [155].

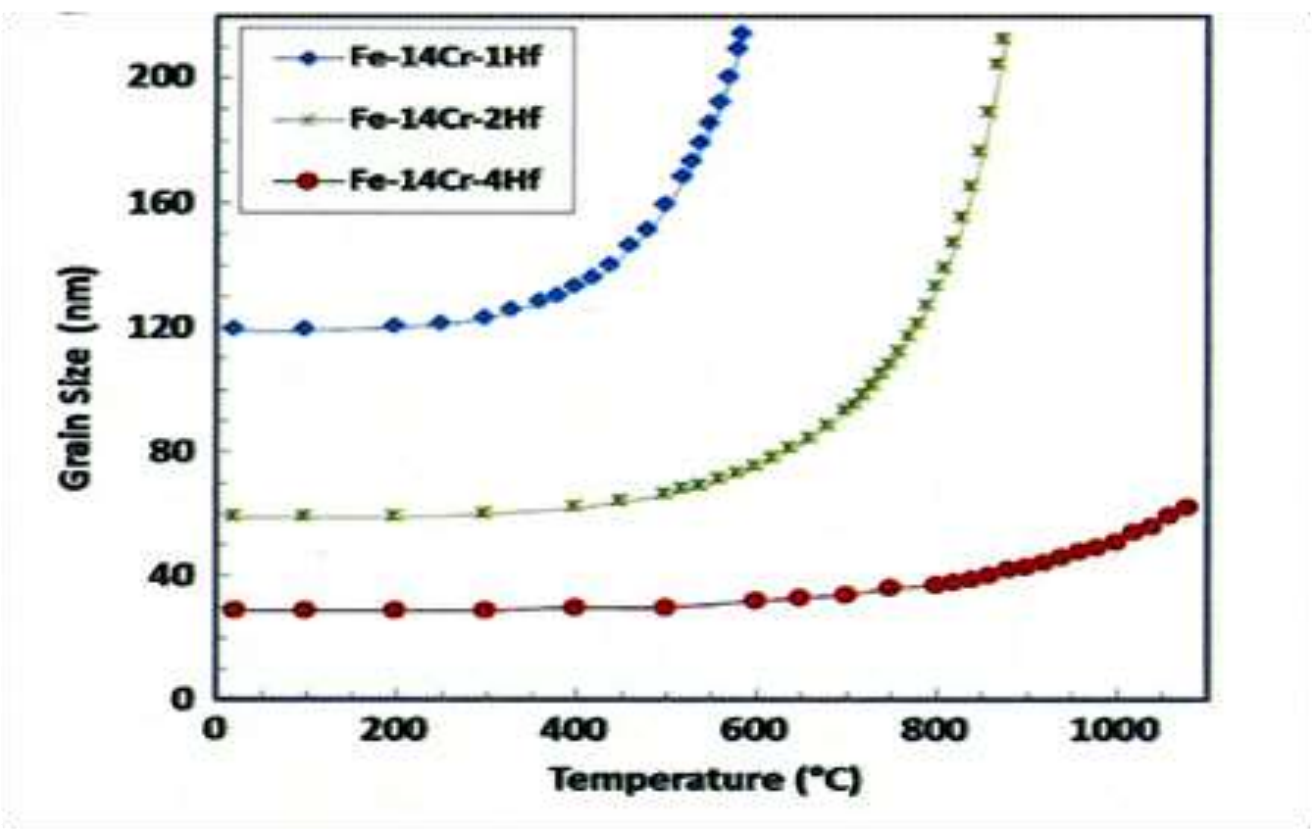



examine data from the literature and looking at the maximum homologous temperature for which

531 the alloy remains nanocrystalline (grain size $<100 \mathrm{~nm}$ ) and the specifics of the experimental 532 results decide whether the stabilization was due to the thermodynamic mechanism, a kinetic 533 mechanism, a combination of the two, or due to kinetic and complexion stabilization.

534 From the experimental data shown in Figure 12, it would suggest that the most effective 535 mechanisms for thermal stabilization of nanocrystalline grain size are kinetic (Zener pinning by 536 nanoscale particles) or a combination of this and thermodynamic stabilization by solute 537 segregation to grain boundaries. The one data point for $\mathrm{Cu}-3$ at.\% $\mathrm{Zr}$ where Zener pinning is 538 combined with the complexion (an amorphous grain boundary layer) that gives thermal 539 stabilization almost to the melting temperature, points to a possible fertile research field to 540 improve the properties of nanocrystalline alloys. 


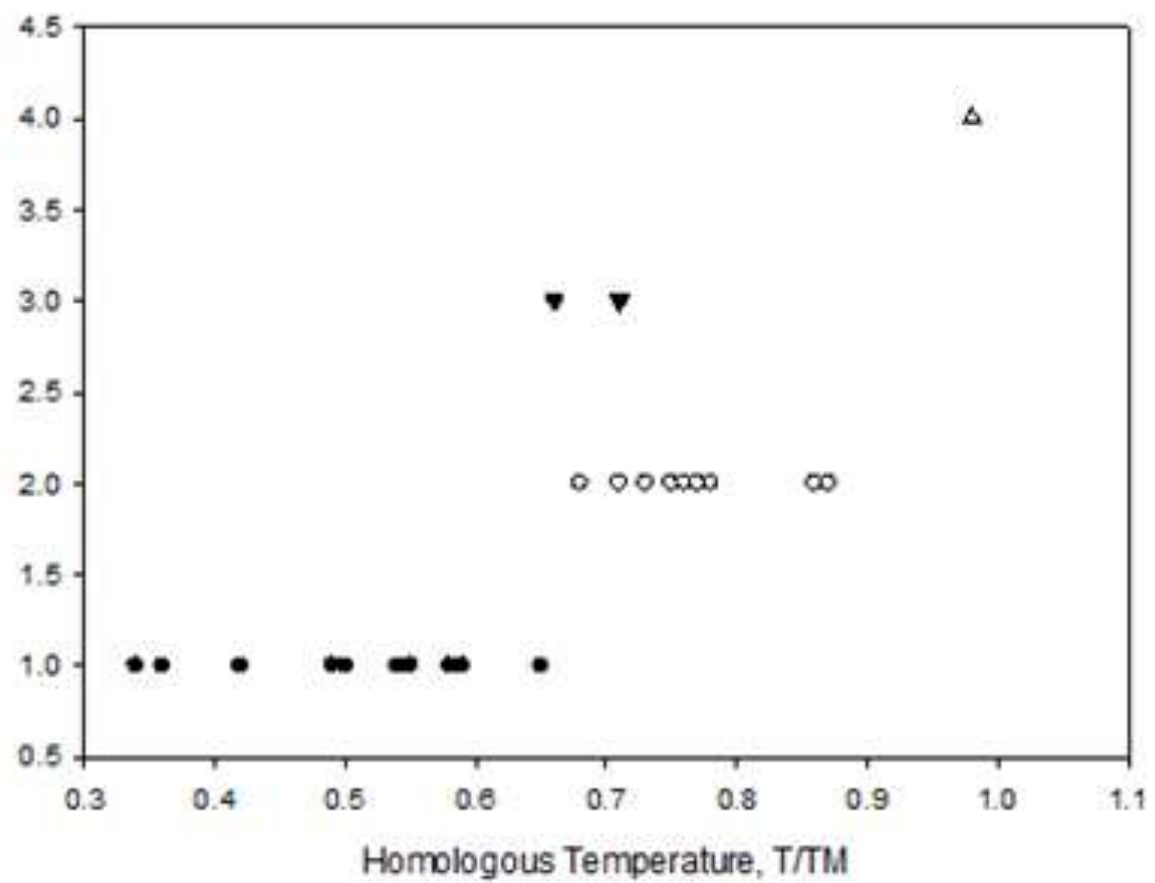

541

542

543

544

545

546

547

548

549

550

551

552

553 short time and large quantities. Cryomilled NC powder that can be used to manufacture bulk

554 nanostructured and ultrafine-grained (UFG) alloys with attractive combinations of physical and

555 mechanical properties. Inspection of the scientific literature shows that this technique has been

556 widely used to synthesize NC metals, alloys, and composites, such as Al [157-159] , Ni [160]

Figure 12. Literature data for thermal stabilization mechanisms vs. maximum homologous temperature for stabilization. The symbols are: thermodynamic stabilization: $\bullet$, kinetic stabilization: $\odot$, kinetic and thermodynamic stabilization: $\boldsymbol{\nabla}$, kinetic and complexion stabilization: $\Delta$

\section{CRYOMILLING AND APPLICATIONS}

Cryomilling, i.e., mechanical milling of alloys at cryogenic temperatures is representative of a class of powder synthesis techniques that attain the nanostructured state via severe plastic deformation. The cryogenic milling process has attracted considerable interest, primarily as a result of its ability to generate nanocrystalline (NC) and non-equilibrium structures in relatively 
557 Fe [161], Ti [162 ], Zn [ 163], Mg [164,165 ], Pd-10Rh [166], high entropy alloys (HEAs)

558 [167,168], and $\mathrm{Al}-\mathrm{B}_{4} \mathrm{C} / \mathrm{SiC}$ composites $[169,170]$. In certain fec materials, cryomilling can

559 promote deformation twinning, which is beneficial, given that deformation twins provide for

560 strength enhancement without a loss in ductility. Cryomilling in a liquid nitrogen environment

561 facilitates the formation of nitrogen-containing dispersoids that substantially increase the thermal

562 stability of nanostructures. Thermal stability is critical to retaining fine grain sizes during

563 consolidation of the cryomilled powder when subjected to temperature and pressure. The use of

564 light-weight, higher-strength alloys, such as NC Al alloys, for the construction of vehicles will

565 substantially reduce their weight and lead to improved fuel consumption, range, reliability, and

566 speed. In this section, published data related to cryomilled alloys are reviewed with particular

567 emphasis on cryomilling mechanisms, microstructure, deformation twining, thermal stability of

568 cryomilled powders, and some examples of practical Al alloys fabricated by cryomilling and

569 consolidation.

570 A. Cryomilling

571 During cryomilling, the as received powder forms a slurry with a milling attritor, comprising

572 of a rotating impeller within a vessel, and accommodating a flow of incoming cryogenic liquid,

573 normally liquid $\mathrm{N}_{2}$ or liquid Ar. In the laboratories at UC Irvine (Irvine, CA), the system with

574 the largest capability can mill up to $5 \mathrm{~kg}$ of $\mathrm{Al}$ alloy powder at a time, but there is potential to

575 substantially increase the scale of this operation for commercial exploitation.

576 During cryomilling, similar to conventional mechanical milling, the particles of the powder

577 are repeatedly deformed by compressive and shear stresses arising from being trapped between

578 the balls during collisions and localized rolling. Powder evolution during the milling process

579 generally involves five stages [157,158]: 1) initially, particle flattening as a result of shear band 
nucleation under localized deformation conditions [171], which then spread throughout the entire

581 sample, forming flakes; 2) when two or more particles are trapped between the balls, they are

582 crushed and cold-welded together to form particles of a larger size with a lamellar structure; 3)

583 equiaxed particle formation due to fracture deformed particles; 4) random welding of powder

584 particles; and 5) steady-state deformation, during which a balance between fracture and cold

585 welding is established as particle size and microstructural refinement progresses. Given that

586 severe plastic deformation during milling is a cyclic process, the milling time dominates the

587 overall deformation strain.

588 Cryomilling leads to the formation of a high density of dislocations in the cryomilled powder

589 because milling induces heavy cyclic deformation, and the cryogenic temperature suppresses the

590 annihilation of dislocations. As an example, a high density of dislocations of $1.7 \times 10^{17} \mathrm{~m}^{-2}$ was

591 observed in a cryomilled Al-Mg alloy [172,173]. The dense dislocation networks rearrange to

592 form nanoscale subgrains with low-angle grain boundaries (GBs) during further milling, and

593 then re-orient and transform into grains with high-angle GBs. With an increase in milling time,

594 the mean grain size initially decreases rapidly from the micrometer scale, then slowly decrease

595 down to a saturated value, a few tens of nanometers, determined by the material properties [174,

596 175]. When a minimum grain size is reached, additional straining does not further reduce the

597 grain size because of the intrinsic instability of nano-sized grains. Thus, strain-induced grain

598 refinement ceases as a dynamic balance is reached between structure refinement and coarsening

599 of the refined grains.

600 The value of the minimum grain size that is attained during milling is related to the intrinsic

601 properties of the materials [174] as well as the milling conditions. It has been proposed that the

602 minimum grain size obtainable by milling scales inversely with melting temperature and bulk 
603 modulus of a material. To that effect a dislocation model was developed to quantitatively

604 describe the minimum grain size obtainable during milling [175]. According to this model, the

605 minimum grain size is governed by the balance between the hardening rate introduced by

606 dislocation generation, and the recovery rate arising from dislocation annihilation and

607 recombination. The minimum grain size, $d_{\min }$, is given by [175]:

$$
\frac{d_{\min }}{b}=A_{3} \exp \left(\frac{-\beta Q}{4 R T}\right)\left(\frac{D_{\mathrm{PO}} G b^{2}}{v_{0} k_{\mathrm{B}} T}\right)^{0.25}\left(\frac{\gamma}{G b}\right)^{0.5}\left(\frac{G}{\sigma}\right)^{1.25}
$$

609 where $b$ is the magnitude of the Burgers vector, $A_{3}$ a dimensionless constant, $\beta$ constant, $Q$ the 610 self-diffusion activation energy, $R$ the gas constant, $T$ the absolute temperature, $D_{P O}$ the diffusion 611 coefficient, $G$ the shear modulus, $v_{0}$ the initial dislocation velocity, $k_{B}$ Boltzmann's constant, $\gamma$ the 612 stacking fault energy (SFE) and $\sigma$ is the applied stress. The model predicts that the minimum 613 grain size scales inversely with hardness, proportionally with the SFE and exponentially with the 614 activation energy for recovery.

615 Grain refinement may also occur via recrystallization when a new grain structure forms by 616 nucleation and growth in cold deformed alloys with sufficient stored energy. It is generally 617 argued that recrystallization is not able to occur during cryomilling because recrystallization is 618 thermally activated and depends on a critical temperature and deformation conditions. 619 Interestingly, however, it has been reported that recrystallization does indeed occur in cryomilled $620 \mathrm{Zn} \mathrm{[163]} \mathrm{and} \mathrm{Mg}$ [176]. High density of lattice defects, including stacking faults [177], 621 dislocation, deformation twins [178], and increased GBs generated due to heavy deformation in 622 cryomilled NC hexagonal close packed (HCP) Mg alloys have been reported. In fact, the high 623 density of accumulated lattice defects, particularly dislocations, results in a high stored energy, $E$ $624=G b^{2} \rho$, which may trigger dynamic recrystallization (DRX) even at cryogenic temperatures. In 
625 addition, a high density of dislocations causes the critical temperature for recrystallization $T_{c}$ to

626 decrease. Recrystallization of cryomilled $\mathrm{Mg}$ powder in liquid Ar may also be thermally

627 activated at room temperature due to the presence of relative elevated temperatures ( $88 \mathrm{~K}$ to 298

$628 \mathrm{~K})$ when the cryomilled $\mathrm{Mg}$ powder is collected at room temperature. The conditions for 629 nucleation of DRX are described by [179]:

630

$$
\frac{\rho^{3}}{\dot{\varepsilon}}>\frac{2 \gamma_{b}}{K M L G^{2} b^{5}}
$$

631 where $\rho$ is the dislocation density, $\dot{\varepsilon}$ is the strain rate. $\gamma_{b}$ is the specific boundary energy, $M$ is the 632 grain boundary mobility, $L$ is the mean slip distance of the dislocations, $G$ is shear modulus, $b$ is 633 Burger vector, $K$ is a constant. There is a critical value of $\rho / \dot{\varepsilon}$ to be achieved for the nucleation 634 of DRX. When materials with a low SFE, such as Zn, Mg and their alloys with low SFE are 635 deformed at cryogenic temperature, dislocation recovery is slow and the dislocation density 636 could be increased to the critical value necessary for facilitating DRX.

637 The cryomilling technique possesses several characteristics and advantages that distinguish it 638 from the conventional mechanical milling that is typically performed at ambient temperatures, 639 including: 1) powder agglomeration and welding to the milling media are suppressed, resulting 640 in a more efficient milling outcome; 2) oxidation reactions during milling are reduced under the 641 protection of a liquid nitrogen or argon environment; 3) the milling time required to attain a 642 nanostructure is significantly reduced relative to that required of conventional milling. Figure 13 643 shows a comparison of the average grain size evolution with milling time for $\mathrm{Zn}$ powder milled 644 at room temperature and at liquid $\mathrm{N}_{2}$ temperature [179]. It has been consistently reported that 645 the average grain size of cryomilled $\mathrm{Zn}$ is consistently smaller than that of room temperature 646 milled $\mathrm{Zn}$ with the same amount of milling time. Cryomilling takes the advantage of the 
647 extremely low temperature of the liquid $\mathrm{N}_{2}$ or Ar medium, which suppresses the recovery and 648 leads to more rapid grain refinement and finer grain structures. In addition, the lower temperature 649 also decreases the ductility of the powder, reducing the amount of welding between the particles. 650 Thus, the amount of process control agent (PCA) required to prevent excessive agglomeration of 651 the particles is reduced, decreasing the amount of interstitial contamination introduced during the 652 milling process.

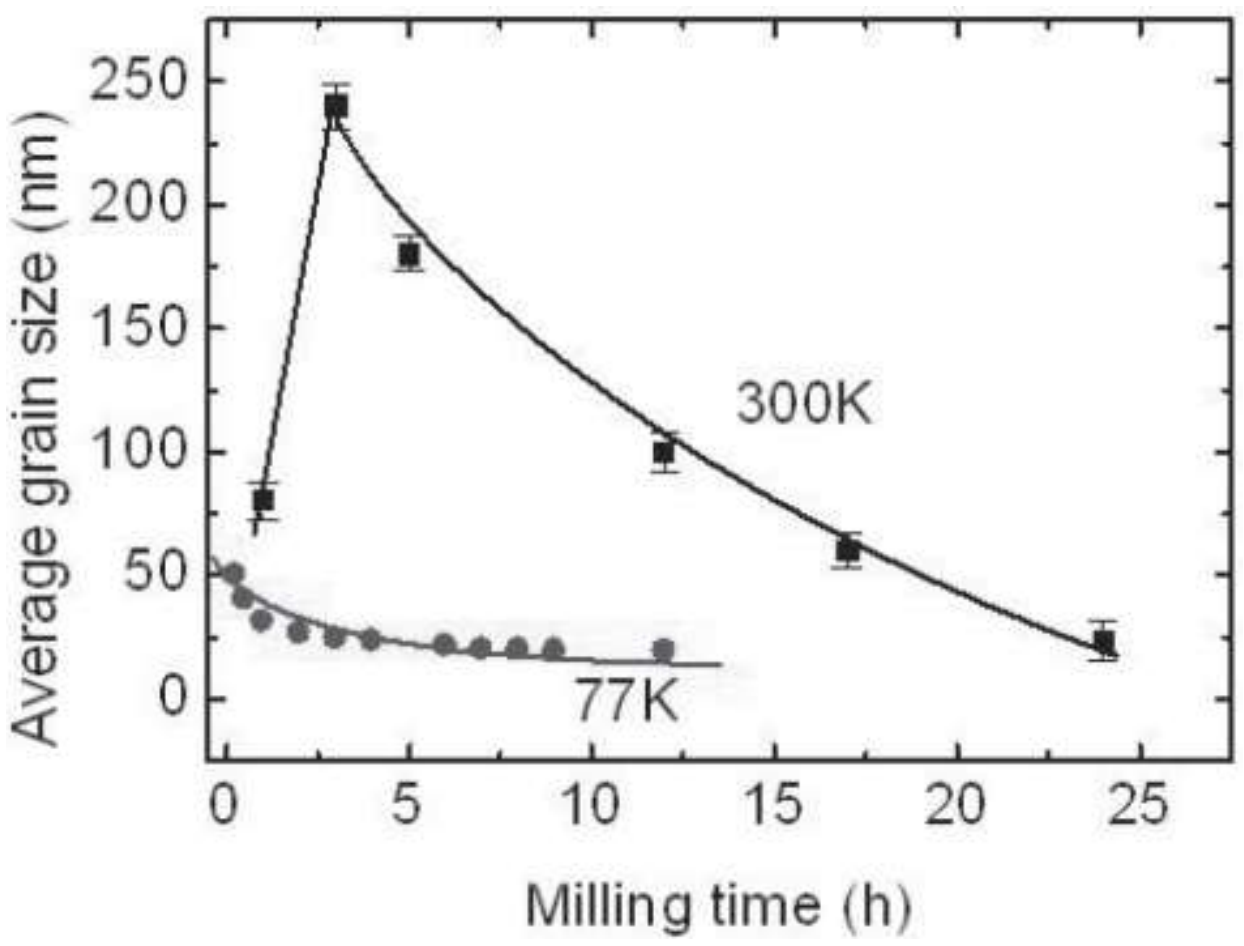

655 Figure 13 Comparison of the average grain size evolution with milling time for Zn powder 656 milled at room temperature and at liquid nitrogen temperature. Reprinted with permission from 657 reference [179].

Even in the presence of hard particles, such as in the case of cryomilling of a 660 matrix/reinforcement (typically a ceramic) mixture, the ductile matrix is deformed, flattened and 661 cold welded [174]. During cryomilling the reinforcement particles are entrapped in the matrix 
662 material, which can eliminate the voids between the matrix and the ceramic reinforcement and

663 potentially promote solid state bonding between them. Another advantage of using cryomilling

664 to synthesize metal matrix composite powders is that it facilitates the formation of a

665 homogeneous distribution of the reinforcement particles in the matrix. Conventional blending

666 methods often lead to clustering of the reinforcement, resulting in poor mechanical behavior.

667 Published studies suggest that a homogeneous distributions of reinforcements in a matrix can 668 readily be achieved by using cryomilling 169,170].

669 In addition, the presence of hard particles in a powder mixture can facilitate deformation and

670 fracture of the matrix and thereby facilitate grain refinement. As a consequence, a shorter milling

671 time may be required to attain steady state conditions during milling. In related studies it was

672 reported that the introduction of a small volume fraction of AlN particles $(2 \mu \mathrm{m})$ into $\mathrm{Ni}$

673 facilitated grain refinement during cryomilling [180]. This enhancement was rationalized on the

674 basis of the interactions of dislocations with hard particles, and the thermally induced dislocation

675 generation due to the difference in thermal expansion coefficient between matrix and

676 reinforcement $[180,181]$

677 B. Deformation Twining by Cryomilling

678 It is well known that NC alloys are significantly stronger than their coarse-grained 679 counterparts [157,182], but their ambient temperature uniform tensile ductility is usually 680 disappointingly low due to the fact that GBs experience much larger plastic strain than that 681 sustained by grain interiors. Attempts to retain or increase the ductility during grain refinement 682 have frequently resulted in reduced strength [182,183]. However, it was reported that dislocation 683 accumulation at twin boundaries in NC metals provides strength enhancement without a loss in 684 ductility $[184,185]$. Twin boundaries with extremely low excess energy can effectively hinder 
685 dislocation motion, acting as stable interfaces leading to the increase of both the strength and

686 ductility in NC materials [186,187]. Moreover, it has been well documented that a smaller grain

687 size impedes deformation twinning and there are many experimental studies providing support to

688 this finding [188-191]. On one hand, the stress required for activating twinning increases much

689 faster with decreasing grain size relative to that required for dislocation slip which competes with

690 twinning; accordingly, a smaller grain size renders deformation twinning more difficult. On the

691 other hand, a lower temperature and higher strain rate usually promote deformation twinning

692 [191]. The increase in twinning tendency at low temperatures and higher strain rates can be

693 largely attributed to the increase in flow stress of materials, which increases with decreasing

694 temperature and increasing strain rate. When flow stress increases, the motion of dislocations

695 becomes more difficult, while deformation twining readily occurs. There is an equivalent effect

696 of low temperature and high strain rate, as the dislocation generation rate is faster than the

697 annihilation of dislocation during deformation at low temperature and high strain rates [191]. As

698 cryomilling is characterized by relatively high strain rates (up to $6.35 \times 10^{3} \mathrm{~s}^{-1}$ [192]) and

699 cryogenic temperatures, deformation twinning is facilitated in cryomilled metals and alloys.

700 In the face centered cubic (FCC) case, the twinning plane is the close-packed (111), and twin

701 nucleation and growth are controlled by well-defined partial dislocations that co-operatively

702 move and propagate on successive (111) planes [194]. A material with high SFE, such as Al

703 (160- $200 \mathrm{~J} / \mathrm{m}^{2}$ ), will be less susceptible to twinning than materials with low SFE, like Cu alloys

$704\left(70-78 \mathrm{~J} / \mathrm{m}^{2}\right)$. SFE is equivalent to twin energy, and the propensity for deformation twinning

705 increases with decreasing SFE [195]. Twins are abundant in many low SFE metals, but are rarely

706 seen in high SFE metals like Al [196-198], because when the SFE is low, the mobility of

707 dislocations in a material decreases, while deformation twining become more feasible. Notably, 
708 the first report of twinning in $\mathrm{NC}$ fcc Al was observed in cryomilled Al [193], as shown in 709 Figure 14, which shows an HRTEM image of twin with dimension of approximately $10 \mathrm{~nm}$ in 710 cryomilled Al-7.5Mg powder. The black arrow shows that atoms on (110) have a strain along $711<112>$ direction, and twinning occurred on the (111) plane.

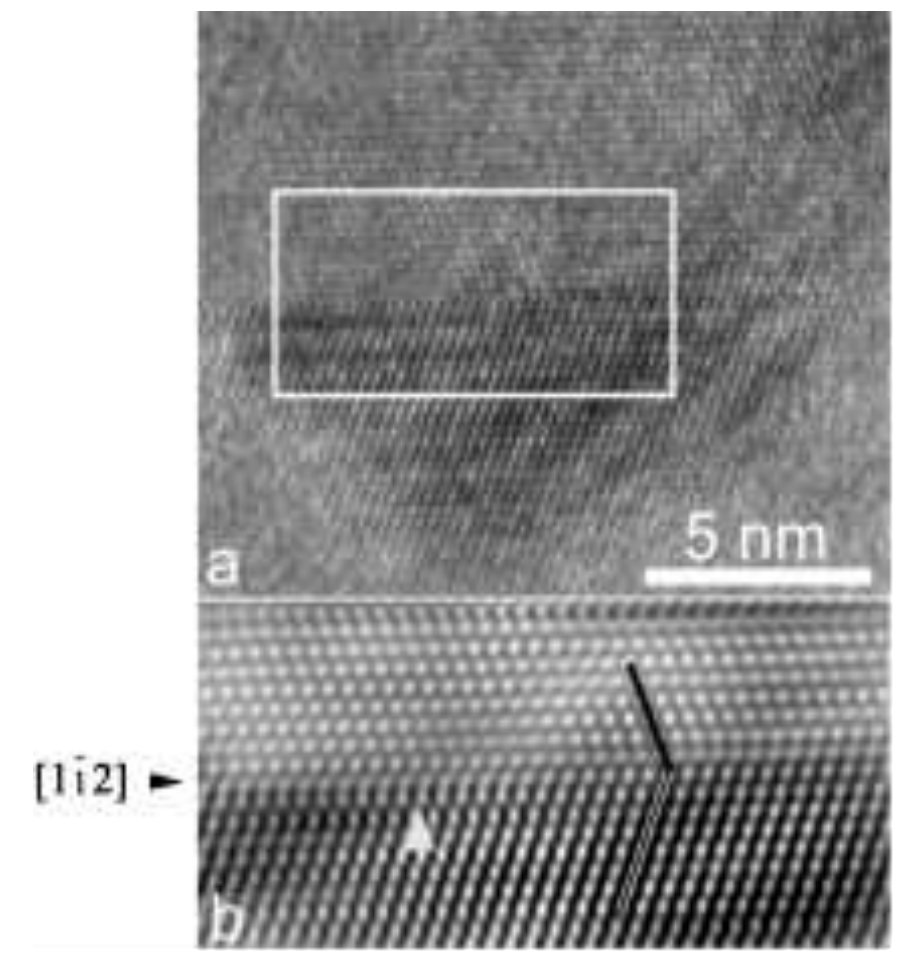

Figure 14 HREM image of Al-7.5Mg alloy cryomilled for $8 \mathrm{~h}$, (a) Image of a whole

714 nanoscale twin. (b) Local magnification of a twin. Reprinted with permission from reference [193].

717 In most HCP metals and alloys, deformation twins are readily nucleated. This is true, for 718 example, in the case of coarse grained $\mathrm{Mg}$ and $\mathrm{Mg}$ alloys, due to the low SFE of $\mathrm{Mg}\left(30 \mathrm{~mJ} / \mathrm{m}^{2}\right.$ 719 [199]) in combination with a limited number of independent slip systems. The SFE in Mg-(3$7209 \mathrm{wt} . \%$ ) $\mathrm{Al}$ alloys is $5.8-27.8 \mathrm{~mJ} / \mathrm{m}^{2}$, and decreases with increasing $\mathrm{Al}$ content [200]. For $\mathrm{HCP}$ $721 \mathrm{Mg}$, the activation of primary slip system is limited and hindered on account of large CRSS 
722 values at cryogenic temperature. Twinning, however, remains a deformation mechanism that

723 could be activated with secondary slip of partial dislocations under these conditions. The low

724 temperature renders recovery more difficult by limiting the mobility of dislocations [201].

725 Lattice friction stress also strongly depends on temperature, and increases with decreasing 726 temperature [202], which makes dislocation glide through the lattice and GB sliding more

727 difficult. As deformation intensity increases at cryogenic temperatures with high strain rate, the

728 number of dislocations increases, and a higher dislocation density accumulates on the GB

729 regions, which lead to a highly localized stress concentration at GBs, and act as the driving force

730 for twinning nucleation. In essence, the combination of low temperature and high local stresses

731 that is characteristic of cryomilling promote the activation of twinning mechanisms.

732 During cryomilling, the flow stress of $\mathrm{Mg}$ increases with decreasing temperature and 733 increasing strain rate [203], and accordingly so does the critical stress required to nucleate and 734 propagate a twin. The most commonly observed twinning plane is the (10-12) in the $\langle 10-1-1\rangle$ 735 direction for $\mathrm{Mg}$ [204]. This phenomenon has now been documented in a number of $\mathrm{NC} \mathrm{Mg}$ 736 alloys, such as Mg-10at.\%Ti [205], Mg-30wt.\%Al [206], as well as cryomilled AZ80 (Mg$7378 \mathrm{wt} . \% \mathrm{Al}-0.5 \mathrm{wt} . \% \mathrm{Zn}$ )[164]. Moreover the formation of nano-sized twins in cryomilled pure $\mathrm{Mg}$ 738 powders was documented using HRTEM [165]. The formation of nano twins in NC pure Mg was 739 attributed to the combination of: a high strain rate, cryogenic temperature, and high local shear 740 stresses present around the GBs during deformation by cryomilling. Such low temperature 741 deformation processing has also been reported to facilitate deformation twinning in other 742 cryomilled NC alloys and ceramics, such as Al-7\% $\mathrm{Mg}$ [193, 207-209], $\mathrm{Cu}$ [210], and $\mathrm{B}_{4} \mathrm{C}$ [211].

743 The formation of twins by cryomilling provides a promising approach to improve the mechanical 744 properties of NC metals and alloys. 
746 NC metals and alloys are thermally unstable when compared to the behavior of their coarse-

747 grained counterparts. From a thermodynamic viewpoint, nano-grains grow at lower temperatures

748 than those required by their coarse grained counterparts [212,213]. There is a large amount of

749 enthalpy that is stored in the high-density GBs, which provides a substantial driving force for

750 grain coarsening [186]. The reduced thermal stability of nanostructured materials not only limits

751 their technological and practical applications, but also renders their processing a challege.

752 A review of the literature reveals that there are kinetic and/or thermodynamic strategies that

753 have been proposed in an effort to stabilize metallic nanostructures [213]. One approach involves

754 the pinning of GBs by promoting the drag of second-phase, solutes, and chemical ordering [214]

755 in order to decrease their mobility for kinetic stabilization. From a thermodynamic perspective,

756 the driving force of grain coarsening is proportional to the grain-boundary energy. The specific

757 grain-boundary energy can be reduced by solute segregation in the GBs, resulting in a high

758 entropy GBs[ 214,215]. A theoretical framework that incorporates the influence of second-phase

759 particles and solute segregation at GBs on stress-induced GB migration and grain rotation was

760 formulated [216]. The modelling results suggest that both second-phase particles and solute

761 atoms segregated at GBs reduce the rate of GB migration and grain rotation.

762 Cryomilling in a liquid $\mathrm{N}_{2}$ environment generates nitrogen containing nano-sized dispersoids

763 are formed [217-219] which can increase the strength of the alloys by pinning dislocations [161].

764 The significance of the nitrogen-containing dispersoids is that they substantially increase the

765 thermal stability of the microstructure for Al-containing alloys [219-221]. This is important in

766 retaining fine grain sizes during consolidation when the cryomilled powder subjected to 
767 temperature and pressure, the combined effects of which would otherwise lead to rapid grain 768 growth.

769 A low ductility and limited thermal stability represent intrinsic limitations of NC structural 770 materials. Stabilizing nanostructures by interface complexions to decrease the grain-boundary 771 mobility does not improve their ductility. It is necessary to provide work-hardening and strain 772 delocalization during deformation in the nanostructures to enhance their ductility [186]. In 773 related work it has been reported that twin boundaries with extremely low excess energy 774 effectively hinder dislocation and GBs motion and can thus act as stable interfaces. Twin 775 boundaries with nanoscale spacing are effective to improve strength, ductility and thermal 776 stability. This might be another reason for the observed high thermal stability of cryomilled 777 nanostructured materials because cryomilling can promote deformation twining [9, 37].

778 There are numerous published studies documenting the thermal stability of cryomilled alloys. 779 For example, in the case of cryomilled $5083 \mathrm{Al}$ alloy processed via HIP and extrusion results 780 from creep tests at two temperatures: 573 and $623 \mathrm{~K}$ [222] show surprising thermal stability. An 781 average grain size of $200 \mathrm{~nm}$ was observed in the microstructure of the cryomilled $5083 \mathrm{Al}$. 782 After a long time exposure for nearly $1000 \mathrm{~h}$ at temperatures of 573 and $623 \mathrm{~K}\left(0.61-0.66 T_{m}\right.$, 783 where $T_{m}$ is the melting temperature of the materials), there is only a slight grain growth. An 784 average grain size of approximately $220 \mathrm{~nm}$ and an average grain size of approximately $280 \mathrm{~nm}$ 785 were observed after holding for $996 \mathrm{~h}$ at a temperature of $573 \mathrm{~K}$ and $938 \mathrm{~h}$ at a temperature of $786623 \mathrm{~K}$, respectively. After holding at elevated temperatures, fine precipitates of approximately $78720-50 \mathrm{~nm}$ were observed. During cryomilling in liquid $\mathrm{N}_{2}$, most of the alloying elements are 788 essentially dissolved into the aluminum matrix, forming a supersaturated solid solution. Small 789 amounts of impurity elements $(\mathrm{O}, \mathrm{N}, \mathrm{C}, \mathrm{H}, \mathrm{Fe}, \mathrm{Cr}$, etc.) are also introduced into the $\mathrm{Al}$ alloys 
790 during cryomilling, with some of them forming nanoscale dispersions [223], which can enhance

791 the retarding force on GB migration. The presence of second phases (nanoscale aluminum

792 oxides, nitrides, carbides, or precipitates), in combination with GB segregation of solute and/or

793 impurity elements is considered to play a significant role in stabilizing the microstructure.

794 Burke developed a model of grain growth based on the drag forces exerted by the dispersion 795 particles on the migrating GBs [224]. In this model, it is considered that the grain growth rate is 796 controlled by the decreasing difference between the ultimate limiting grain size and the changing

797 value of the instantaneous grain size. Burke assumed that the drag force is independent of grain 798 size, which is reasonable under the condition that the source of pinning does not depend on grain 799 size. This situation exists when pinning is produced from dispersion particles or pores. Burke's 800 model may be expressed by the following equation:

$$
\frac{D_{0}-D}{D_{\mathrm{m}}}+\ln \left(\frac{D_{\mathrm{m}}-D_{0}}{D_{\mathrm{m}}-D}\right)=\frac{k_{0} t}{D_{\mathrm{m}}^{2}} \exp \left(\frac{-Q}{R T}\right)
$$

802 where $\mathrm{D}$ is the average instantaneous grain size, $k_{0}$ is a constant and $Q$ is the activation energy 803 for grain growth, $t$ is the annealing time, and $D_{m}$ is the limiting ultimate grain size for the 804 particular annealing temperature. By differentiating Eq. (4), the following growth rate equation is 805 obtained:

$$
\frac{\mathrm{d} D}{\mathrm{~d} t}=k\left(\frac{1}{D}-\frac{1}{D_{\mathrm{m}}}\right)
$$

From the linear plot of $d D / d t-1 / D$, the value of slope (k) at the different annealing 808 temperature can be determined. Using Beck's equation, the value of activation energy for grain 809 growth can be determined from the plot of $\ln (k)$ as a function of $1000 / R T$ [221]. From values of 810 activation energy for grain growth, two-grain growth regimes were identified: the low- 
811 temperature region $\left(<573 \mathrm{~K}\left(300^{\circ} \mathrm{C}\right)\right)$ and the high-temperature region $\left(>573 \mathrm{~K}\left(300^{\circ} \mathrm{C}\right)\right)$. For

812 temperatures lower than $573 \mathrm{~K}\left(300^{\circ} \mathrm{C}\right)$, the activation energy of $25 \pm 5 \mathrm{~kJ} / \mathrm{mol}$ was determined.

813 This low activation energy represents the energy for the reordering of GBs in the UFG material.

814 For temperatures higher than $573 \mathrm{~K}\left(300^{\circ} \mathrm{C}\right)$, the activation energy of $124 \pm 5 \mathrm{~kJ} / \mathrm{mol} \mathrm{was}$

815 measured. This activation energy, $124 \pm 5 \mathrm{~kJ} / \mathrm{mol}$, lies between that for GB diffusion and lattice

816 diffusion in analogous $\mathrm{Al}$ polycrystalline systems [221].

817 D. Engineering Applications

818 A specific example of a practical application of cryomilled NC Al alloys involves target

819 components in the U.S. Marine Corps Assault Amphibious Vehicle (AAV7A1) [225], which

820 provides a range of services on a battlefield. The weight of an empty AAV7A1 is $21 \mathrm{t}$, and the Al

821 hull, made from Al 5083 (Al-4.4Mg-0.7Mn-0.15Cr, UTS of $310 \mathrm{MPa}$ ), contributes about $14 \mathrm{t}$ to

822 this weight. Another significant proportion of the additional weight is the steel armor that is

823 bolted on. Reducing the overall weight of the AAV7A1 is a prime objective given the need to

824 decrease the fuel consumption. As a consequence, an important technical goal is to increase the

825 strength of the Al 5083 while retaining its welding and anticorrosion properties, and

826 consequently decreasing the overall amount of material required (and thereby overall weight).

827 Similarly, improving the ballistic performance of Al 5083 will also decrease the amount of

828 additional steel armor needed. Initial results obtained from a research program funded by the

829 Navy suggests that these dual objectives can be achieved through the implementation of

830 cryomilling, which can produce NC Al 5083 with a UTS greater than $700 \mathrm{MPa}$ [159]. In terms

831 of ballistics performance, the resistance of consolidated (HIP, extrusion, and rolling) cryomilled

832 Al 5083 strip against a small-caliber, armor-piercing threat has been established and based on the

833 test results [69], it is estimated that, a $13 \mathrm{~mm}$ thick cryomilled plate is equivalent to a $19 \mathrm{~mm}$ 
834 standard plate, which represents $33 \%$ less weight required to stop the same threat, saving over

$8354.5 \mathrm{t}$ on a hull weighing $14 \mathrm{t}$.

836 In terms of corrosion, comparison tests of consolidated cryomilled Al 5083 with standard

837 coarse grained Al 5083 were completed to evaluate their corrosion behavior in salt-containing

838 aqueous solutions and their susceptibility to intergranular corrosion in the nitric acid mass loss

839 test [226]. Results show that there was not a significant difference in the corrosion behavior

840 between the two types of materials, and that the cryomilled material exhibited less susceptibility

841 to intergranular corrosion.

842 Finally, in terms of joining, tungsten inert gas welding was used to join a plate made from

843 cryomilled materials to a standard Al 5083 plate, resulting in a weld with the same hardness as

844 that of the standard plate. Similarly, two tubes of cryomilled Al 5083 were inertia welded

845 together, without any drop in hardness at the weld interface [225]. The hardness of a joint of

846 friction-stir welded cryomilled Al 5083 dropped slightly to $~ 125$ diamond-pyramid hardness

847 (DPH).

848

852 CCK wishes to thank NSF and DOE for support of his research on this topic under grants

853 number DMR-1401725 and DE-0000538 respectively. EJL is grateful for the funding provided

854 by the Office of Naval Research that supported the work by his group reviewed in this article:

855 Grant No. ONR N00014-12-1-0237 under the guidance of Dr. Larry Kabacoff and Grant No.

856 N00014-12-C-0241 under the guidance of Rod Peterson and Bill Golumbfskie. The work of

857 TGL was supported by the U.S. National Science Foundation under Grant No. DMR-1160966. 


\section{REFERENCES}

860 1. H. Gleiter, Progress in Materials Science, (1989) 33, 223-315.

861 2. U. Erb, K. T. Aust, G. Palumbo, Chapter 6 in Nanostructured Materials, Processing,

862 Properties, andApplications, $2^{\text {nd }}$ edition, ed. C. C. Koch, William Andrew, Norwich, NY

8632007.

864 3. Y. Yoshizawa, S. Oguma, K. J. Yamauchi, J. Appl. Phys.(1988) 64, 6044.

865 4. R. Z. Valiev, R. K. Ishamgaliev, I. V. Alexandrov, Prog. Mater. Sci. (2000) 45, 103.

866 5. J. R. Groza and R. J. Dowding, NanoStructured Materials, (1996) 7, 749.

867 6. S. Yu, C-J. Sun, G-M. Chow, Chapter 1 in Nanostructured Materials, Processing,

868 Properties, and Applications, $2^{\text {nd }}$ edition, ed. C. C. Koch, William Andrew, Norwich, NY,

8692007.

7. R.Z. Valiev, Y. Estrin, Z. Horita, T.G. Langdon, M.J. Zehetbauer, and Y.T. Zhu: JOM, 2006, vol. 58 (4), pp. 33-39.

8. J.T. Wang: Mater. Sci. Forum, 2006, vol. 503-504, pp. 363-370.

9. T.G. Langdon: Mater. Sci. Forum, 2011, vol. 667-669, pp. 9-14.

10. S. Srinivasan and S. Ranganathan: India's Legendary Wootz Steel: An Advanced Material of the Ancient World, National Institute of Advanced Studies and IISc, Bangalore, India, 2004.

11. O.D. Sherby and J. Wadsworth: J. Mater. Proc. Technol., 2001, vol. 117. pp. 347-363.

12. P.W. Bridgman: Phys. Rev., 1935, vol. 48, pp. 825-847.

13. P.W. Bridgman: Studies in Large Scale Plastic Flow and Fracture, McGraw-Hill, New York, NY, U.S.A., 1952.

14. K. Edalati and Z. Horita: Mater. Sci. Eng. A, 2016, vol. A652, pp. 325-352.

15. N.A. Smirnova, V.I. Levit, V.I. Pilyugin, R.I. Kuznetsov, L.S. Davydova, and V.A. Sazonova: Fiz. Metal. Metalloved., 1986, vol. 61, pp. 1170-1177.

16. V.M. Segal, V.I. Reznikov, A.E. Drobyshevskiy, and V.I. Kopylov: Russian Metal., 1981, vol. 1, pp. 99-105.

17. R.Z. Valiev, O.A. Kaibyshev, R.I. Kuznetsov, R.Sh. Musalimov, and N.K. Tsenev: Dokl. Akad. Nauk SSSR, 1988, vol. 301, pp. 864-866.

18. T.G. Langdon: Int. J. Mater. Res., 2007, vol. 98, pp. 251-254.

19. R.Z. Valiev, N.A. Krasilnikov, and N.K. Tsenev: Mater. Sci. Eng. A, 1991, vol. A137, pp. $35-40$.

20. R.Z. Valiev, A.V. Korznikov, and R.R. Mulyukov: Mater. Sci. Eng. A, 1993, vol. A168, pp. 141-148.

21. Y. Saito, N. Tsuji, H. Utsunomiya, T. Sakai, and R.G. Hong: Scr. Mater., 1998, vol. 39, pp. 1221-1227.

22. Y. Saito, H. Utsunomiya, N. Tsuji, and T. Sakai: Acta Mater., 1999, vol. 47, pp. 579-583.

23. O.R. Valiakhmetov, R.M. Galeyev, and G.A. Salishchev: Fiz. Metall. Metalloved, 1990, vol. 10, pp. 204-206.

24. S.V. Zherebtsov, G.A. Salishchev, R.M. Galeyev, O.R. Valiakhmetov, S.Yu. Mironov and S.L. Semiatin: Scripta Mater., 2004, vol. 51, pp. 1147-1151.

25. B. Cherukuri, T.S. Nedkova, and R. Srinivasan: Mater. Sci. Eng. A, 2005, vol. A410-411, pp. 394-397. 
26. A. Kundu, R. Kapoor, R. Tewari, and J.K. Chakravarty: Scr. Mater., 2008, vol. 58, pp. 235-238.

27. J. Richert and M. Richert: Aluminium, 1986, vol. 62, pp. 604-609.

28. M. Richert, H.P. Stüwe, M.J. Zehetbauer, J. Richert, R. Pippan, Ch. Motz, and E. Schafler: Mater. Sci. Eng.A, 2003, vol. A355, pp. 180-185.

29. Y.T. Zhu, H.G. Jiang, J.Y. Huang, and T.C. Lowe: Metall. Mater. Trans., 32A (2001), pp. 1559-1562.

30. J.Y. Huang, Y.T. Zhu, H.G. Jiang, and T.C. Lowe : Acta Mater., 49 (2001), pp. 1497-1501.

31. Y. Beygelzimer, D. Orlov, and V. Varyukhin: Ultrafine Grained Materials II, ed. Y.T. Zhu, T.G. Langdon, R.S. Mishra, S.L. Semiatin, M.J. Saran, T.C. Lowe, TMS, Warrendale, PA, pp. 297-304 (2002).

32. V. Varyukhin, Y. Beygelzimer, S. Synkov, and D. Orlov: Mater. Sci. Forum, 2006, vol. 503-504, pp. 335-340.

33. T.G. Langdon: Acta Mater. 2013, vol. 61, pp. 7035-7059.

34. A.P. Zhilyaev, S. Lee, G.V. Nurislamova, R.Z. Valiev, and T.G. Langdon: Scr. Mater., 2001, vol. 44, pp. 2753-2758.

35. A.P. Zhilyaev, G.V. Nurislamova, B.K. Kim, M.D. Baró. J.A. Szpunar, and T.G. Langdon: Acta Mater., 2003, vol. 51, pp. 753-765.

36. J. Wongsa-Ngam, M. Kawasaki, and T.G. Langdon: J. Mater. Sci., 2013, vol. 48, pp. 46534660.

37. X.C. Xu, Q. Zhang, N. Hu, Y. Huang, and T.G. Langdon: Mater. Sci. Eng. A, 2013, vol. A588, pp. 280-287.

38. P.M. Bhovi, D.C. Patil, S.A. Kori, K. Venkateswarlu, Y. Huang, and T.G. Langdon: $J$. Mater. Res. Tech., 2016, vol. 5, pp. 353-359.

39. R.Z. Valiev and T.G. Langdon: Prog. Mater. Sci., 2006, vol. 51, pp. 881-981.

40. Y. Iwahashi, J. Wang, Z. Horita, M. Nemoto, and T.G. Langdon: Scr. Mater., 1996, vol. 35, pp. 143-146.

41. M. Furukawa, Z. Horita, Y. Iwahashi, M. Nemoto, and T.G. Langdon: Mater. Sci. Eng. A, 1998, vol. A257, pp. 328-332.

42. Y. Iwahashi, Z. Horita, M. Nemoto, and T.G. Langdon: Acta Mater., 1997, vol. 45, pp. 4733-4741.

43. Y. Iwahashi, Z. Horita, M. Nemoto, and T.G. Langdon: Acta Mater., 1998, vol. 46, pp. 3317-3331.

44. M. Kawasaki, Z. Horita, and T.G. Langdon: Mater. Sci. Eng. A, 2009, vol. A524, pp. 143150.

45. C. Xu, M. Furukawa, Z. Horita, and T.G. Langdon: Mater. Sci. Eng. A, 2005, vol. A398, pp. 66-76.

46. M. Prell, C. Xu, and T.G. Langdon: Mater. Sci. Eng. A, 2008, vol. A480, pp. 449-455.

47. C. Xu, Z. Horita, and T.G. Langdon: Mater. Sci. Eng. A, 2011, vol. A528, pp. 6059-6065.

48. A.P. Zhilyaev and T.G. Langdon: Prog. Mater. Sci., 2008, vol. 53, pp. 893-979.

49. R.Z. Valiev, Yu.V. Ivanisenko, E.F. Rauch, and B. Baudelet: Acta Mater., 1996, vol. 44, pp. $4705-4712$.

50. F. Wetscher, A. Vorhauer, R. Stock, and R. Pippan: Mater. Sci. Eng. A, 2004, vol. 387-389, pp. 809-816.

51. C. Xu, Z. Horita, and T.G. Langdon: Acta Mater., 2007, vol. 55, pp. 203-212.

52. C. Xu, Z. Horita, and T.G. Langdon: Acta Mater., 2008, vol. 56, pp. 5168-5176. 
53. Y. Estrin, A. Molotnikov, C.H.J. Davies, and R. Lapovok: J. Mech. Phys. Solids, 2008, vol. 56, pp. 1186-1202.

54. M. Kawasaki, R.B. Figueiredo, and T.G. Langdon: Acta Mater., 2011, vol. 59, pp. 308-316.

55. M. Kawasaki, B. Ahn, and T.G. Langdon: Mater. Sci. Eng. A, 2010, vol. A527, pp. 70087016.

56. M. Kawasaki: J. Mater. Sci., 2014, vol. 49, pp. 18-34.

57. J. Wongsa-Ngam and T.G. Langdon: Mater. Sci. Forum, 2014, vol. 783-786, pp. 26352640.

58. R.Z. Valiev and T.G. Langdon: Adv. Eng. Mater., 2010, vol. 12, pp. 677-691.

59. R.Z. Valiev and T.G. Langdon: Metall. Mater. Trans. A, 2011, vol. 42A, pp. 2942-2951.

60. R.Z. Valiev, I. Sabirov, A.P. Zhilyaev, and T.G. Langdon: JOM, 2012, vol. 64, pp. 11341142.

61. K. Nakashima, Z. Horita, M. Nemoto, and T.G. Langdon: Mater. Sci. Eng. A, 2000, vol. A281, pp. 82-87.

62. G.I. Raab: Mater. Sci. Eng. A, 2005, vol. 410-411, pp. 230-233.

63. M.Yu. Murashkin, E.V. Bobruk, A.R. Kil'mametov, and R.Z. Valiev: Phys. Metals Metallog., 2009, vol. 108, pp. 415-423.

64. R.Z. Valiev, M.Yu. Murashkin, E.V. Bobruk, and G.I. Raab: Mater. Trans., 2009, vol. 50, pp. 87-91.

65. I. Sabirov, M.T. Perez-Prado, M. Murashkin, J.M. Molina-Aldareguia, E.V. Bobruk, N.F. Yunusova, and R.Z. Valiev: Int. J. Mater. Form., 2010, vol. 3 (suppl. 1), pp. 411-414.

66. D. Green: J. Inst. Metals, 1972, vol. 100, pp. 295-300.

67. C. Etherington: J. Eng. Ind., 1974, vol. 96, pp. 893-900.

68. G.J. Raab, R.Z. Valiev, T.C. Lowe, and Y.T. Zhu: Mater. Sci. Eng. A, 2005, vol. A382, pp. 30-34.

69. G.I. Raab, R.Z. Valiev, D.V. Gunderov, T.C. Lowe, A. Misra, and Y.T. Zhu: Mater. Sci. Forum, 2008, vol. 584-586, pp. 80-85.

70. S. Katsas, R. Dashwood, G. Todd, M. Jackson, and R. Grimes: J. Mater. Sci., 2010, vol. 45, pp. 4188-4195.

71. V.M. Segal: J. Mater. Process. Tech., 2010, vol. 210, pp. 542-549.

72. C. Xu, S. Schroeder, P.B. Berbon, and T.G. Langdon: Acta Mater., 2010, vol. 58, pp. 13791386.

73. A.V. Polyakov, I.P. Semenova, G.I. Raab, V.D. Sitdikov, and R.Z. Valiev: Rev. Adv. Mater. Sci., 2012, vol. 31, pp. 78-84.

74. I.P. Semenova, A.V. Polyakov, G.I. Raab, T.C. Lowe, and R.Z. Valiev: J. Mater. Sci., 2012, vol. 47, pp. 7777-7781.

75. D.V. Gunderov, A.V. Polyakov, I.P. Semenova, G.I. Raab, A.A. Churakova, E.I. Gimaltdinova, I. Sabirov, J. Segurado, V.D. Sitdikov, I.V. Alexandrov, N.A. Enikeev, and R.Z. Valiev: Mater. Sci. Eng. A, 2013, vol. A562, 128-136.

76. J.T. Wang, Z. Li, J. Wang, and T.G. Langdon: Scr. Mater., 2012, vol. 67, pp. 810-813.

77. P.W. Bridgman: J. Appl. Phys., 1943, vol. 14, pp. 273-283.

78. Z. Li, P.F. Zhang, H. Yuan, K. Lin, Y. Liu, D.L. Yin, J.T. Wang, and T.G. Langdon: Mater. Sci. Eng. A, 2016, vol. A658, pp. 367-375.

79. T.H. Fang, W.L. Li, N.R. Tao, and K. Lu: Science, 2011, vol. 331, pp. 1587-1590.

80. X. Wu, P. Jiang, L. Chen, F. Yuan, and Y.T. Zhu: Proc. Natl. Acad. Sci. USA, 2014, vol. 111, pp. 7197-7201. 
994

995

996

997

998

999

1000

1001

1002

1003

1004

1005

1006

1007

1008

1009

1010

1011

1012

1013

1014

1015

1016

1017

1018

1019

1020

1021

1022

1023

1024

1025

1026

1027

1028

1029

1030

1031

1032

1033

1034

1035

1036

1037

1038

1039

81. K. Lu: Science, 2014, vol. 345, pp. 1455-1456.

82. W. Wang, F. Yuan, and X. Wu, Comput. Mater. Sci., 2015, vol. 110, pp. 83-90.

83. A.V. Korznikov, I.M. Safarov, D.V. Laptionok, and R.Z. Valiev: Acta Metall. Mater., 1991, vol. 39, pp. 3193-3197.

84. H. Shen, B. Guenther, A.V. Korznikov, and R.Z. Valiev: Nanostruct. Mater., 1995, vol. 6, pp. 385-388.

85. R.Z. Valiev, R.S. Mishra, J. Groza, and A.K. Mukherjee: Scr. Mater., 1996, vol. 34, pp. 1443-1448.

86. J. Sort, A.P. Zhilyaev, M. Zielinska, J. Nogues, S. Suriñach, J. Thibault, and M.D. Baró: Acta Mater., 2003, vol. 51, pp. 6385-6393.

87. Z. Lee, F. Zhou, R.Z. Valiev, E.J. Lavernia, and S.R. Nutt: Scr. Mater., 2004, vol. 51, pp. 209-214.

88. K.V. Rajulapati, R.O. Scattergood, K.L. Murty, Z. Horita, T.G. Langdon, and C.C. Koch: Metall. Mater. Trans. A, 2008, vol. 39A, pp. 2528-2534.

89. K. Kaneko, T. Hata, T. Tokunaga, and Z. Horita: Mater. Trans., 2009, vol. 50, pp. 76-81.

90. K. Edalati, Z. Horita, H. Fujiwara, and K. Ameyama: Metall. Mater. Trans. A, 2010, vol. A41, pp. 3308-3317.

91. K. Edalati, S. Toh, M. Watanabe, and Z. Horita: Acta Mater., 2012, vol. 60, pp. 3885-3893.

92. K. Edalati, S. Toh, M. Watanabe, and Z. Horita: Scr. Mater., 2012, vol. 66, pp. 386-389.

93. K. Edalati, S. Toh, H. Iwaoka, M. Watanabe, Z. Horita, D. Dashioka, K. Kishida, and H. Inui: Scr. Mater., 2012, vol. 67, pp. 814-817.

94. J.M. Cubero-Sesin and Z. Horita: Mater. Sci. Eng. A, 2012, vol. A558, pp. 462-471.

95. P. Jenei, J. Gibicza, E.Y. Yoon, and H.S. Kim: J. Alloys Compd., 2012, vol. 539, pp. 32-36.

96. E.Y. Yoon, D.J. Lee, T.S. Kim, H.J. Chae, P. Jenei, J. Gubicza, T. Ungár, M. Janecek, J. Vratna, S. Lee, and H.S. Kim: J. Mater. Sci., 2012, vol. 47, pp. 7117-7123.

97. A.P. Zhilyaev, G. Ringot, Y. Huang, J.M. Cabrera, and T.G. Langdon: Mater. Sci. Eng. A, 2017 (in press).

98. E. Menéndez, J. Sort, V. Langlais, A. Zhilyaev, J.S. Muñoz, S. Suriñach, J. Nogués, and M.D. Baró: J. Alloys Compd., 2007, vol. 434-435, pp. 505-508.

99. E. Menéndez, G. Salazar-Alvarez, A.P. Zhilyaev, S. Suriñach, M.D. Baró, J. Nogués, and J. Sort: Adv. Funct. Mater., 2008, vol. 18, pp. 3293-3298.

100. H. Li, A. Misra, Y. Zhu, C.C. Koch, and T.G. Holesinger: Mater, Sci. Eng. A, 2009, vol. A523, pp. 60-64.

101. H. Li, A. Misra, Z. Horita, C.C. Koch, N.A. Mara, P.O. Dickerson, and Y. Zhu: J. Appl. Phys., 2009, vol. 95, pp. 071907(1-4).

102. A. Bachmaier, A. Hohenwarter, and R. Pippan: Scr. Mater., 2009, vol. 61, 1016-1019.

103. J. Sort, D.C. Ile, A.P. Zhilyaev, A. Concustell, T. Czeppe, M. Stoica, S. Suriñach, J. Eckert, and M.D. Baró: Scr. Mater., 2004, vol. 50, pp. 1221-1225.

104. A.R. Yavari, W.J. Botta, C.A.D. Rodrigues, C. Cardoso, and R.Z. Valiev: Scr. Mater., 2002, vol. 46, pp. 711-716.

105. Z. Kovács, P. Henits, A.P. Zhilyaev, and A. Révész: Scr. Mater., 2006, vol. 54, pp. 17331737.

106. N. Boucharat, R. Hebert, H. Rösner, R.Z. Valiev, and G. Wilde: J. Alloys Compds., 2007, vol. 434-435, pp. 252-254.

107. T. Czeppe, G. Korznikova, J. Morgiel, A. Korznikov, N.Q. Chinh, P. Ochin, and A. Sypien J. Alloys Compds., 2009, vol. 483, pp. 74-77. 
1040

1041

1042

1043

1044

1045

1046

1047

1048

1049

1050

1051

1052

1053

1054

1055

1056

1057

1058

1059

1060

1061

1062

1063

1064

1065

1066

1067

1068

1069

1070

1071

1072

1073

1074

1075

1076

1077

1078

1079

1080

1081

1082

1083

1084

108. A.P. Zhilyaev, A.A. Gimazov, G.I. Raab, and T.G. Langdon: Mater. Sci. Eng. A, 2008, vol. A486, pp. 123-128.

109. A.P. Zhilyaev, S. Swaminathan, A.A. Gimazov, T.R. McNelley, and T.G. Langdon: J. Mater. Sci., 2008, vol. 43, pp. 7451-7456.

110. K. Edalati, Y. Yokoyama, and Z. Horita: Mater. Trans., 2010, vol. 51, pp. 23-26.

111. K. Edalati and Z. Horita: Scr. Mater., 2010, vol. 63, pp. 174-177.

112. M.C. Chen, H.C. Hsieh, and W. Wu: J. Alloys Compds., 2006, vol. 416, pp. 169-172.

113. M.C. Chen, C.W. Kuo, C.M. Chang, C.C. Hsieh, Y.Y. Chang, and W. Wu: Mater. Trans., 2007, vol. 48, pp. 2595-2598.

114. M. Eizadjou, A.K. Talachi, H.D. Manesh, H.S. Shahabi, and K. Janghorban: Compos. Sci. Technol., 2008, vol. 68, pp. 2003-2009.

115. R.N. Dehsorkhi, F. Qods, M. Tajally Mater. Sci. Eng. A, 2011, vol. A530, pp. 61-72.

116. N. Chang, M.Y. Zheng, C. Xu, G.D. Fan, H.G. Brokmeier, and K. Wu: Mater. Sci. Eng. A, 2012, vol. A543, pp. 249-256.

117. B. Beausir, J. Scharnweber, J. Jaschinski, H.G. Brokmeier, C.G. Oertel, W. Skrotzki: Mater. Sci. Eng. A, 2010, vol. A527, pp. 3271-3278.

118. K. Oh-ishi, K. Edalati, H.S. Kim, K. Hono, and Z. Horita: Acta Mater., 2013, vol. 61, pp. 3482-3489.

119. O. Bouaziz, H.S. Kim, and Y. Estrin: Adv. Eng. Mater., 2013, vol. 15, pp. 336-340.

120. B. Ahn, A.P. Zhilyaev, H.J. Lee, M. Kawasaki, and T.G. Langdon: Mater. Sci. Eng. A, 2015, vol. A635, pp. 109-117.

121. M. Kawasaki, B. Ahn, H.J. Lee, A.P. Zhilyaev, and T.G. Langdon: J. Mater. Res., 2016, vol. 31, pp. 88-99.

122. B. Ahn, H.J. Lee, I.C. Choi, M. Kawasaki, J.I. Jang, and T.G. Langdon: Adv. Eng. Mater., 2016, vol. 18, pp. 1001-1008.

123. M. Kawasaki, B. Ahn, P. Kumar, J.I. Jang, and T.G. Langdon: Adv. Eng. Mater., 2017, vol. 19, pp. 1600578(1-17).

124. R.B. Figueiredo, P.R. Cetlin, and T.G. Langdon: Mater. Sci. Eng. A, 2011, vol. A528, pp. 8198-8204.

125. R.B. Figueiredo, P.H.R. Pereira, M.T.P. Aguilar, P.R. Cetlin, and T.G. Langdon: Acta Mater., 2012, vol. 60, pp. 3190-3198.

126. M. Kawasaki, S.N. Alhajeri, C. Xu, and T.G. Langdon: Mater. Sci. Eng. A, 2011, vol. A529, pp. 345-351.

127. H.J. Lee, S.K. Lee, K.H. Jung, G.A. Lee, B. Ahn, M. Kawasaki, and T.G. Langdon: Mater. Sci. Eng. A, 2015, vol. A630, pp. 90-98.

128. K. Lu: Science, 2010, vol. 328, pp. 319-320.

129. R. Birringer: Mater. Sci. Eng. A, 1989, vol. A117, pp. 33-43.

130. B. Gunther, A. Kumpmann, and H.-D. Kunze: Scripta Metall. Mater.1992, vol.27, pp. 833838.

131. M. Ames, J. Markmann, R. Karos, A. Michels, A. Tschope, and R. Birringer: Acta Mater. 2008, vol. 56, pp. 4255-4266.

132. F. J. Humphreys, and M. Hatherly: Recrystallization and Related Annealing Phenomena, chapter 9, (Elsevier Science, Inc., Tarrytown, NY, 1996), pp. 289-295.

133. C. E. Krill, H. Ehrhardt, and R. Birringer: Z. Metallkd. 2005, vol. 96, pp. 1134-1141

134. J. W. Cahn: Acta Metallurgica, 1962, vol.10, pp. 768-798. 
1085

1086

1087

1088

1089

1090

1091

1092

1093

1094

1095

1096

1097

1098

1099

1100

1101

1102

1103

1104

1105

1106

1107

1108

1109

1110

1111

1112

1113

1114

1115

1116

1117

1118

1119

1120

1121

1122

1123

1124

1125

1126

135. K. Lücke, and H. P. Stüwe: Acta Metallurgica, 1971, vol.19, pp. 1087-1099.

136. P. Knauth, A. Charai, and P. Gas: Scripta Metall. Mater. , 1993, vol.28, pp. 325-330.

137. A. Michels, C. E. Krill, H. Ehrhardt, R. Birringer, and D. T. Wu: Acta Mater., 1999, vol.47, pp. 2143-2152.

138. R. D. Doherty, Mater. Sci. Forum, 2012, vol. 715, pp. 1-12.

139. R. J. Perez, H. G. Jiang, C. P. Dogan, and E. J. Lavernia: Metall. Mater. Trans. A, 1998, vol.29A, pp. 2469-2475.

140. H. J. Hofler, and R. S. Averback: Scripta Metall. Mater., 1990, vol. 24, pp. 2401-2406.

141. Z. Gao, and G. Fultz: NanoStructured Mater., 1994, vol. 4, pp. 939-947.

142 Y. Estrin, G. Gottstein, E. Rabkin, and L. S. Shvindlerman: Scripta Mater., 2000, vol. 43, pp. 141-147.

143. E. D. Hondros, and M. P. Seah: in Physical Metallurgy, $3^{\text {rd }}$ edition, ed. R. W. Cahn and P. Haasen, Elsevier Sci. Publ. BV, (1983) p. 856.

144. J. Weissmuller: NanoStructured Mater., 1993, vol. 3, pp. 261-272, \& J. Mater. Res., 1994, vol. 9, pp. 4-7.

145. R. Kirchheim: Acta Mater., 2002, vol. 50, pp. 413-419.

146. J. R. Trelewicz, and C. A. Schuh: Phys. Rev. B, 2009, vol. 79, p. 094112.

147. M. Saber, H. Kotan, C. C. Koch, and R. O. Scattergood: J. Appl. Phys., 2013, vol. 113 p. 063515.

148. P. Wynblatt, and R. C. Ku: Surf. Sci. 1977, vol. 65, pp. 511-531.

149. T. Chookajorn, H. A. Murdoch, and C. A. Schuh: Science, 2012, vol. 337, pp. 951-954.

150. A. R. Kalidindi, T. Chookajorn, and C. A. Schuh: JOM, 2015, vol. 67, pp. 2834-2843.

151. S. J. Dillon, M. Tang, W. C. Carter, and M. P. Harmer: Acta Mater., 2007, vol. 55, pp. 6208-6218.

152. T. J. Rupert: Current Opinion in Solid State and Mater. Sci., 2016, vol. 20, pp. 257-267.

153. A. Khalajhedayati, and T. J. Rupert: JOM, 2015, vol. 67, pp. 2788-2801.

154. M. Saber, H. Kotan, C. C. Koch, and R. O. Scattergood: Mater. Sci. Engr. A, 2012, vol. 556, pp. 664-670.

155. L. Li, M. Saber, W. Xu, Y. Zhu, C. C. Koch, and R.O. Scattergood: Mater. Sci. Engr. A, 2014, vol. 613, pp. 289-295.

156. M. Saber, H. Kotan, C. C. Koch, and R.O. Scattergood: J. Appl. Phys., 2013, vol.114, p. 103510.

157. E.J. Lavernia, B.Q. Han, and J.M. Schoenung: Mater. Sci. Eng. A, 2008, vol. 493, pp. 207214.

158. H.J. Fecht: Nanophase Materials: Synthesis, Properties, Applications, in: G.C.

Hadjipanayis, R.W. Siegel (Eds.), Kluwer Academic, Dordrecht, Netherlands, 1994.

159. D.B. Witkin, and E.J. Lavernia: Prog. Mater. Sci., 2006, vol. 51, pp. 1-60.

160. J.A. Picas, A. Forn, L. Ajdelsztajn, and J. Schoenung: Powder Tech., 2004, vol. 148, pp. 20-23.

161. B. Huang, R.J. Perez, and E.J. Lavernia: Mater. Sci. Eng. A, 1998, vol. 255, pp. 124-132.

162. O. Ertorer, T. Topping, Y. Li, W. Moss, and E.J. Lavernia: Scripta Mater., 2009, vol. 60, pp. 586-589. 
163. X. Zhang, H. Wang, R.O. Scattergood, J. Narayan, and C.C. Koch: Acta Mater., 2002, vol. 50, pp. 3995-4004.

164. B. Zheng, O. Ertorer, Y. Li, Y. Zhou, S. N. Mathaudhu, C. Y.A. Tsao, and E.J. Lavernia: Mater. Sci. Eng. A, 2011, vol. 528, pp. 2180-2191.

165. B. Zheng, Y. Li , W. Xu, Y. Zhou, S.N. Mathaudhu, Y. Zhu, and E.J. Lavernia, Phil. Mag. Lett., 2013, vol. 93, pp. 457-464.

166. N. Yang, J.K. Yee, Z. Zhang, L. Kurmanaeva, P. Cappillino, V. Stavila, E.J. Lavernia, and C. San Marchi: Acta Mater., 2015, vol. 82, pp. 41-50.

167. K.M. Youssef, A.J. Zaddach, C. Niu, D.L. Irving, and C.C. Koch: Mater. Res. Lett., 2015, vol. 3, pp. 95-99.

168. B. Zheng, Z. Fu, L. Kurmanaeva, Y. Lin, J. Ivanisenko, Y. Zhou, F. Chen, H. Hahn, L. Zhang, and E.J. Lavernia: TMS2016, Nashville TN, 2016.

169. J. Ye, J. He, and J.M. Schoenung: Metall. Mater. Trans. A, 2006, vol. 37, pp. 3099-3109.

170. F. Tang, M. Hagiwara, and J.M. Schoenung: Scripta Mater., 2005, vol. 53, pp. 619-624.

171. H.-J. Fecht: Nanostruct. Mater., 1995, vol. 6, pp. 33-42.

172. F. Zhou, X.Z. Liao, Y.T. Zhu, S. Dallek, and E.J. Lavernia: Acta Mater., 2003, vol. 51, pp. 2777-2791.

173. X.Z. Liao, J.Y. Huang, Y.T. Zhu, F. Zhou, and E.J. Lavernia: Phil. Mag., 2003, vol. A83, pp. 3065-3075.

174. J. Eckert, J.C. Holzer, C.E. Krill III, and W.L. Johnson: J. Mater. Res., 1992, vol. 7, pp. 1751-1761.

175. F.A. Mohamed: Acta Mater., 2003, vol. 51, pp. 4107-4119.

176. B. Zheng, D. Zhang, Y. Zhou, S.N. Mathaudhu, and E.J. Lavernia: in D.C.a.R.M. Gasior (Ed.) Adv. in Powder Metall. \& Particulate Mater. 2013, Metal Powder Industries Federation, Chicago, IL, 2013.

177. D.T.A. Matthews, V. Ocelík, P.M. Bronsveld, and J.T.M. De Hosson: Acta Mater., 2008, vol. 56, pp. 1762-1773.

178. K. Hajlaoui, A.R. Yavari, B. Doisneau, A. LeMoulec, W.J. Botta F,G. Vaughan, A.L. Greer, A. Inoue, W. Zhang, and Å. Kvick: Scripta Mater., 2006, vol. 54, pp. 1829-1834.

179. X. Zhang, H. Wang, and C.C. Koch: Rev. Adv. Mater. Sci., 2004, vol. 6, pp. 53-93.

180. K.H. Chung, D.H.S. J. He, and J.M. Schoenung: Mater. Sci. Eng. A, 2003, vol. 356, pp. 23 31.

181. R. Vogt, Z. Zhang, Y. Li, M. Bonds, N.D. Browning, E.J. Lavernia, and J.M. Schoenung: Scripta Mater., 2009, vol. 61, pp. 1052-1055.

182. C.C. Koch: in H. R.W. Siegel , M.C. Roco (Ed.) Final report by WTEC panel, 1999, pp. 93.

183. Y.T. Zhu, and X. Liao: Nature Mater., 2004, vol. 3, pp. 351-352.

184. L. Lu, Y.F. Shen, X.H. Chen, L.H. Qian, and K. Lu: Science, 2004, vol. 304, pp. 422-426.

185. Y.H. Zhao, J.F. Bingert, X.Z. Liao, B.Z. Cui, K. Han, A.V. Sergueeva, A.K. Mukherjee, R.Z. Valiev, T.G. Langdon, and Y.T. Zhu: Adv. Mater., 2006, vol. 18, pp. 2949-2953.

186. K. Lu, Nature Rev. Mater., 2016, vol. 1, \#16019, pp. 1-13.

187. L. Lu, Y.F. Shen, X.H. Chen, L.H. Qian, and K. Lu: Science, 2004, vol. 304, pp. 422-426.

188 M.A. Meyers, O. Vohringer, and V.A. Lubarda: Acta Mater., 2001, vol. 49, pp. 40254039.

189. M.A. Meyers, A. Mishra, and D.J. Benson: Prog. Mater. Sci., 2006, vol. 51, pp. 427-556. 
1172

1173

1174

1175

1176

1177

1178

1179

1180

1181

1182

1183

1184

1185

1186

1187

1188

1189

1190

1191

1192

1193

1194

1195

1196

1197

1198

1199

1200

1201

1202

1203

1204

1205

1206

1207

1208

1209

1210

1211

1212

1213

1214

1215

1216

190. E. El-Danaf, S.R. Kalidindi, and R.D. Doherty: Metall. Mater. Trans. A, 1999, vol. 30, pp. 1223-1233.

191. Y.T. Zhu, X.Z. Liao, and X.L. Wu: Prog. Mater. Sci., 2012, vol. 57, pp. 1-62.

192. B. Zheng, Y. Li , W. Xu , Y. Zhou, S.N. Mathaudhu, Y. Zhu, and E.J. Lavernia, Phil. Mag. Let., 2013, vol. 93, pp. 457-464.

193. J. He, K.H. Chung, X.Z. Liao, Y.T. Zhu, and E.J. Lavernia: Metall. Mater. Trans. A, 2003, vol. 34A, pp. 707-712.

194. S. Mahajan, and G.Y. Chin: Acta Mater, 1973, vol. 21, pp. 1353-1363.

195. W.B. Jones, and H.I. Dawson: in R.W. Rohde, B.M. Butcher, J.R. Holland, C.H. Karnes (Eds.) Metallurgical Effects at High Strain Rates, Plenum Press, New York, NY, 1973, pp. 443-459.

196. V. Yamakov, D. Wolf, S.R. Phillpot, A.K. Mukherjee, and H. Gleiter: Nature Mater., 2002, vol. 1, pp. 45-49.

197. J.A. Venables: in R.E. Reed-Hill, J. P. Hirth, H.C. Rogers (Eds.) Deformation Twinning, Gordon \& Breach, NY, 1964, pp. 77-116.

198. K.W. Jacobsen, and J. Schiøtz: Nature Mater., 2002, vol. 1, pp. 15-16.

199. Y. Wang, L.Q. Chen, Z.K. Liu, and S.N. Mathaudhu: Scripta Mater., 2010, vol. 62, pp. 646-649.

200. H. Somekawa, K. Hirai, H. Watanabe, Y. Takigawa, and K. Higashi: Mater. Sci. Eng. A, 2005, vol. 407, pp. 53-61.

201. F. Zhou, X.Z. Liao, Y.T. Zhu, S. Dallek, and E.J. Lavernia: Acta Mater., 2003, vol. 51, pp. 2777-2791.

202. F. Louchet, L.P. Kubin, and D. Vesely: Phil. Mag. A, 1979, vol. 39, pp. 433-454.

203. J.L. Sun, P.W. Trimby, X. Si, X.Z. Liao, N.R. Tao, and J.T. Wang: Scripta Mater., 2013, vol. 68, pp. 475-478.

204. J.W. Christian, and S. Mahajant: Prog. Mater. Sci., 1995, vol. 39, pp. 1-157.

205. X.L. Wu, K.M. Youssef, C.C. Koch, S.N. Mathaudhu, L.J. Kecskes, and Y.T. Zhu: Scripta Mater., 2011, vol. 64, pp. 213-216.

206. M. Pozuelo, C. Melnyk, W.H. Kao, and J.-M. Yang: J. Mater. Res., 2011, vol. 26, pp. 904911.

207. Y. Li, Y.J. Lin, Y.H. Xiong, J.M. Schoenung, and E.J. Lavernia: Scripta Mater., 2011, vol. 64, pp. 133-136.

208. S.N. Mathaudhu, J. Taek-Im, R.E. Barber, I.E. Anderson, I. Karaman, K.T. Hartwig, Mater. Res. Soc. Symp. Proc., 2003, vol. 754, pp. CC3.5.1-8.

209. Y. Lin, and E.J. Lavernia: Metall. Mater. Trans. A, 2006, vol. 37, pp. 3317-3322.

210. H. Wen, Y.H. Zhao, Y. Li, O. Ertorer, K.M. Nesterov, R.K. Islamgaliev, R.Z. Valiev, and E.J. Lavernia: Phil. Mag., 2010, vol. 90, pp. 4541-4550.

211. Y. Li, Y. H. Zhao, W. Liu, Z. H. Zhang, R. G. Vogt, E. J. Lavernia, and J.M. Schoenung: Phil. Mag., 2010, vol. 90, pp. 783-792.

212. C.C. Koch, J. Mater. Sci., 2007, vol. 42, pp. 1403-1414.

213. C. Koch, R. Scattergood, K. Darling, and J. Semones: J. Mater. Sci., 2008, vol. 43, pp. 7264-7272.

214. P.V. Liddicoat, X. Liao, Y. Zhao, Y. Zhu, M.Y. Murashkin, E.J. Lavernia, R.Z. Valiev, and S.P. Ringer: Nature Commun., 2010, vol. 7, pp. 1-7.

215. N. Zhou, T. Hu, J. Huang, and J. Luo: Scripta Mater., 2016, vol. 124, pp. 160-163. 
216. Y. Lin, H. Wen, Y. Li, B. Wen, W. Liu, and E.J. Lavernia: Acta Mater., 2015, vol. 82, pp. 304-315.

217. B.J.M. Aikin, R.M. Dickerson, D.T. Jayne, S. Farmer, and J.D. Whittenberger: Scripta Metall. Mater., 1994, vol. 30, pp. 119-122.

218. R.W. Hayes, P.B. Berbon, and R.S. Mishra: Metall. Mater. Trans. A, 2004, vol. 35, pp. 3855-3861.

219. Y. Li, W. Liu, V. Ortalan, W.F. Li, Z. Zhang, R. Vogt, N.D. Browning, E.J. Lavernia, and J.M. Schoenung: Acta Mater., 2010, vol. 58, pp. 1732-1740.

220. F. Zhou, J. Lee, S. Dallek, and E.J. Lavernia: J. Mater. Res., 2001, vol. 16, pp. 3451-3458.

221. I. Roy, M. Chauhan, F.A. Mohamed, and E.J. Lavernia: Metall. Mater. Trans. A, 2006, vol. 37, pp. 721-730.

222. B.Q. Han, Z. Zhang, and E.J. Lavernia: Phil. Mag. Lett., 2005, vol. 85, pp. 97-108.

223. V.L.Tellkamp, A. Melmed, and E.J. Lavernia: Metall. Mater.Trans. A, 2001, vol. 32, pp. 2335-2345.

224. J.E. Burke: Trans.TMS-AIME, 1949, vol. 180, pp. 73-79.

225. A.P. Newbery, S.R. Nutt, and E.J. Lavernia: JOM, 2006, vol. 58, pp. 56-61.

226. E. Kuş, Z. Lee, S. Nutt, and F. Mansfeld: Corrosion, 2006, vol. 62, pp. 152-154.

\section{Figure Captions.}

Fig. 1 OIM images for high purity aluminum in (a) the initial unprocessed condition and after ECAP through (b) 1, (c) 2, (d) 3, (e) 4, (f) 8 and (g) 12 passes using route $\mathrm{B}_{\mathrm{C}}$ at RT: the grain colors correspond to the orientations in the unit triangle [44].

Fig. 2 EBSD orientation images of $\mathrm{Cu}-0.1 \% \mathrm{Zr}$ disks processed by HPT for (a) $1 / 4$ turn, (b) 5 turns and (c) 10 turns: the columns display images from the center of the disk (on left) and at the edge of the disk (on right) [57].

Fig. 3 Schematic illustration of the principle of the ECAP-Conform process [72].

Fig. 4 Multilayered structure with alternate distribution of finer and coarser grains fabricated by an ABAB-type $5 \mathrm{~N}-\mathrm{Al} / 4 \mathrm{~N}-\mathrm{Al}$ bimetallic tube with 2 turns of t-HPS at RT: the $4 \mathrm{NAl}$ layers have finer grain $\operatorname{size}(<1 \mu \mathrm{m})$ and the $5 \mathrm{~N}$ Al layers have relatively coarser grains [78].

Fig. 5 Color-coded contour maps of the Vickers microhardness for the Al/Mg system after HPT for 1 turn (upper), 5 turns (center) and 10 turns (lower): the values associated with the various colors are given in the hardness color key on the right [120]. 
1254 Fig. 6 The range of fracture toughness and strength-to-weight ratio for many metals and materials [128] where the synthesized Al-Mg system shown in Fig. 5 after HPT is incorporated into the diagram as HPT-induced aluminum MMNCs without delineating any upper limits for these values [122].

Fig.7: Model predictions of (a) grain size, and (b) interfacial solute excess for Fe-Zr alloys [147].

Fig. 8: The nanostructure stability map for tungsten-based alloys at $1373 \mathrm{~K}\left(1100^{\circ} \mathrm{C}\right)$, calculated on the basis of variation of the enthalpy parameters. For each combination of parameters, the free energy of nanocrystalline structures is compared to that of the bulk regular solution. An example for the nanocrystalline stable region in given in (B) for W-Sc. A bulk stable case is given in (C) for W-Ag. (Reproduced with permission from reference [149]).

Fig. 9. Bright field grain size histogram for $\mathrm{Fe}-10$ at.\% $\mathrm{Cr}-2$ at.\% $\mathrm{Zr}$ sample annealed at

Fig. 10. Figure 10. Hall-Petch plot of $\mathrm{Fe}-14 \mathrm{Cr}-4 \mathrm{Hf}$ alloy along with the base $\mathrm{Fe}-14 \mathrm{Cr}$ alloy $1173 \mathrm{~K}\left(900^{\circ} \mathrm{C}\right)[154]$. [155].

Fig. 11. Model prediction for $\mathrm{Fe}-14 \mathrm{Cr}-\mathrm{x}$ Hf alloys for grain size [156].Fig. 12: Literature data for thermal stabilization mechanisms vs. maximum homologous temperature for stabilization.

Fig. 12. Figure 12. Literature data for thermal stabilization mechanisms vs. maximum homologous temperature for stabilization [156]. The symbols are: thermodynamic stabilization: $\bullet$, kinetic stabilization: $\circ$, kinetic and thermodynamic stabilization: $\mathbf{\nabla}$, kinetic and complexion stabilization: $\Delta$

1277 Fig. 13: Comparison of the average grain size evolution with milling time for $\mathrm{Zn}$ powder milled at room temperature and at liquid nitrogen temperature [179].

Fig. 14: HREM image of Al-7.5Mg alloy cryomilled for $8 \mathrm{~h}$, (a) Image of a whole nanoscale twin. (b) Local magnification of a twin [193]. 
1288

1289 
Article File with Track Changes.

As per the Response Letter, we have not made any changes in the original manuscript.

C. C. Koch, T. G. Langdon, E. J. Lavernia 

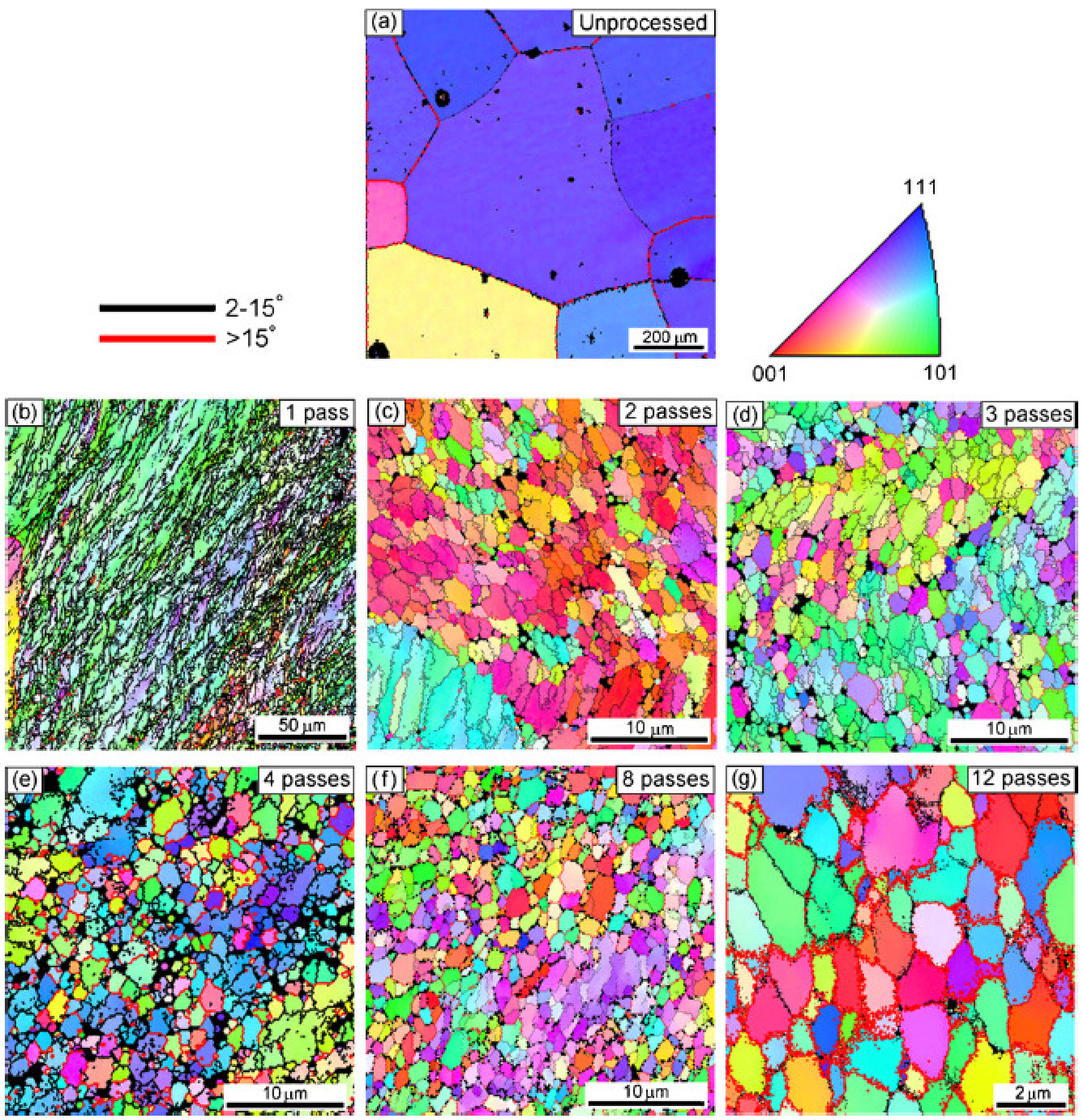


\section{Cu-0.1 wt.\% Zr HPT: $6.0 \mathrm{GPa}$, RT}
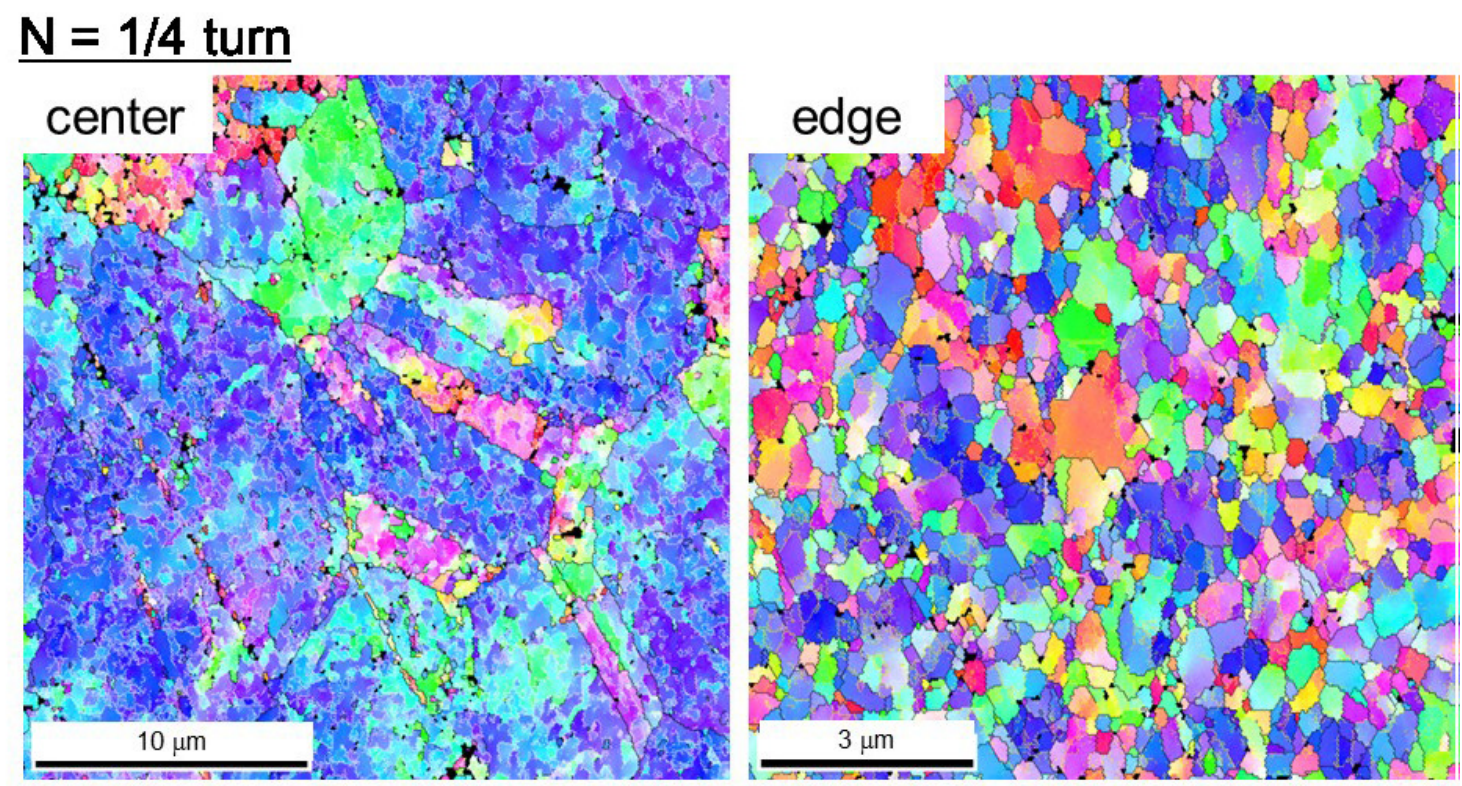

(a)

\section{$\mathrm{N}=5$ turns}
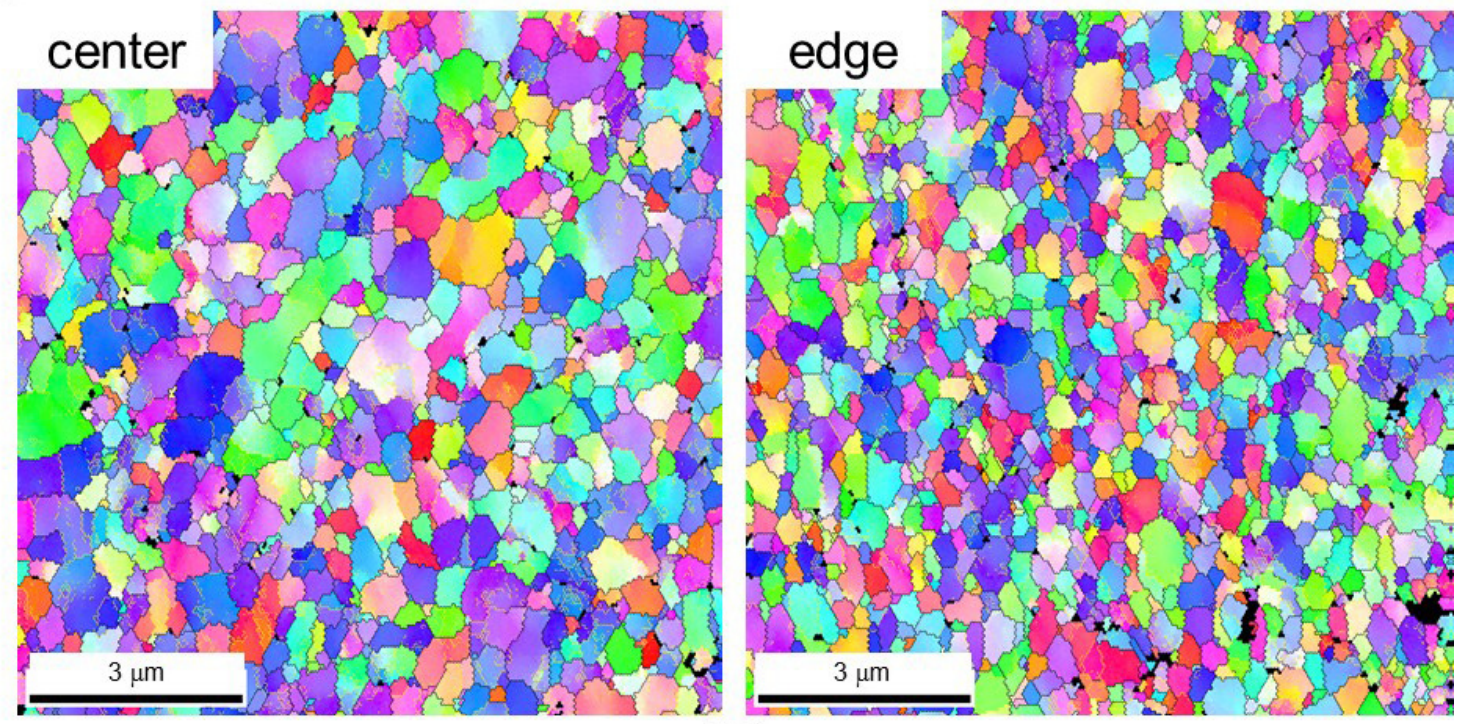

(b)

\section{$\underline{N}=10$ turns}
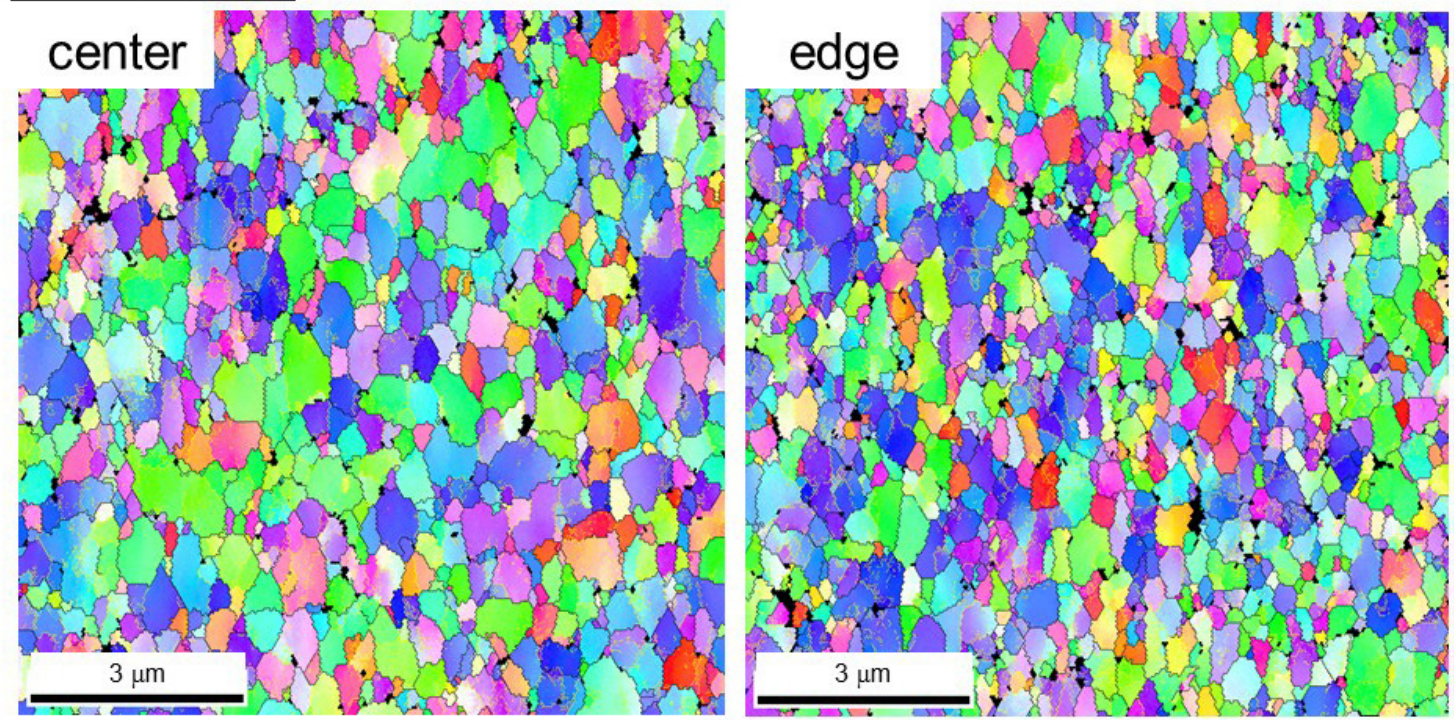

(c) 
Stationary die constructed from steel

Internal channel

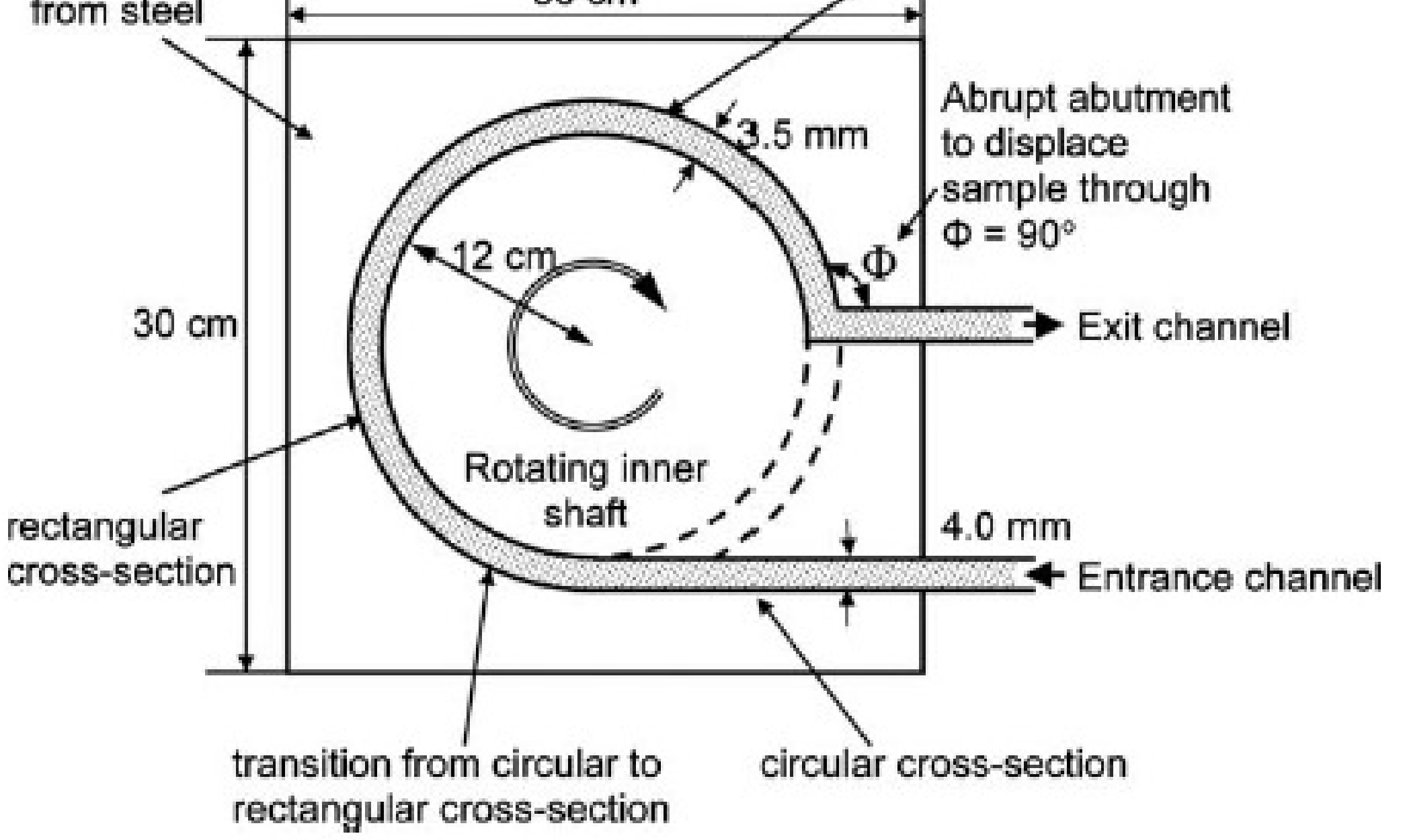



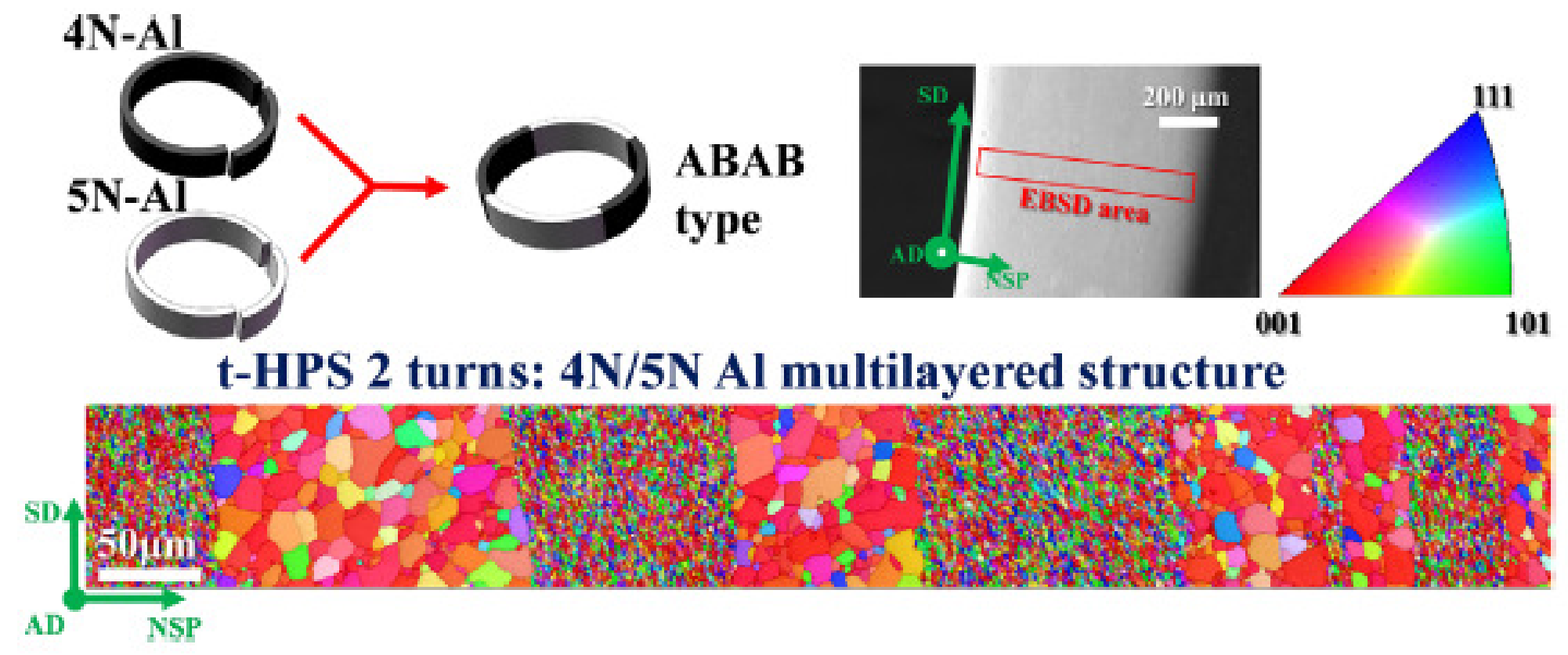


\section{HPT: 1 turn, 6.0 GPa, RT, 1 rpm}

\section{HPT: 5 turns, $6.0 \mathrm{GPa}$, RT, $1 \mathrm{rpm}$}

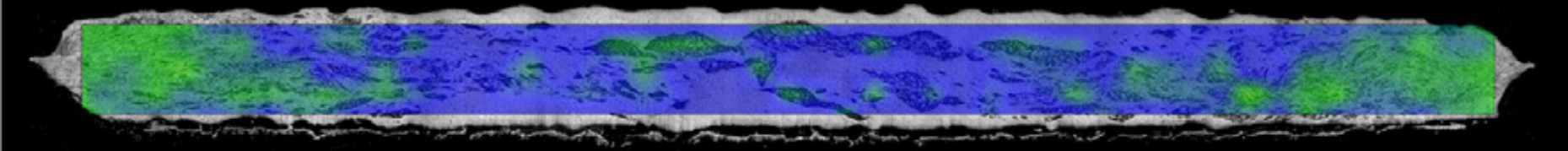

\section{HPT: 10 turns, 6.0 GPa, RT, 1 rpm}

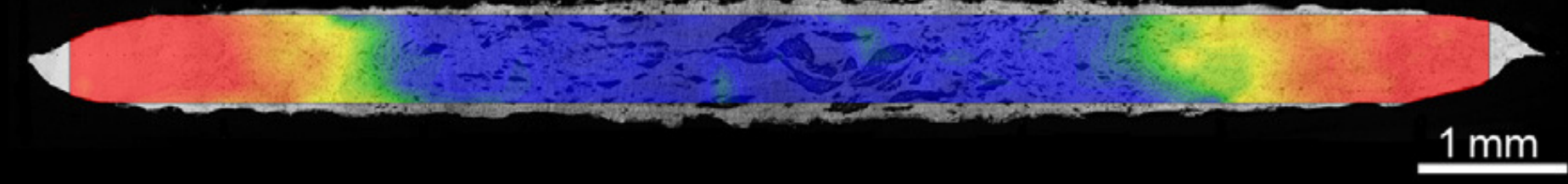

\begin{tabular}{|l|}
\hline $\mathrm{Hv}$ \\
\hline 270 \\
240 \\
210 \\
180 \\
150 \\
\hline 120 \\
\hline 90 \\
\hline 60 \\
\hline 30 \\
\hline
\end{tabular}



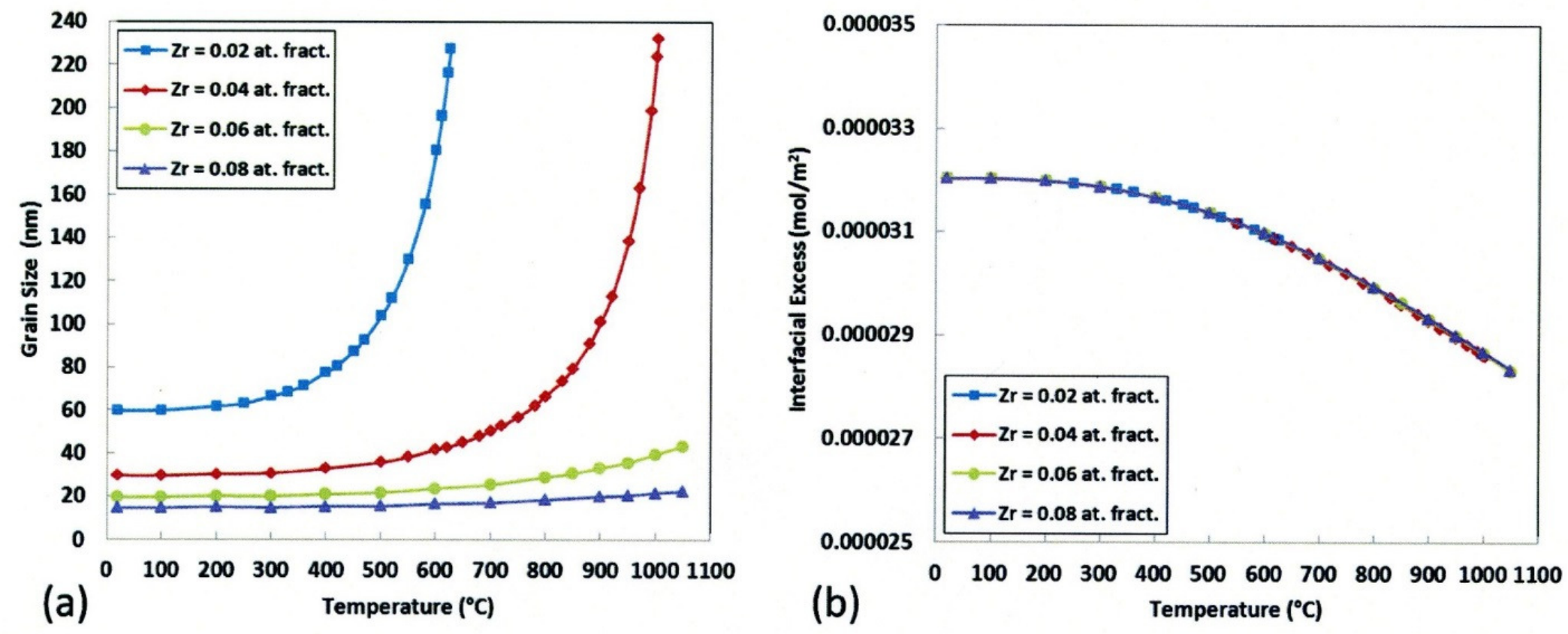

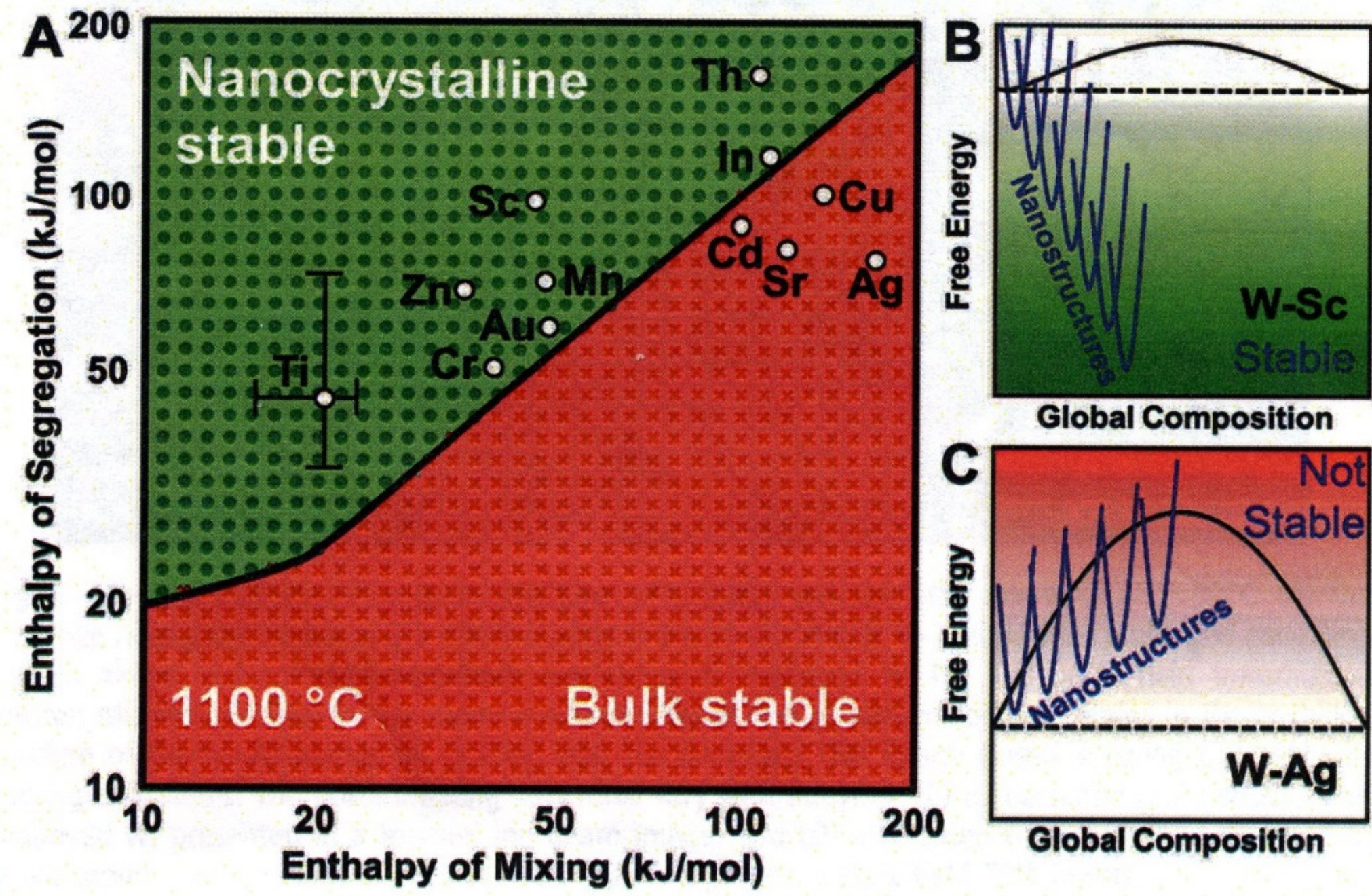

Global Composition

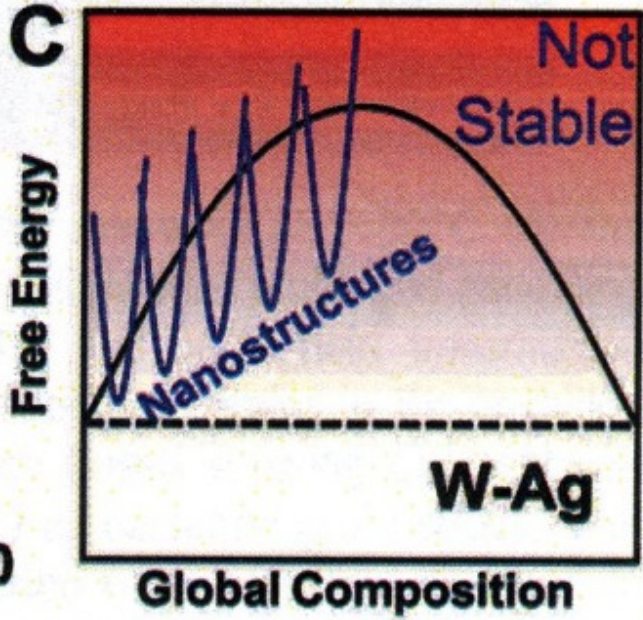




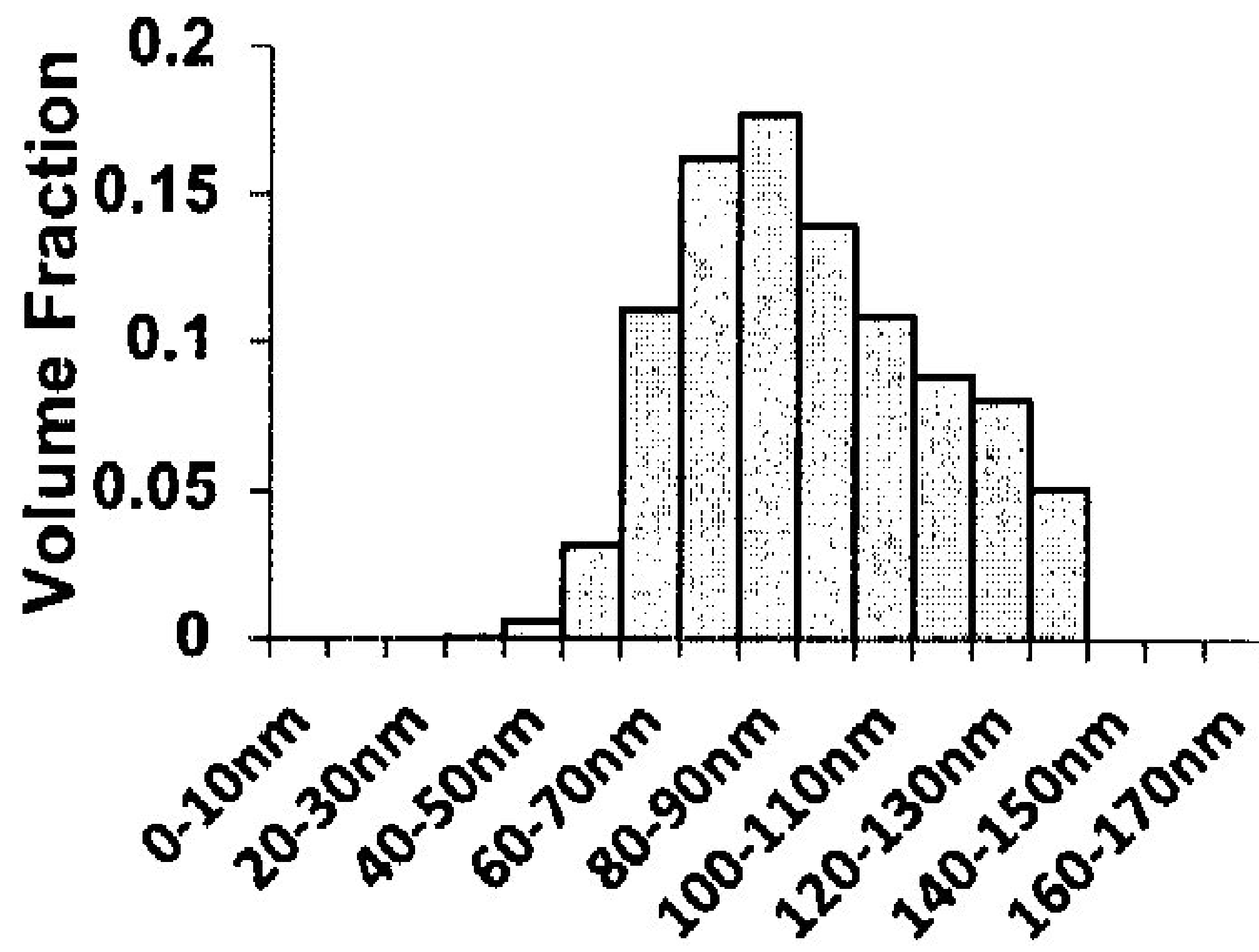




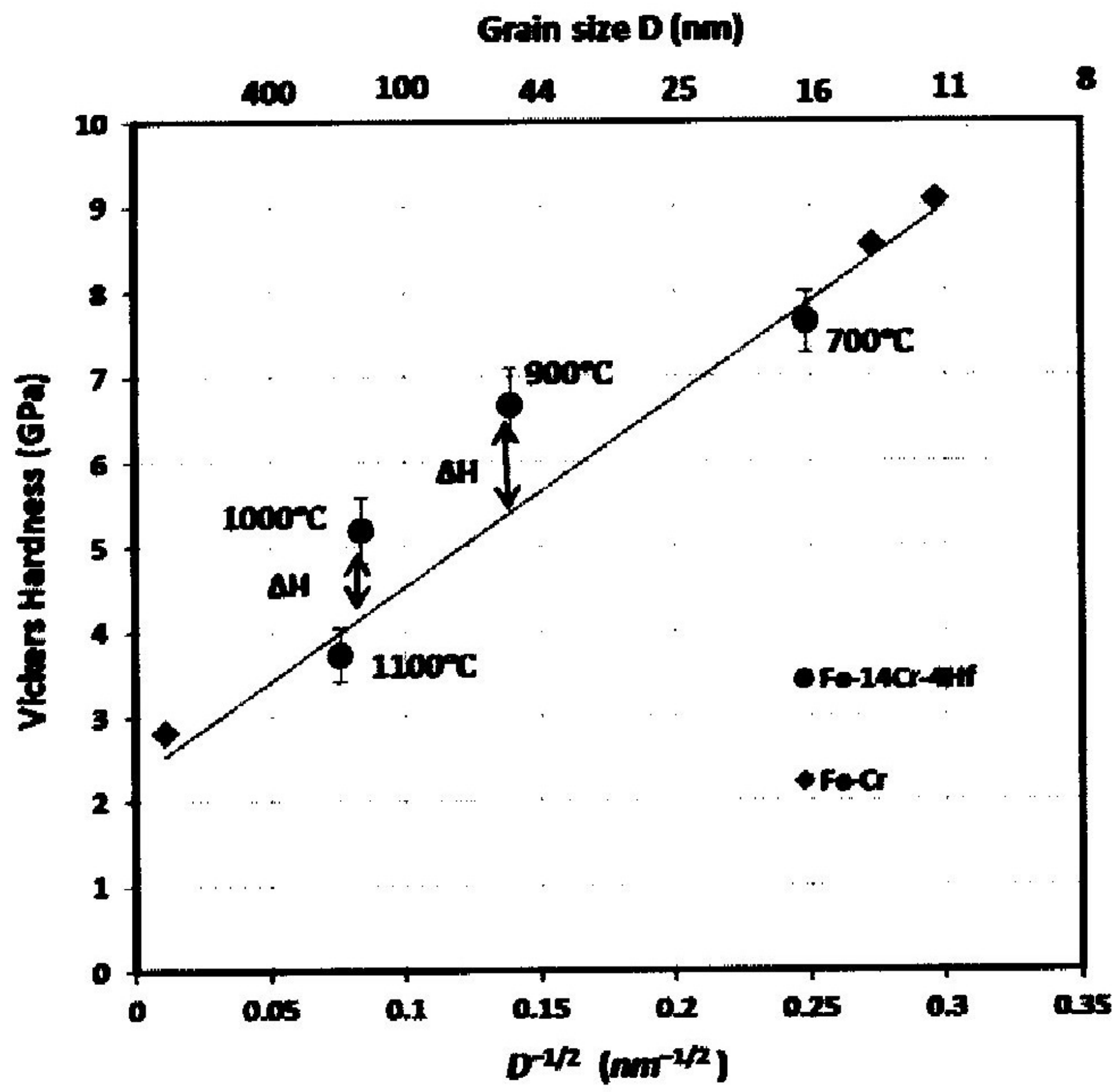




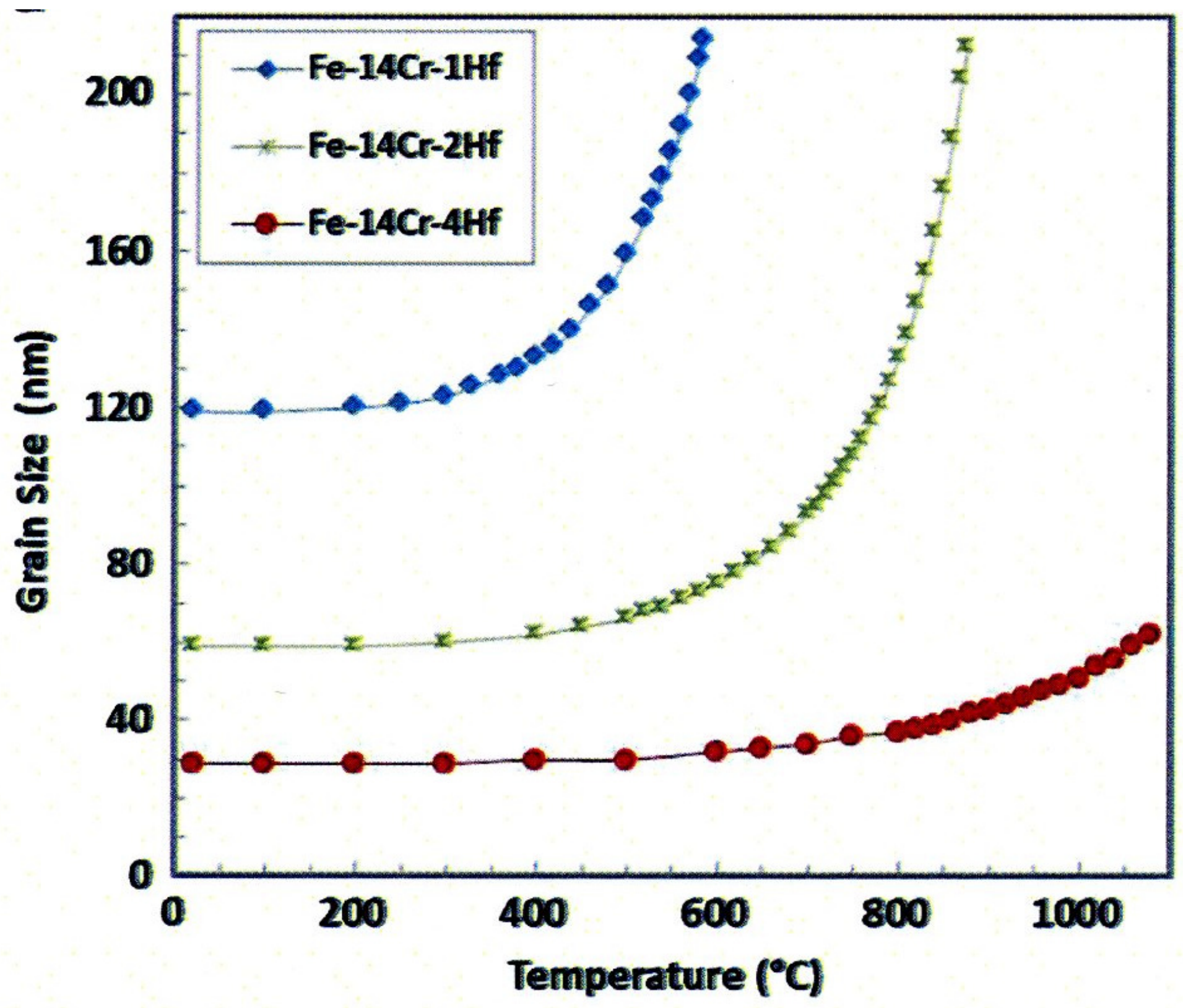




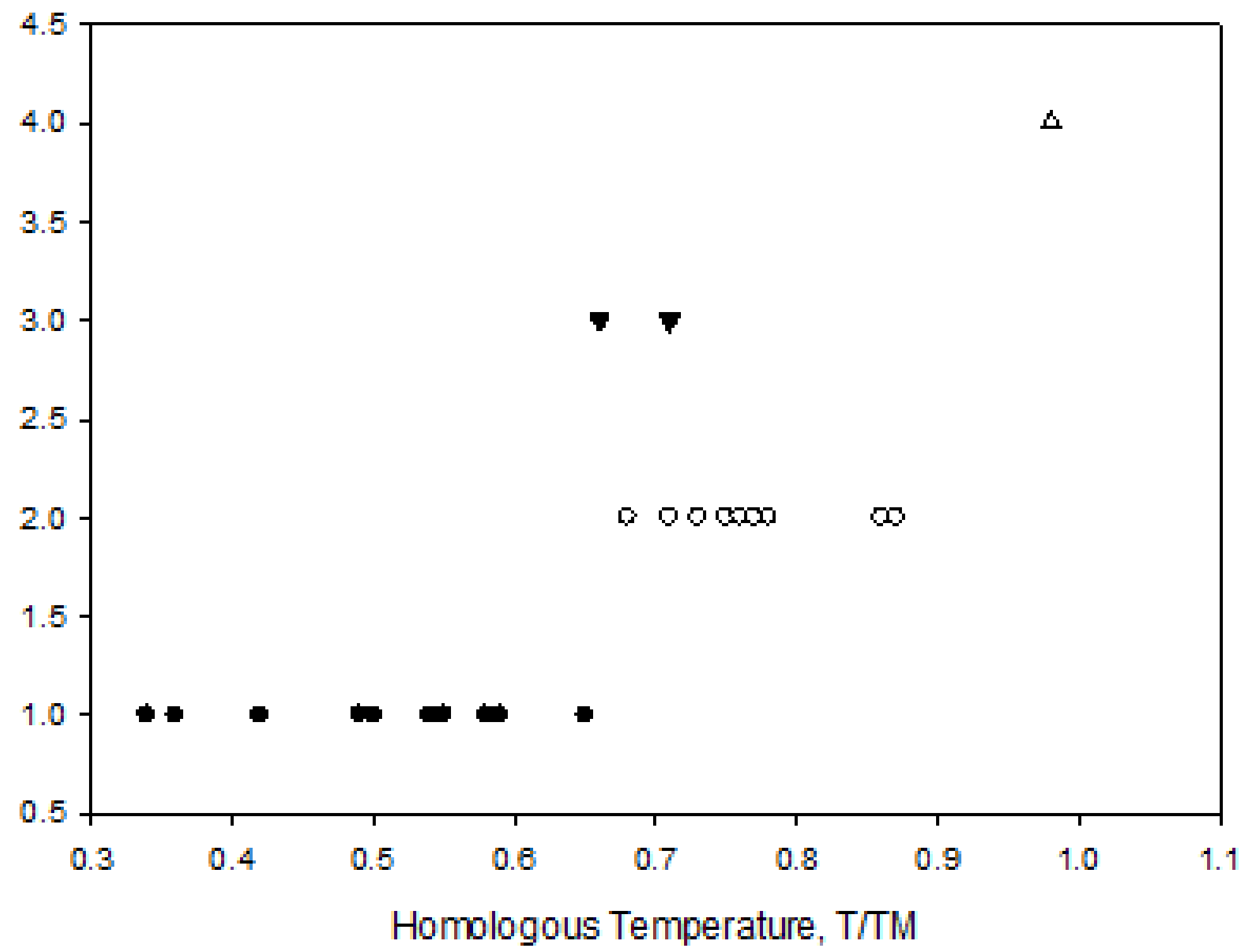




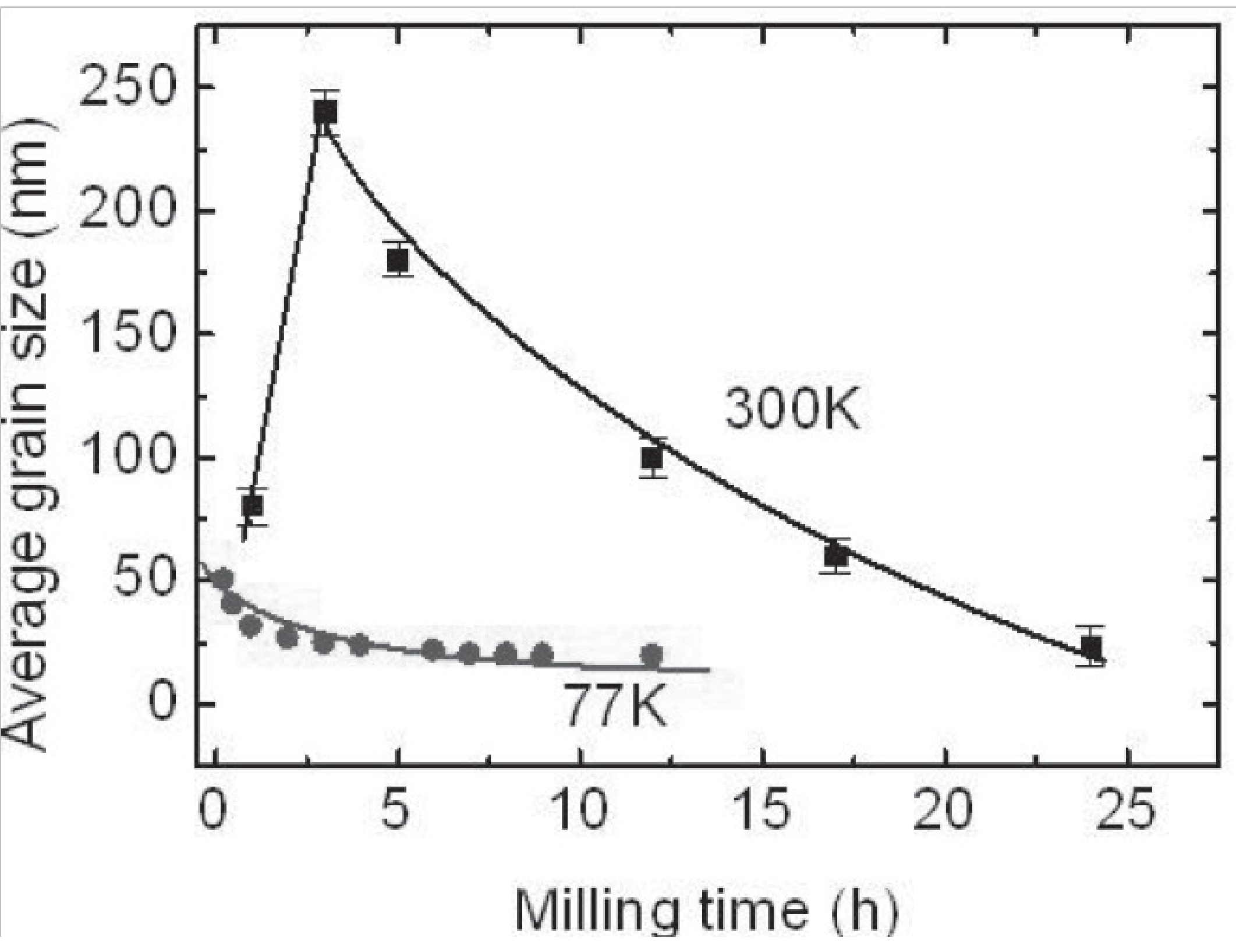




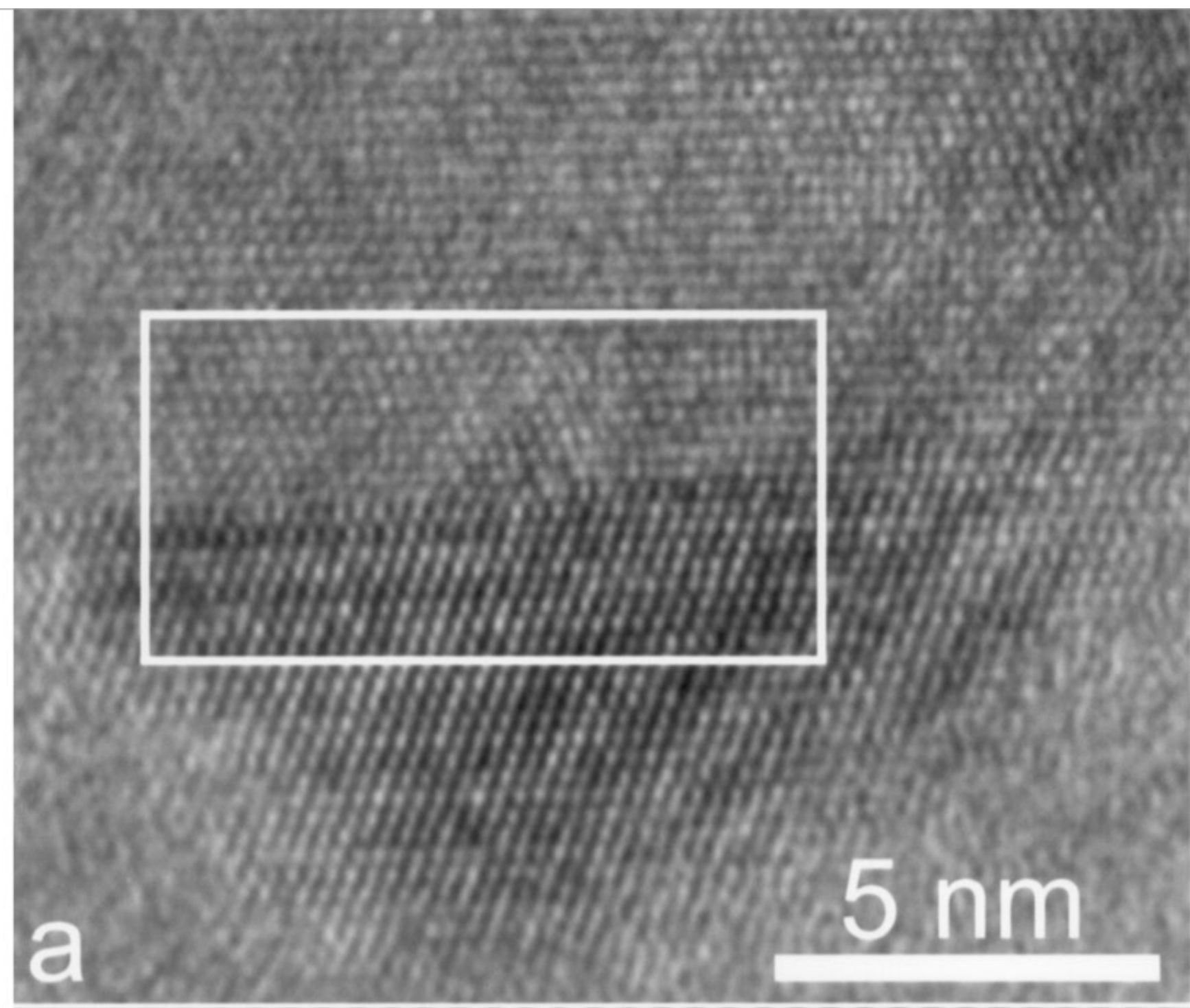

[1i2] -

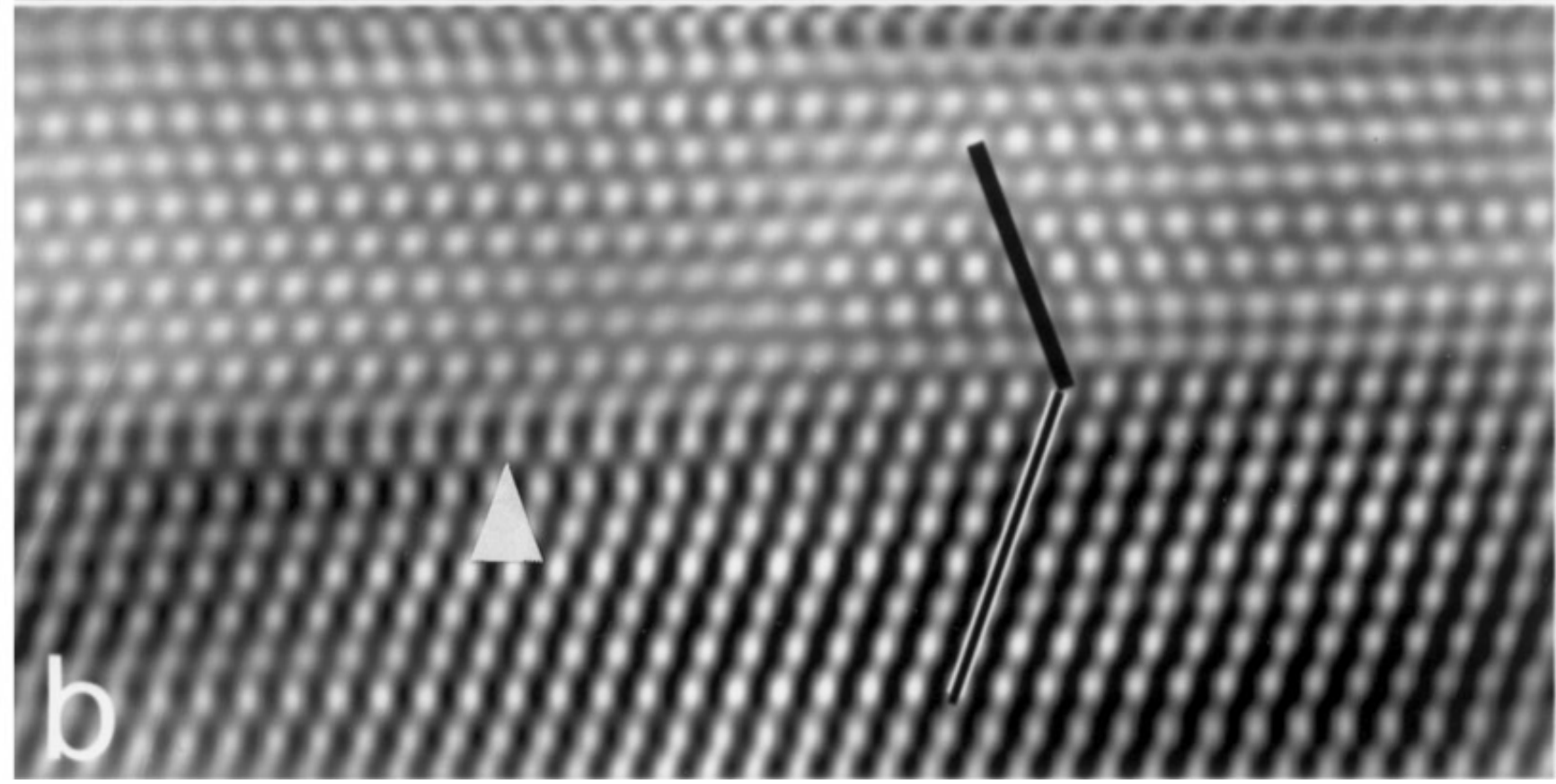

